\title{
THE IMPACT OF A LARGE ARCTIC STORM SURGE ON CHIRONOMID COMMUNITY ASSEMBLAGES, MACKENZIE DELTA, NORTHWEST TERRITORIES, CANADA
}

\author{
By \\ Courtney Steele \\ B.Sc. Physical Geography, Carleton University, 2010
}

A thesis submitted to the Faculty of Graduate and Postdoctoral Affairs in partial fulfillment of the requirements for the degree of

Master of Science

in

Physical Geography

Carleton University

Ottawa, Canada

(C) 2013

Courtney Steele 
Library and Archives

Canada

Published Heritage

Branch

395 Wellington Street

Ottawa ON K1A ON4

Canada
Bibliothèque et

Archives Canada

Direction du

Patrimoine de l'édition

395 , rue Wellington

Ottawa ON K1A ON4

Canada
Your file Votre référence

ISBN: 978-0-494-94664-0

Our file Notre référence

ISBN: 978-0-494-94664-0
NOTICE:

The author has granted a nonexclusive license allowing Library and Archives Canada to reproduce, publish, archive, preserve, conserve, communicate to the public by telecommunication or on the Internet, loan, distrbute and sell theses worldwide, for commercial or noncommercial purposes, in microform, paper, electronic and/or any other formats.

The author retains copyright ownership and moral rights in this thesis. Neither the thesis nor substantial extracts from it may be printed or otherwise reproduced without the author's permission.
AVIS:

L'auteur a accordé une licence non exclusive permettant à la Bibliothèque et Archives Canada de reproduire, publier, archiver, sauvegarder, conserver, transmettre au public par télécommunication ou par l'Internet, prêter, distribuer et vendre des thèses partout dans le monde, à des fins commerciales ou autres, sur support microforme, papier, électronique et/ou autres formats.

L'auteur conserve la propriété du droit d'auteur et des droits moraux qui protege cette thèse. $\mathrm{Ni}$ la thèse ni des extraits substantiels de celle-ci ne doivent être imprimés ou autrement reproduits sans son autorisation.
In compliance with the Canadian Privacy Act some supporting forms may have been removed from this thesis.

While these forms may be included in the document page count, their removal does not represent any loss of content from the thesis.
Conformément à la loi canadienne sur la protection de la vie privée, quelques formulaires secondaires ont été enlevés de cette thèse.

Bien que ces formulaires aient inclus dans la pagination, il n'y aura aucun contenu manquant. 


\section{$\underline{\text { Abstract }}$}

During this century, sea level is expected to increase as large ice sheets melt and temperatures warm, causing thermal expansion of the oceans. Across the Arctic, rising sea level coupled with increasing storminess and decreasing sea-ice cover, will make low-lying coastal regions more susceptible to storm surges.

In September 1999, a storm impacted $200 \mathrm{~km}^{2}$ of the outer Mackenzie Delta causing saltwater to move inland and flood freshwater lakes. The aim of this study is to (1) quantify what impacts the 1999 storm surge had on the abundance and community composition of chironomids in these lakes, and (2) determine if ecological recovery has occurred since the storm surge.

The earliest portion of the lake sediment record from Lake DZO-29 (which is undated, but probably represents the past several centuries) is dominated by the chironomid taxa Cricotopus/Orthocladius, Chironomus and Paratanytarsus. This early assemblage suggests relatively cold temperatures and likely represents the end of Little Ice Age climatic conditions. A significant increase in the relative abundance of Corynocera oliveri type-I in DZO-29 and in another lake (DZO-30), suggest warming conditions following the end of the Little Ice Age that persist throughout the $20^{\text {th }}$ century. In cores DZO-29 and DZO-30, the suggested warming is interrupted during the past $\sim 10$ years following the inundation by saltwater in September 1999. After this, chironomid communities appear to be driven by salinity changes as opposed to temperature. No significant chironomid assemblage shifts occurred in a third lake (C-27), which was not impacted by the storm surge. 


\section{Dedication}

To my parents and Cale, who believed I could keep going even when I thought I couldn't. 


\section{Acknowledgements}

I would like to acknowledge my supervisor Dr. Michael Pisaric for the opportunity given to me to travel to a truly beautiful and inspiring place for field work as well as to be part of such an interesting project. It is rewarding to see a project through from beginning to end, from the collection of the cores to the analyzing of results and the writing of this thesis. I would also like to thank my supervisor for his support and encouragement when things didn't go quite according to plan and despite this project taking longer than I had anticipated. I would also like to thank Dr. Jesse Vermaire for his unfailing patience, ability to answer almost any question no matter how minute, and much needed guidance and direction at times. Without your help, I would have been completely lost.

Additional recognition goes to Josh Thienpont, and Peter deMontigny for their assistance in the field and amazing ability to collect cores on a windy day despite a 'mysteriously vanishing' anchor. Thanks are also due to Stephanie Delaney for the hours of sample preparation and chironomid picking, which takes the patience of a saint. Dr. Michael Pisaric, Dr. Dave Porinchu, Josh Kurek and Dr. Derek Mueller must be recognized for their knowledge, input and suggestions to help improve the quality of this manuscript. As the saying goes, 'take it seriously, not personally' a somewhat difficult, but essential lesson to learn.

Final appreciation goes to the many, both at Carleton and outside, who have made this journey a great one and an experience I will never forget. You know who you are. It 
is now time to move on and tackle my next adventure. Thanks to everyone for your support. 


\section{Table of Contents}

Title Page

Abstract

ii

Dedication

iii

Acknowledgements

iv

Table of Contents

vi

List of Figures

viii

List of Tables

ix

Chapter 1: Introduction

1.1 Study context

1.2 Thesis organization

Chapter 2: Literature Review

2.1 Sea ice, climate change and the connection with arctic cyclones $\quad 8$

2.2 Storm surges in the Beaufort Sea and Mackenzie Delta 11

2.3 An overview of the outer Mackenzie Delta 15

2.4 Modern climate regime of the Mackenzie Delta region 17

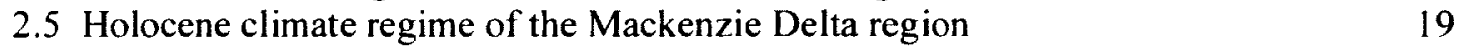

2.6 Palaeoecological studies in the context of climate records 20

2.7 Chironomids as paleoecological indicators 23

2.8 Documented ecological impacts of storm surges $\quad 29$ 
Chapter 3: The impact of a large Arctic storm surge on chironomid community assemblages, Mackenzie Delta, Northwest Territories, Canada

3.1 Introduction

3.2 Methods

3.2.1 Site description

3.2.2 Field methods

3.2.3 Chronological dating and laboratory analysis 48

3.2.3.1 ${ }^{210} \mathrm{~Pb}$ chronology development $\quad 48$

$\begin{array}{ll}3.2 .3 .2 \text { Chironomid analysis } & 49\end{array}$

$\begin{array}{lr}3.2 .3 .3 \text { Statistical analysis } & 50\end{array}$

3.3 Results 52

3.3.1 Physical nature of DZO-29, DZO-30 and C-27 52

3.3.2 Chironomid assemblage changes of storm surge impacted lake
DZO-29

3.3.3 Chironomid assemblage changes of storm surge impacted lake 57 DZO-30

3.3.4 Chironomid assemblage changes of control lake C-27 59

3.4 Discussion 70

3.4.1 Chironomid response to the 1999 storm surge event 70

3.4.2 Temperature, ice cover and changing aquatic communities

$\begin{array}{ll}3.5 \text { Conclusion } & 77\end{array}$

Chapter 4: Conclusion $\quad 80$

4.1 Study conclusions $\quad 80$

4.2 Future research 83

$\begin{array}{lr}\text { References } & 85\end{array}$ 


\section{List of Figures}

Figure

$1 \quad$ Typical life cycle of aquatic Chironomidae 25

2 Images of Corynocera oliveri type-1 head capsules taken from DZO-29 27

3 Map of study site (outer Mackenzie Delta, Northwest Territories, Canada) 41

$4 \quad$ Vegetation affected by 1999 storm surge surrounding DZO-29 42

5 Severely impacted vegetation of the outer Mackenzie Delta 'dead zone' $\quad 43$

6 Aerial view of the outer Mackenzie Delta 'dead zone' 44

$7 \quad$ Collection of cores from DZO-29 45

$8 \quad$ Vegetation affected by 1999 storm surge surrounding DZO-30 46

9 Aerial view of the most northern portion of the 'dead zone' 47

10 Age-depth relationships $\left({ }^{210} \mathrm{~Pb}\right)$ for $\mathrm{DZO}-30$ and $\mathrm{C}-27 \quad 53$

11 a Relative abundance stratigraphic plot (impacted lake DZO-30) 62

$11 \mathrm{~b} \quad$ Relative abundance stratigraphic plot (impacted lake DZO-29) 63

$11 \mathrm{c} \quad$ Relative abundance stratigraphic plot (control lake C-27) 64

12 Temperature reconstructions for DZO-29, DZO-30 and C-27 65

13a Total chironomid accumulation rate (CAR) plot (impacted lake DZO-30) 66

$13 \mathrm{~b}$ Total chironomid accumulation rate (CAR) plot (impacted lake DZO-29) 66

13c Total chironomid accumulation rate (CAR) plot (control lake C-27) 69

14a Uninterpolated and interpolated taxon richness plot $\quad 67$ (impacted lake DZO-30)

14b Uninterpolated and interpolated taxon richness plot 68 (impacted lake DZO-29)

14c Uninterpolated and interpolated taxon richness plot $\quad 69$ (control lake C-27) 


\section{List of Tables}

\section{Table}

1 Select physical and chemical variables (DZO-29, DZO-30 and C-27)

2 Chironomid taxa composition of study lakes (DZO-29, DZO-30 and C- 27) 


\section{Chapter One}

\section{Introduction}

\subsection{Study context}

Some of the largest increases in temperature during the past few decades have occurred in polar regions. Rigor et al. (2000) analyzed Arctic surface air temperature (SAT) observations and found that temperatures have warmed as much as $2^{\circ} \mathrm{C}$ between 1979 and 1997 in portions of the Arctic, including northwest North America where recent warming trends are amongst the largest. Temperature records from Arctic regions indicate that the Arctic has warmed faster than the global average since the 1960 s and that this trend is expected to continue (Simmonds \& Keay, 2009).

Warmer temperatures in the Arctic are having a number of cascading impacts on Arctic systems. Among the best quantified of the changes occurring in the Arctic since the late 1970s are those associated with sea ice cover (Comiso et al., 2008). Despite marked seasonal, regional and interannual variabilities, an overall decreasing trend of $2.8 \%$ per decade in Arctic sea ice cover has been observed since the latter part of the 1970s (Parkinson et al., 1999). More recent studies indicate that the pace of this overall decline is increasing, with 2012 recording the lowest sea ice extent since satellite observations began (Stroeve et al., 2012). Climatic warming has not only caused a decrease in the extent of sea ice cover, but the thickness of sea ice has also declined in recent decades (Polyak et al., 2010). As sea ice cover continues to decline and sea-level increases globally due to warming temperatures, the retreat of Arctic coastlines will continue to be a growing problem (Manson \& Solomon, 2007). 
The retreat of Arctic coastlines is related to a number of factors, including (1) the material that comprises the coastline (i.e., ice-rich permafrost versus bedrock); (2) the frequency, intensity and track of storms; (3) the duration of sea ice cover and persistence of landfast ice; and (4) the rate of sea level rise (Manson \& Solomon, 2007). As global temperatures continue to warm, the frequency and intensity of Arctic storms is expected to increase (Sepp \& Jaagus, 2011). Sea ice extent is widely reported to be declining at unprecedented rates during the past decade (Simmonds \& Keay, 2009), while the length of ice free season has synchronously increased (Polyak et al., 2010). Superimposed on these changes to the climate and cryosphere systems are increases in sea level that have been occurring throughout the $20^{\text {th }}$ century. These increases in sea level are expected to be amplified as temperatures continue to rise during the $21^{\text {st }}$ century. The combination of these factors suggest that increased wave energy, leading to greater coastal erosion, will be a growing concern in the coming decades throughout the Arctic (Manson \& Solomon, 2007).

The Mackenzie Delta, located where the Mackenzie and Peel Rivers meet the Beaufort Sea, is a sensitive region. Spanning more than $13,000 \mathrm{~km}^{2}$, it is the world's second largest Arctic delta and the largest cold-region delta in North America (Marsh \& Schmidt, 1993). An important feature of the Mackenzie Delta is the large number of freshwater lakes, which cover up to $50 \%$ of the deltaic plain (Emmerton et al., 2007; Goulding et al., 2009).

Disturbance in the outer Mackenzie Delta is largely driven by two, very different processes; (1) high-frequency, freshwater flooding associated with the spring freshet; and (2) low-frequency marine storm-surge flooding during the open water season (Marsh \& 
Hey, 1994). Freshwater flooding across the outer Mackenzie Delta occurs almost annually during the spring freshet (Goulding et al., 2009). The spring freshet and breakup of river ice in the Mackenzie Delta normally occurs in late April or early May and has long been recognized as an important environmental process in the delta region (Brown, 1957; Kriwoken, 1983). Ice jams can occur during the spring break-up, leading to shortduration flooding that is a critical hydrologic feature and the main source of sediment and nutrient recharge for approximately 25,000 lakes throughout the Mackenzie Delta (Marsh \& Hey, 1994). Terrestrial and aquatic ecosystems throughout the Mackenzie Delta are tolerant of spring flooding since most of these systems are still dormant, the ground is normally frozen or in the case of lakes, remain cutoff due to the persistence of lake ice cover at the time of the spring freshet (Marsh \& Hey, 1994). In fact, the influx of warmer water due to the spring flooding hastens the retreat of winter conditions in the delta, causing the ground to thaw earlier, plant growth to commence sooner and lake ice cover to degrade more rapidly than on the adjacent uplands where snow may persist and the ground remain frozen into June (Marsh \& Hey, 1994).

Conversely, marine intrusions associated with storm-induced surges appear to be less common (Solomon et al., 2000; Pisaric et al., 2011) and occur during the warmer part of the season when lakes are ice free, the active layer has thawed and vegetation is not dormant. Marine storm surges can produce flooding levels 1-2 $\mathrm{m}$ above the low-lying land surfaces of the outer Mackenzie Delta and bring brackish water well inland due to the relatively low topography that typifies the outer Mackenzie Delta (Kokelj et al., 2012). Thus, the impacts of marine storm surges are potentially more problematic for Arctic ecosystems. 
A very intense storm surge in September 1999 left nearly $200 \mathrm{~km}^{2}$ of the Mackenzie Delta front impacted due to saltwater inundation (Pisaric et al., 2011; Kokelj et al., 2012). Not only did the rapid introduction of saltwater result in the death of most of the vegetation in the affected area, it also impacted the freshwater lake systems as the influx of saltwater caused the lakes and ponds to rapidly shift to brackish or saltwater systems (Deasley et al., 2012; Pisaric et al., 2011).

Recently, concerns have been expressed regarding the implications of climate warming and its potentially damaging ecological impact on the Mackenzie Delta system (Marsh \& Schmidt, 1993). Unfortunately, records of ecological and environmental change in this region are short and largely incomplete. For example, tidal records from Tuktoyaktuk only cover the period from 1961 onwards and contain significant time-gaps (Reimnitz \& Maurer, 1979). Consequently, two storm surges that impacted the outer Mackenzie Delta in 1944 and 1970, and believed to be amongst the largest of the $20^{\text {th }}$ century, are only known from local accounts of the events as neither was recorded in the instrumental tidal records for the region (Harper et al., 1988). Therefore, there is a need to develop proxy records of environmental and ecological change across this region to understand the frequency and various impacts of disturbances such as marine storm surges. This is especially relevant given increasing potential for industrial activities in the region, such as oil and gas drilling operations which pump a saline mixture into bore holes in an attempt to prevent them from freezing. If these types of development were to fail, they could potentially cause similar impacts to those of marine storm surges. Therefore, it is important to develop a longer-term perspective of ecological change in 
this region prior to industrial development and to establish baseline ecological data that can be used to assess industrial impacts in the future.

Paleolimnology refers to the study of past conditions of water bodies (lakes and streams; freshwater, brackish, or saline). Paleolimnological studies are commonly based on meticulous analyses of sediment cores, including the physical chemical and mineralogical properties of sediments, as well as diverse biological records (Walker, 1987). It is a mechanism that can be used to develop a longer-term perspective of ecological events (Smol, 1990). While ecology is generally focused on ecological change over timescales varying from days, months, years to perhaps several decades, paleolimnology can inform ecological questions over timescales from centuries to millennia.

Paleolimnologists have a long tradition of using biological proxies as indicators of ecological change within lacustrine ecosystems (Porinchu \& MacDonald, 2003). A multitude of biological proxies are often preserved in lake sediment records, including diatoms, cladoceran, daphnia and chironomids (Battarbee et al., 2005). The dipteran family Chironomidae is cosmopolitan in distribution and is frequently the most widely distributed and most abundant group of insects in freshwater with representatives in both terrestrial and marine environments (Armitage et al., 1995). Chironomids are becoming increasingly popular amongst paleolimnologists to classify lakes in terms of their trophic status or biological productivity and to quantitatively reconstruct past ecological changes in lake conditions (Porinchu \& MacDonald, 2003) as they provide a wealth of information on the ecological characteristics of a lake system through time (Hofmann, 1988). The capacity of the Chironomidae family to thrive under a variety of 
environmental gradients related to $\mathrm{pH}$, salinity, water depth, oxygen concentration, and temperature enables members of the Chironomidae to occupy virtually every available niche present in freshwater environments (Porinchu \& MacDonald, 2003). Individual species of chironomids generally have narrow tolerances to these environmental variables and are responsive to changes in their environment as a result. Therefore, they are ideal for paleolimnological studies because small changes in the physical or chemical environment could lead to changes in chironomid community assemblages. In addition to wide distribution and abundance, Chironomidae are well suited for paleolimnological studies because they possess chitinous head capsules which are well-preserved and relatively easily recovered and identified enabling high taxonomic precision and fine temporal and spatial resolution (Porinchu \& MacDonald, 2003).

This study analyzes chironomid remains from two storm surge impacted lakes (DZO-29 and DZO-30) and one control lake (C-27) situated outside the impacted zone of the 1999 storm surge. The objectives of this thesis are (1) to determine the ecological impact of the 1999 marine storm surge on chironomid communities in freshwater lakes of the outer Mackenzie Delta. In particular, were chironomid communities eradicated from these lakes or did the community composition change as a result of the rapid shift from freshwater adapted ecosystems to brackish systems in September 1999; and (2) to determine if any ecological recovery has occurred in the decade since the marine storm surge event in 1999. Ultimately, this research will increase our knowledge and understanding of the salinity tolerances of chironomid species in sensitive coastal Arctic lake ecosystems as well as to emphasize their importance as proxies in characterizing past ecological changes resulting from storm surge events. As global temperatures 
continue to increase, the frequency and intensity of Arctic storms are also expected to increase. Assessing the ecological responses of aquatic ecosystems adapted to freshwater conditions to changes in their environment will be critical as climate changes and industrial activity grows across this region in the future (Deasley et al., 2012).

\subsection{Thesis organization}

This thesis will be divided into four main chapters. The first chapter features a brief introduction to climatic warming in the Arctic and highlights the implications for sea ice cover and cyclonic activity in the Arctic Ocean as well as the resulting threat of storm surges along the Beaufort Sea coast and outer Mackenzie Delta. Chapter one introduced how paleolimnology using chironomids can be utilized to document ecological changes in freshwater lakes associated with these saltwater inundation events. Chapter two is a literature review structured into seven sections including; 1) sea ice, climate change and the connection with arctic cyclones, 2) storm surges in the Beaufort Sea and Mackenzie Delta, 3) an overview of the Mackenzie Delta, 4) the climate regime of the Mackenzie Delta region, 5) paleoecological studies in the context of climate records, 6) chironomids as paleoecological indicators and 7) the ecological impacts of storm surges. Chapter three presents the main part of the study and includes a detailed description of the study site as well as field, laboratory and analytical methods used, study results, and a discussion/interpretation of these results. This is followed by chapter four which synthesizes the major conclusions of this study. 


\section{Chapter Two}

\section{Literature Review}

\subsection{Sea ice, climate change and the connection with Arctic cyclones}

Sea ice is an important component of the Arctic climate system. The geographic extent and duration of sea ice cover are influenced by atmospheric and oceanic conditions including temperature, wind and ocean circulation (Sepp \& Jaagus, 2011). In turn, sea ice modulates climate at broad scales by altering surface albedo (Deser et al., 2000). The surface albedo effect is considered to be one of the dominant factors in polar amplification of global warming due to increased greenhouse gas concentrations simulated in many climate models (e.g. Manabe et al., 1992; Randall et al., 1998). Polar amplification refers to the greater temperature increases in the Arctic region compared to the earth as a whole as a result of the effect of positive feedback mechanisms (McBean $e t$ al., 2005). This phenomenon is not observed in the Antarctic, largely because the Southern Ocean acts as a heat sink and the lack of seasonal snow cover (McBean, 2005). Changes in Arctic surface conditions, including sea ice, represent important modifications to atmospheric forcing including the development and characteristics of Arctic cyclones in particular (Simmonds et al., 2008). As the extent of Arctic sea ice decreases, the amount of open water increases. This combined with winds similar to present day and a longer ice-free season implies not only increased wave energy, but also a greater available fetch for storm surge development (Manson \& Solomon, 2007). Fetch, also called fetch length, is the length of water over which a given wind can blow. This along with the wind speed determines the size of waves produced (Manson \& Solomon, 2007). The longer the fetch and the faster the wind speed, the more wind 
energy is imparted to the water surface and the larger the resulting waves will be (Manson \& Solomon, 2007).

The Arctic has experienced dramatic changes to the cryosphere and climate during recent decades including reductions in sea ice extent and snow cover, increases in annual precipitation, and pronounced warming of surface air temperature (Serreze \& Barry, 2005). Increases in surface air temperature driven by anthropogenic forcing during the $20^{\text {th }}$ century, has significant implications for Arctic sea ice extent (Serreze \& Barry, 2005). Sea ice occurs in varying stages of development: new or young ice is generally less than $30 \mathrm{~cm}$ thick, first-year ice is generally between 30 and $200 \mathrm{~cm}$ thick, and multiyear ice, representing ice floes that have persisted for more than one year, are typically more than $200 \mathrm{~cm}$ thick (French \& Slaymaker, 1993). Hudson (1987) determined that the predominately multi-year sea ice of the northeastern Beaufort Sea was mainly comprised of large floes, with a mean diameter of $700 \mathrm{~m}$ (Hudson, 1987). Two decades ago, multiyear sea ice was present throughout the year in the Beaufort Sea, except near the mainland coast in summer (French \& Slaymaker, 1993). In fact, away from the coast, ice cover often approached $100 \%$ for nine or ten months of the year (French \& Slaymaker, 1993). However, recent modeling experiments and satellite observations indicate that summer sea ice extent is declining rapidly (Lindsay \& Zhang, 2005; Holland et al., 2006; Lindsay et al., 2009). It is predicted that summer Arctic sea ice extent will decrease by 80 $\%$ by 2100 when the Arctic Ocean will be nearly ice free in summer, resulting in drastic changes in the Arctic climate system (Bengtsson et al., 2004).

A number of recent studies have revealed noteworthy changes in the circulation and structure of the Arctic Ocean, particularly due to a greater intrusion of Atlantic 
waters into the Arctic (Simmonds et al., 2008). This 'Atlantification' is reflected in the transition of the Arctic Ocean toward a new, warmer state (Simmonds et al., 2008). Lindsay and Zhang (2005) have argued that the late 1980s and early 1990s could be considered a tipping point during which the ice-ocean system entered a new era of thinning ice and increasing summer open water due to positive feedbacks. Comiso (2006) suggests that a dramatic decade of change in Arctic cyclone activity has arrived as a result of these changes.

Although Northern Hemisphere cyclone tracks are not expected to change, the frequency and intensity or 'deepening' of Arctic cyclones are expected to increase in northern regions of cyclogenesis (Manson \& Solomon, 2007). During the period 19482002, the frequency of cyclones entering into the Arctic basin increased significantly, while the number of storms forming in the Arctic basin did not change (Sepp \& Jaagus, 2011). The results of the analysis presented by Sepp \& Jaagus (2011) are in line with the conclusions of other studies (Serreze et al., 2000; McCabe et al., 2001) which indicate that cyclonic activity in the Arctic basin increased significantly during the second half of the twentieth century. Sepp \& Jaagus (2011) also indicate that one of the more substantial changes revealed by their analysis is the 'deepening' or 'strengthening' of Arctic cyclones. This suggests that the advection of warm air masses may be more intense than it was 50 years ago. In terms of the persistence of Arctic sea ice coverage, intense warming of the Arctic Ocean and the occurrence of stronger storms in this region could further destroy ice cover resulting in a modification in albedo, as the ice-free sea surface absorbs more radiation (Simmonds et al., 2008). A study conducted by Simmonds and Keay (2009) adds to the evidence which suggests that the decline in Arctic ice thickness 
and extent has started to render this region particularly vulnerable to anomalous cyclonic activity.

\subsection{Storm surges in the Beaufort Sea and Mackenzie Delta}

Polar amplification in Arctic regions could lead to accelerated sea-level rise, more frequent and extreme storm winds and storm surge flooding, decreased sea-ice extent, more frequent and higher waves, and increased air temperatures (Marsh \& Schmidt, 1993). Changes to the Beaufort Sea shoreline are occurring due to the impact of these storms and rising relative sea level (Manson \& Solomon, 2007). During the October to June ice season, wave and surge development are suppressed (Murty \& Polavarapu, 1979). In contrast, during the ice-free season (June-October), storm waves and surges impact the coastline left unprotected by the ice-free conditions. Storm surges in the Beaufort Sea, as opposed to surges affecting the southern Canadian east and west coasts, are invariably influenced by the presence of sea ice, which either reduces the effective fetch available for surge build-up (Mason \& Solomon, 2007). In the early winter when ice growth is accelerating, the open water area available for surge build-up can be significantly affected by rapid changes in ice cover due to wind-induced ice movement (Manson \& Solomon, 2007). The combination of winds with greatly increased amounts of open-water and a longer open water season implies increased wave energy available for storm development (Simmonds et al., 2008). When considered with increased temperatures and sea-level rise, accelerated rates of coastal change and increased occurrence and severity of flooding are likely along the shorelines of the Beaufort Sea (Manson \& Solomon, 2007). 
The Mackenzie Delta is influenced by low frequency, high magnitude events, which exert acute, unpredictable effects such as short-lived, extreme increases in sea level rise (i.e. storm surges) (Cahoon, 2006). These disturbances are ecologically important in this region because they can affect a large area, due to the low relief that characterises much of the delta. Storm surges in the Beaufort Sea have previously been identified and discussed elsewhere (Henry, 1975; Henry \& Heaps, 1976; Reimnitz \& Maurer, 1978; Harper et al., 1988). The most notable storm surge that have been documented to date in the Mackenzie Delta-Tuktoyaktuk region occurred in 1970, when a severe storm tracking eastward in the Beaufort Sea generated a storm surge that affected the Yukon coast, the Mackenzie Delta and the coastal hamlet of Tuktoyaktuk with wave heights up to $4.2 \mathrm{~m}$ (Reimnitz \& Maurer, 1979). The Tuktoyaktuk tidal gauge was not operating at the time of the 1970 surge, so the exact surge height is unknown, though estimates have been made through the combination of surveying of log debris lines and observations from local residents (Harper et al., 1988). The frequency and magnitude of storm surge occurrence is typically documented through the analysis of long-term tidal records and the return periods of particular surge elevations identified (Harper et al., 1988). Unfortunately, tidal records for this region extend back only as far as 1961 and the record contains numerous gaps such that some of the largest known surges in this region, in 1944, 1970 and August $23^{\text {rd }} 1986$, were not recorded. As a result, an insufficient number of large surges have been recorded to accurately estimate return periods of potentially destructive surges (Simmonds et al., 2008).

Kokelj et al. (2012) used field data, remote sensing, and Inuvialuit knowledge to document regional ecological change in the outer Mackenzie Delta and to explore the 
timing, causes, and implications of the 1999 storm surge. The 1999 storm surge event was different than previously documented storm surges in the region and had such dramatic and devastating impacts on the outer Mackenzie Delta for a number of reasons. On a broad scale, climate warming and particularly "polar amplification" has resulted in numerous impacts to the Arctic environment. For example, as sea ice extent declines, fetch (the distance of open water across which the wind blows and generates waves) increases. Coupled with higher sea levels and increases in the intensity and frequency of arctic cyclones, conditions for heightened storm surge development are expected (Sepp \& Jaagus, 2011).

More specifically, in the days leading up to the 1999 storm surge, the conditions were favourable for the creation of a large Arctic cyclone capable of producing a sizable storm surge (Kokelj et al., 2012). The 1999 cyclone was a mesoscale Arctic storm that developed over the northeast Pacific and western Bering Sea, intensified explosively in the Gulf of Alaska and developed into a meteorological bomb (Perrie et al., 2008). The storm made landfall at Cape Newenham, Alaska, crossed the Rocky Mountains to the Yukon and Northwest Territories and re-intensified over a zone of high sea surface temperature gradients in the southern Beaufort Sea. Prior to the arrival of the cyclone, winds were blowing from the south and offshore, pushing the freshwater cap that resides adjacent to the outer Mackenzie Delta away from the coast (Kokelj et al., 2012). This may have allowed more saline water to upwell near the coast, replacing the normally freshwater with brackish water. As the storm moved to the east and away from the Mackenzie Delta, strong northwest winds developed and began pushing water from the Beaufort Sea into the Mackenzie Delta. The storm surge that developed was likely one of 
the largest to impact the delta in the past century and possibly in the last several centuries (Pisaric et al., 2011; Vermaire et al., 2013). With no freshwater cap and sea ice cover not yet formed, the low-lying coastline was left vulnerable to the rapid inundation of the cold and brackish waters from the Beaufort Sea.

These circumstances, late in the season during a warm year when lakes and ponds had not yet completely frozen over and freezing of the active layer was not complete, provided ideal conditions for this storm surge to have significant ecological impacts for the outer Mackenzie Delta. The ecological impact was driven by the high salinity flood waters that flowed over the surface of the outer delta causing the death of much of the shrub and herbaceous vegetation that dominated the area prior to this event (Pisaric et al., 2011). A decade later, soils across the impacted area still have exceedingly high chloride concentrations, inhibiting the re-establishment of vegetation communities (Pisaric et al., 2011). Similarly, elevated lake-water salinity levels have also driven ecological changes in diatom and cladocera communities (Deasley et al.. 2012; Thienpont et al. 2012). but the impacts to chironomid communities have yet to be studied.

The rapid loss of coastline is one major consequence of increased storm surge activity in Arctic regions. A recent study conducted by Jones (2009) found that a $\sim 65 \mathrm{~km}$ stretch of Alaska coastline along the Beaufort Sea retreated an average of $6.8 \mathrm{~m}$ per year between 1955 and 1979. During the next 23 years the rate increased by another $2 \mathrm{~m}$ per year. The low-lying coastline then lost $8.5 \mathrm{~m}$ of land per year between 2002 and 2007, and $\sim 14 \mathrm{~m}$ between 2008 and 2009 . These extreme losses are due not only to greater exposure of the land to storms from an increasingly ice-free Arctic, but also to melting permafrost that hastens coastal retreat in the Arctic. 


\subsection{An overview of the Mackenzie Delta}

Spanning an area of more than $13,000 \mathrm{~km}^{2}$, the Mackenzie Delta is the second largest Arctic delta, smaller only than the Lena River Delta in Russia, and lies at the northern margin of North America (Burn \& Kokelj, 2009). The land to the east and south of the delta is the northwest corner of the Interior Plain of Canada, a sedimentary basin between the Cordillera mountain chain and the Canadian Shield. The delta itself fills a portion of the Mackenzie Trough, which trends northwest into the Beaufort Sea and is bordered by the Richardson Mountains to the west (Burn \& Kokelj, 2009). The alluvial plain is approximately $62 \mathrm{~km}$ long and $210 \mathrm{~km}$ wide with an average elevation of 15 meters above sea level (Mackay, 1963). The area of the delta covered by lakes varies from 15 to $30 \%$ of total area in the southern portion of the delta, $30-50 \%$ in the middle and $<15 \%$ percent north of the treeline. In total there are more than 25,000 lakes in the Mackenzie Delta (Mackay, 1963).

There is a northward decrease in the proportion of shrub tundra (including species such as Alnus viridis, tall Salix spp. and Betula glandulosa) across the Mackenzie Delta region (Lantz et al., 2010). The northward decrease in the dominance of shrub tundra corresponds to an increase in the abundance of dwarf shrub tundra including Ledum decumbens, Vaccinium vitis-idaea, Arctostaphylos rubra, Rubus chamaemorus and sedges Eriophorum vaginatum, and Kobresia hyperborean (Lantz et al., 2010). The lowlying ground of the outer Mackenzie Delta is primarily dominated by sedge-wetlands (Cyperaceae), while small willow (Salix sp.) and alder (Alnus sp.) communities are generally found on aggrading point bars and lakes that grade into marshes (Tarnocai et al., 2004). 
The Mackenzie Delta is primarily underlain by 10 to $14 \mathrm{~km}$ of clastic and carbonate sedimentary rock of Cretaceous to Tertiary origin overlain by Wisconsinan till (Dixon et al., 1992). The oldest rocks in the Mackenzie Delta region are argillites that date back to the Precambrian and have been folded and faulted and possibly once formed a mountain chain that has since been eroded (Mackay \& Dyke, 1990). During the Silurian and Ordovician, carbonates were exposed further south in the Campbell Uplift. While the majority of this fossil land surface has since been buried by Cretaceous shale, portions of it remain exposed to this day (Mackay \& Dyke, 1990).

During the Wisconsinan glaciation, the Mackenzie Delta region was almost entirely covered by the Laurentide ice sheet, when the maximum extent of ice was reached about $30 \mathrm{ka} \mathrm{BP}$ or slightly thereafter (Murton, 2009). However, portions of the outer Mackenzie Delta and Richards Islands remained ice-free throughout much of the last glaciation and the region around Inuvik became ice free at approximately $14,500 \mathrm{BP}$ (Ritchie, 1985). The modern Mackenzie Delta is a post-glacial Holocene feature (Murton, 2009). It consists primarily of silt transported seaward following the last glaciation by drainage diverted from the Mackenzie Basin (Murton, 2009). To this day, the Mackenzie Delta continues to grow at a rate of approximately 128 metric tonnes $(\mathrm{Mt})$ of sediment per year, with 83 percent supplied by the Mackenzie River and the remainder by the Peel River (Carson et al., 1998). The sedimentation rate in most delta lakes averages approximately $5 \mathrm{~mm} / \mathrm{yr}$ (Marsh et al., 2002).

Sea level along the Beaufort Sea coast of the outer Mackenzie Delta has risen throughout the Holocene causing a coastal retreat of over $100 \mathrm{~km}$, resulting in four distinct depositional histories for terrestrial sites in the area (Burn, 1997). First, there is 
the portion of the delta that remained above water throughout the Holocene. This upland terrain is mainly comprised of surficial materials that are typically aeolian sand or till (Dallimore et al., 1997). Secondly, parts of the outer Mackenzie Delta have been submerged by rising sea-levels, but have emerged as a result of sedimentation (Murton, 2009). Thirdly, in the majority of the delta, the surface has been rising due to isostatic uplift following the last glaciation. As the land becomes more elevated, permafrost also begins to aggrade, further elevating the surface (Burn, 1997). Finally, in the thermokarst basins of the Tuktoyaktuk coast to the north and east of the delta, the sediments are commonly found to be reworked lacustrine deposits with a layer of peat at the surface (Murton, 1996).

\subsection{Modern climate regime of the Mackenzie Delta region}

The Mackenzie Delta region is located in the high sub-Arctic eco-climatic zone of Canada and is characterized by short, cool summers and very cold winters (Bonsal \& Kochtubajda, 2009). Across Canada, $20^{\text {th }}$ century warming trends have been greatest in northwest Canada and the Mackenzie Basin in particular (Bonsal \& Kochtubajda, 2009). Monthly average temperatures for Inuvik range from $-27^{\circ} \mathrm{C}$ in January to $14^{\circ} \mathrm{C}$ in July (Environment Canada, 1971-2000 climate normals). Extreme daily temperatures have varied from approximately $-56^{\circ} \mathrm{C}$ to $32^{\circ} \mathrm{C}$ (Bonsal \& Kochtubajda, 2009). The Mackenzie Delta region is experiencing rapid changes in terms of temperature as the mean annual air temperature has increased by more than $2.5^{\circ} \mathrm{C}$ since 1970 (Burn \& Kokelj, 2009). Warming has been most pronounced during winter and spring (by $\sim 3.0$ $\left.{ }^{\circ} \mathrm{C}\right)$. 
Annual precipitation has increased by 5-35\% across many parts of Canada during the last half century, with the greatest increases having occurred north of $60^{\circ} \mathrm{N}$ (Zhang et al., 2000). Mean annual precipitation in the Mackenzie Delta region is estimated at $250 \mathrm{~mm}$, but there is large uncertainty due to inadequate sampling and errors with gauge measurements, especially in winter (Goodison et al., 1998). Brown (2000) found that between 1915 and 1997, precipitation values revealed an increase in the proportion of rain and snow falling as heavy events over the region. However, snow cover extent has decreased over most of the Canadian Arctic, particularly during late winter/early spring (Brown, 2000). The warmer springs in the Mackenzie Basin are also reflected in the significantly earlier occurrence (nearly 10 days) of spring melt during the period 1950 to 1998 (Bonsal and Prowse, 2003). In terms of extremes, Bonsal et al. (2001) found that in the Mackenzie Delta region, the period between 1950 and 1998 experienced a trend toward fewer days with extreme low temperatures, and more days with extreme high temperatures during winter, spring, and summer.

Ground temperatures show similar warming trends and provide further the evidence of intense warming across the Arctic region. However, ground temperatures in the delta itself are distinctly different from the uplands located farther inland due to the thermal influence of numerous lakes and shifting channels (Burn \& Kokelj, 2009). Across the Mackenzie uplands adjacent to the delta, ground temperatures have increased $\sim 1.5^{\circ} \mathrm{C}$ since the $1980 \mathrm{~s}$. During the same period, ground temperatures near the coast have increased nearly $2.5^{\circ} \mathrm{C}$ (Burn \& Kokelj, 2009). However, the increase has been less pronounced in the delta, south of treeline, due to the thermal influence of water bodies on ground temperatures. The impact of these increasing temperatures on permafrost is 
evident as the active layer thickness has increased by an average of $8 \mathrm{~cm}$ on Richards Island between 1983 and 2008 (Burn \& Kokelj, 2009). In addition, the southern limit of the sporadic discontinuous zone has migrated northward across the southern Mackenzie Basin by approximately $120 \mathrm{~km}$ since the $1960 \mathrm{~s}$ (Kwong \& Gan, 1994).

Increasing temperatures have had and continue to have discernible environmental impacts in the Mackenzie Delta. For example, the freshwater ice season has become significantly shorter mainly due to earlier break-up (Lacroix et al., 2005). In fact, at the Mackenzie River East Channel, Marsh et al. (2002) found that the timing of spring breakup significantly advanced from an average date of 6 June in the 1960s to 28 May in the 1990s. Mackenzie Basin peak river flows also occur significantly earlier due to an earlier onset of spring snowmelt (Woo \& Thorne, 2003).

\subsection{Holocene climate regime of the Mackenzie Delta region}

Four distinct climatic phases have been recognized in the late glacial and Holocene climate of the Mackenzie Delta area through pollen analysis (Ritchie, 1985). Between 14,500 and 12,000 BP, the climate in the delta region was cold and dry, followed by a gradual warming to the period of maximum solar insolation around 10,000 BP (Ritchie et al., 1983). The warmest period in this region occurred during the early Holocene (10,000 to $6,000 \mathrm{BP})$ and resulted in the advancement of the treeline to beyond its present day location. It was located further north during the early Holocene and extended as far north as Tuktoyaktuk between 8,000 and 7,000 years ago (Ritchie et al., 1983). Following $6,000 \mathrm{BP}$ there was a return to cooler climatic conditions in the Mackenzie Delta region except for a brief period from $\sim 1000$ to $700 \mathrm{BP}$, known as the Medieval Warm Period (Ritchie, 1985). However, during the last 40 years, the western 
Arctic of North America has been one of the most rapidly warming regions on Earth (Serreze et al., 2000). The recent increase in mean annual temperatures is widespread across northwestern Canada and is documented at all stations in the Yukon and Northwest Territories suggesting this warming trend is not peculiar to the Mackenzie Delta region (Burn \& Kokelj, 2009).

\subsection{Paleoecological studies in the context of climate records}

With respect to the concept of ecological history, 'ecology' refers to present-day ecological factors that reflect the extant species' niches, while 'history' accounts for longer term processes linked to ecological succession, range shifts and evolution (Rull, 2010). A relevant question with regards to ecological history is where the boundary between the past (history) ends and the present (ecology) begins (Rull, 2010).

Paleoecology, often defined as "the ecology of the past", is the discipline charged to bridge the gap between ecology and history (Birks \& Birks, 1980). Other possible definitions of paleoecology are much more exhaustive but often incomplete, as they consider only the relationship between organisms and the (physical) environment, thus forgetting biotic interactions (Birks et al., 2010). An explicit and more complete definition would be: "the branch of ecology that studies (the) past (of) ecological systems and their trends in time using fossils and other proxies" (Rull, 2010). Paleoecology uses data from the fossils and subfossils of biological organisms found in the sediment to reconstruct the ecosystems of the past (Sahney et al., 2010). It involves the study of fossil organisms and their associated remains, including their life cycle, living interactions, natural environment, and manner of death and burial to reconstruct the 
paleoenvironment. The aim of paleoecology is therefore to build the most detailed model possible of the ecological conditions in which previously living organisms were found (Sahney et al., 2010).

The most unique aspect of paleoecological research is its ability to provide ecological data for a given area when written or instrumental records do not exist and thereby indirectly extend climate records when the optimal ecological conditions of taxa are understood. Paleoecology provides a unique temporal perspective on patterns, causes, and rates of ecological change due to natural hydrologic and climatic variability, as well as anthropogenic activity (Willard \& Cronin, 2007). Paleoenvironmental reconstructions primarily utilize subfossil assemblage data from biological proxies such as pollen, ostracods, chironomids, diatoms, foraminifera and cladocera. Tree rings, and even geochemical proxies for aquatic or atmospheric conditions can also be used, allowing direct comparisons of biological and physical patterns (Willard \& Cronin, 2007). If aspects of an abiotic component in a past ecosystem can be studied directly or reconstructed indirectly, these variables can be regarded as a set of predictors or forcing functions within the past ecological system under study, provided the community is responsive to these factors. The biotic components of the system can thus be viewed as response variables (Birks et al., 2010). Relative species abundance and species richness describe key elements of biodiversity (Hubbell, 2001). Relative species abundance is a component of biodiversity and refers to how common or rare a species is relative to other species in a defined location or community (Hubbell, 2001). The relative abundance of each species is dependent upon changes in the relative abundance of other species within the defined community, but the total relative abundance must always equal 100 percent 
(Hubbell, 2001). The relative abundance of a particular species within a community will be greater if conditions are found to be optimal for that species, while relative abundance of those species with suboptimal conditions will be less in comparison. Species richness is simply the number of different species represented in an ecological community, landscape or region. It is a count of species, and it does not take into account the abundances of the species or their relative abundance distributions (Colwell, 2009). Important ecological processes and properties such as the nature of biotic responses to environmental change, base-line conditions, thresholds, resilience, and ecosystem novelty can then be deduced from the paleoecological record (Willis \& Bhagwat, 2009; Willis et al. 2010).

Most paleoecological research has focused only as far back as the last two million years (the Quaternary period), because older environments are less well represented in the fossil record due to loss or distortion via the fossilization process or diagenesis of the enclosing sediments (Taylor \& Wilson, 2003). Many studies concentrate on the Holocene epoch $(\sim 11,000$ years), or the last glacial stage of the Pleistocene epoch (from 50,000 to 10,000 years ago) as paleoecological studies are dependent upon the length of cores that can be retrieved from lakes and the time span that these cores represent (Sahney et al., 2010). Only since the first half of the $20^{\text {th }}$ century have scientists used fossils preserved in lake and bog sediments and the composition as well as physical properties of these sediments as a basis for the quantitative reconstruction of the past local and regional environment (Birks et al., 2010). The early studies of Blytt (1881), Iversen (1944), von Post (1946), and others using plant macrofossils, animal remains, pollen assemblages, 
and peat stratigraphy laid the foundation for many of the current quantitative paleoecological reconstructions (Willard \& Cronin, 2007).

\subsection{Chironomids as paleoecological indicators}

The suitability of chironomids for paleolimnological/paleoecological research can be summarized as follows: 1) chironomid faunas of lakes are highly diverse (generally high numbers of both species and individuals in lake sediments); 2) the environments potentially occupied by chironomids are extremely varied because of the ability of individual chironomid species to tolerate large environmental gradients of $\mathrm{pH}$, salinity, depth, oxygen concentration, temperature and productivity (Armitage et al., 1995). However, while the Chironomidae family is broadly tolerant of a variety of conditions, individual species are adapted to particular ecological conditions and habitats making it possible to relate species abundance to particular environmental conditions; 3) the chitinous head capsules of the moulted skins are preserved in lake sediment and are usually abundant enabling continuous, high precision, fine resolution studies; 4) identification of the remains to genus and often species level is possible; 5) due to the ecological requirements of the taxa, the subfossil record is indicative of the ecological conditions at the time of sedimentation; 6) successional changes in the chironomid fauna are documented in the sediment and 7) such faunal successions are indicative of changing ecological conditions during lake development. Thus, subfossil chironomids, in much the same manner as other biological proxies including cladocera and diatoms, provide valuable information on the environmental conditions during lake ontogeny (Hofmann, 1988). 
Geographically, Chironomidae are the most widely ranging family of aquatic inverterbrates with their distribution exceeded only by aquatic collembolans and mites (Armitage et al., 1995). In terms of freshwater aquatic insects, Chironomidae contain the largest number of aquatic species, and comprise roughly $25 \%$ of the freshwater macroinvertebrate group (Cure, 1985). Estimates of global species richness, range from approximately 8,000 to more than 20,000 species (Coffman, 1995). The Chironomidae consists of ten subfamilies worldwide including Chilenomyiinae, Aphroteniinae, Buchonomyiinae, Telmatogetoninae, Podominae, Diamesinae, Prodiamesinae, Orthocladiinae, Tanypodinae and Chironomidae with the last three most commonly encountered in freshwater ecosystems and are the focus of this study (Porinchu \& MacDonald, 2003).

A number of studies including McGarrigle (1980), Pinder (1980) and Winnell \& White (1985) have identified substrate as an important determinant of chironomid community composition and distribution. Chironomids tend to associate with particular substrates during their larval stage. Aquatic vegetation has been suggested to increase the amount of potentially available benthic habitat and most studies indicate a positive relationship between the presence of macrophytes and chironomid taxon abundance and diversity (Porinchu \& MacDonald, 2003). Members of both Orthocladiinae and Chironominae, which have been identified in the Mackenzie Delta area, have been found to prefer plant tissue and submerged wood for habitat over other subtrates (Cranston \& Oliver, 1987).

Chironomids are holometabolous insects, meaning they experience complete metamorphosis during their lifetime from egg-larvae-pupae to adults (Porinchu \& 
MacDonald, 2003) (Fig. 1). During their lifetime chironomid larvae produce four moults (known as instars) of which the head capsules of three are preserved in the sediment (Stahl, 1969).

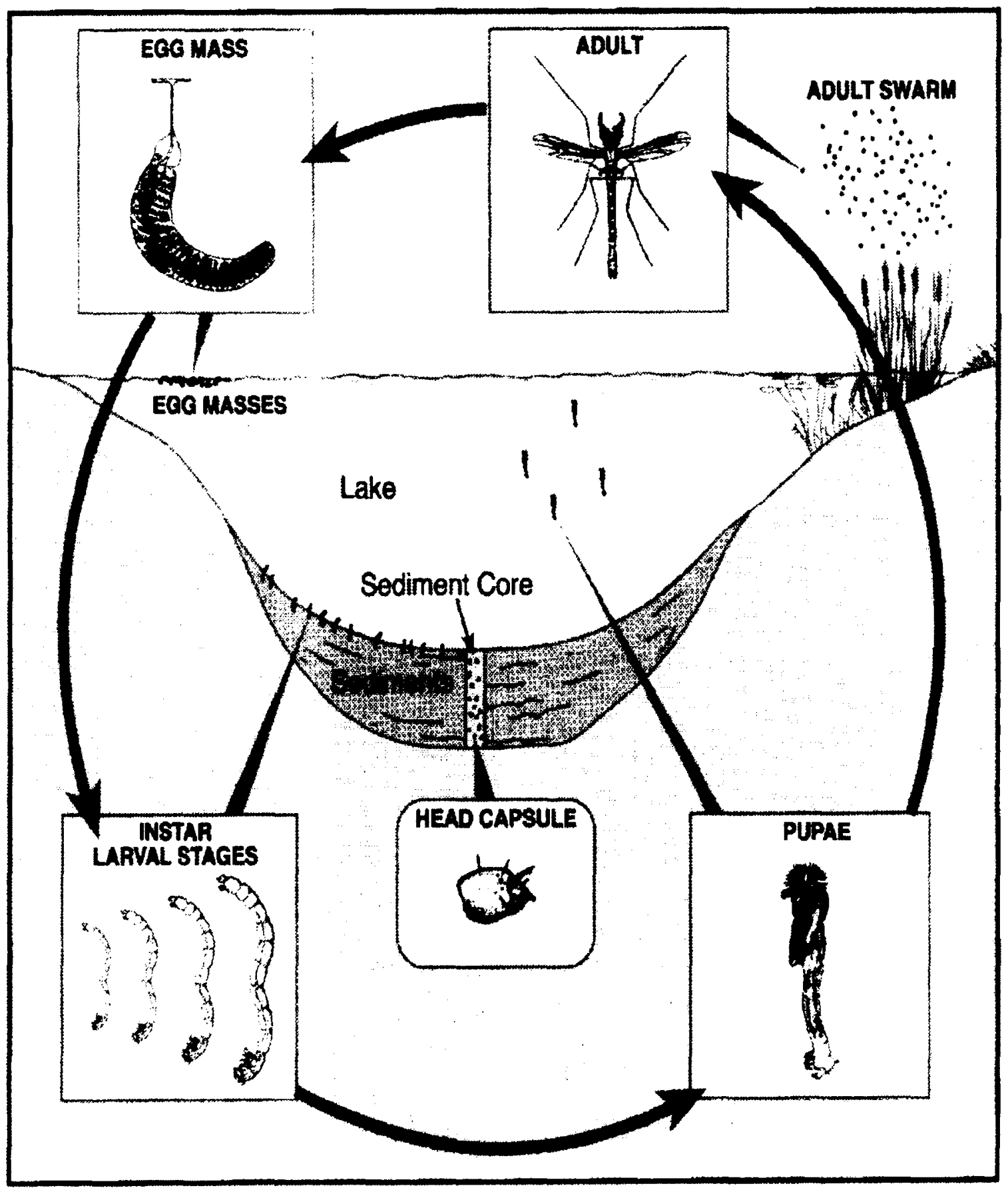

Figure 1 - Typical life cycle of aquatic Chironomidae (Porinchu \& MacDonald, 2003) 
It typically takes a few days to a month for the eggs to hatch and the first of four larval instars to emerge (Porinchu \& MacDonald, 2003). The larvae undergo ecdysis (shedding of the exoskeleton) three times which results in the second to fourth instars. The majority of the larval period is spent in the fourth larval instar stage where the larvae, which appear maggot-like in form, range from 1 to $20 \mathrm{~mm}$ in length (Porinchu \& MacDonald, 2003). While the pupal phase is relatively brief, it is during this phase that the larvae metamorphose into the adult form. Adult chironomids appear quite similar to mosquitoes, though they lack scales on their wings and lengthy proboscis. Adult males form aerial swarms into which females enter, pair-off and mate (Porinchu \& MacDonald, 2003). ) In temperate regions, a life cycle can be completed in one year, as compared to several years in high latitude regions. It has been documented that some of the most common chironomid taxa in cold, arctic waters take 2 to 3 years to complete one generation (Porinchu \& MacDonald, 2003).

Typically, only the remains of the $3^{\text {rd }}$ and $4^{\text {th }}$ instar tend to be preserved well enough in lake sediments for identification (Porinchu \& MacDonald, 2003). However, there are certain constraints on the identification of chironomid head capsule remains. Chironomid taxonomy is primarily based on characteristics of adult males, so in many cases it is impossible to identify a complete larva to species (Hofmann, 1988). In subfossil material, the body of the larva is missing and often the head capsule is rarely complete since the antennae are generally absent. In many specimens only the ventrolateral part of the head capsule with the mentum remains intact (Fig. 2) and as a result, for some taxa including subfossil Chironominae and Orthocladiinae, identification is possible only to the generic rather than species level (Armitage et al., 1995). This may 
have implications with regards to the accuracy of which a particular taxa is identified and may make it more difficult to conduct paleoenvironmental reconstructions without narrowing down the specific environmental optima of a particular species.

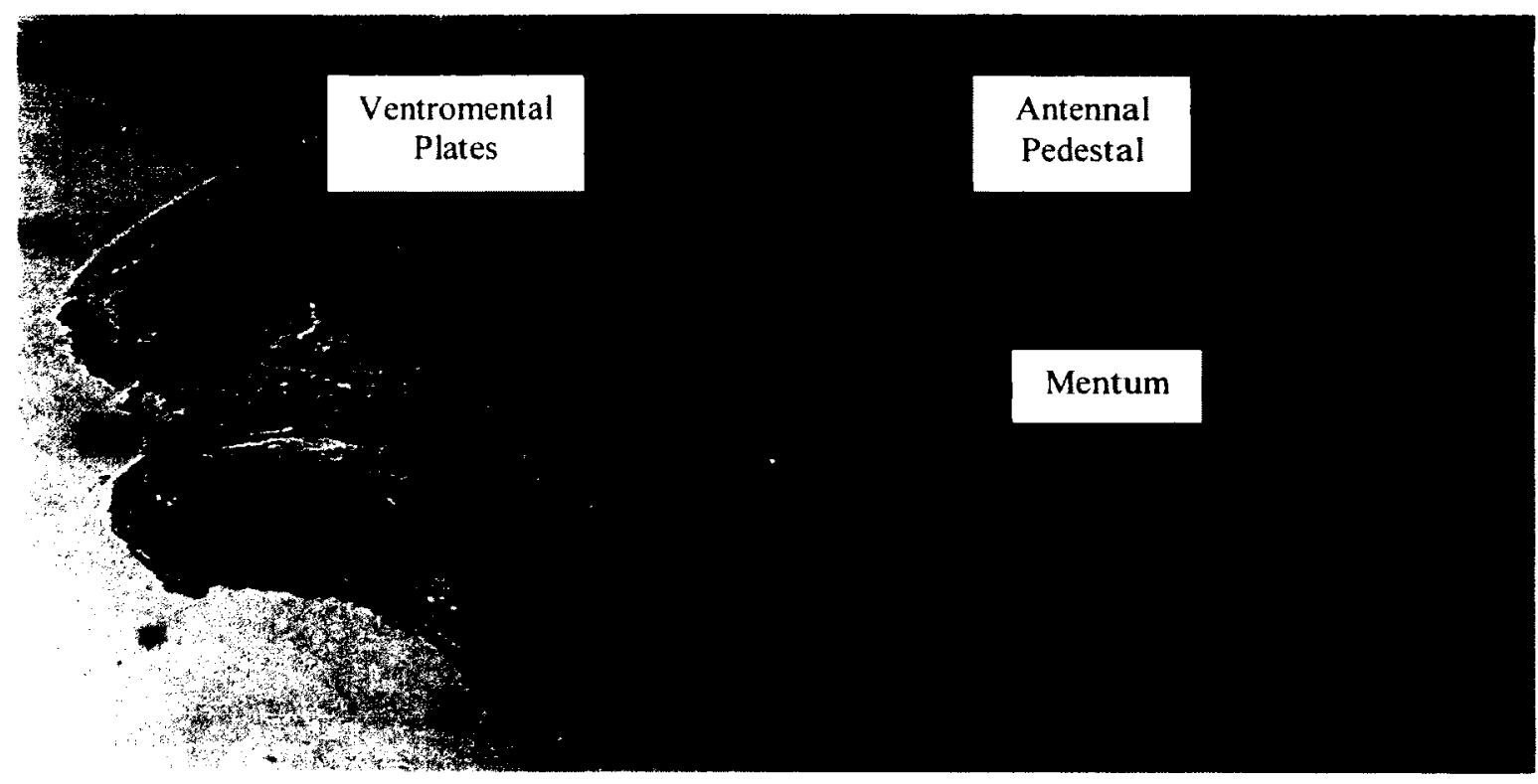

Figure 2 - Images of Corynocera oliveri type-1 chironomid head capsules taken from DZO-29. Distinguishing features include the 3D shape of the mentum with 3 median teeth and 4 lateral teeth on different focal planes. Antennal pedestal lacks any basal spur. 
The ecology of Arctic organisms is particularly interesting as the Arctic environment provides severe and potentially limiting stresses related to dissolved oxygen content, organic matter content, salinity and temperature (Gajewski et al., 2005). While it has long been recognized that correlations can be established between the types of chironomid found in the profundal zone of lakes and the trophic status of the lake, little information appears to be available on the manner in which interactions between the measure of trophic status are related to the composition of the chironomid community in shallow water habitats, particularly in Arctic regions. In addition, it is not well understood how the various biotic and abiotic parameters interact to control the structure and composition of shallow water chironomid communities in Arctic lakes and ponds (Clair \& Paterson, 1974). Several of these could potentially be limiting in the Arctic, where the sediments tend be inorganic and the climate includes low temperatures, a short ice-free season and periods of 24-hour darkness. These conditions vary in time and space, affecting the distribution and abundance of Arctic chironomid organisms (Gajewski $e t$ al., 2005).

Although chironomids are most commonly used in paleolimnological studies to reconstruct lake productivity, they have also proven to be good indicators of fluctuating salinity concentrations in lake environments (Hofmann, 1988). There are a number of physiological adaptations, including osmotic regulation, which chironomids have developed that enable them to tolerate moderate salinities (Porinchu \& MacDonald, 2003). While most chironomids are limited to freshwater environments, some taxa such as Cricotopus/Orthocladius and Tanypus, are associated with saline environments and can be found at salinities exceeding $10,000 \mathrm{mg} \mathrm{L}^{-1}$ (Walker et al., 1995). It is generally 
accepted that diatoms are slightly better salinity indicators than chironomids, however the siliceous remains of diatoms and chrysophytes are often destroyed by dissolution in saline lake sediments (Walker et al., 1995). In these circumstances, the chitinous remains of chironomids may provide the only available means to document salinity as well as to document ecological changes in lakes (Walker et al., 1995).

\subsection{Documented ecological impacts of storm surges}

Periodic pulses of saltwater into freshwater ecosystems will influence the survival and community composition of a range of biota. Although such dramatic increases in chloride concentrations may be rapid and short-lived, the consequences to the freshwater ecology are still relatively unknown (Nielsen et al., 2003). An understanding of the rates and processes of colonization and stabilization of aquatic communities is of importance in predicting the recovery of habitats from natural perturbations such as storm surges (Clair \& Paterson, 1974).

There have been numerous studies that have documented chironomid distributions in lake sediments from the boreal and treeline regions of North America (Walker, 1990; Walker \& MacDonald, 1995; Olander et al., 1997, 1999; Lotter et al., 1999; Brooks \& Birks, 2000), and several recent chironomid-based studies from the Arctic (Quinlan et al., 2005; Rolland et al., 2008; Porinchu et al., 2009). Wooller et al. (2003) show that the $\delta^{18} \mathrm{O}$ values in head capsules of chironomid larvae are equilibrated with the $\delta^{18} \mathrm{O}$ of the lake water in which they live and that chironomid $\delta^{18} \mathrm{O}$ can be used to provide quantitative estimates of past changes in mean annual air temperature. Porinchu et al. (2009) describes the distribution of midges in a suite of 88 lakes in the central Canadian Arctic, in order to develop a quantitative inference model for average July air 
temperature. These lakes spanned five vegetation zones, with the southern-most lakes located in boreal forest and the northern-most lakes located in mid-Arctic tundra. Porinchu et al. (2009) found that a chironomid-based inference model, based on a twocomponent weighted average-partial least squares (WA-PLS) approach, provided robust performance statistics with a high coefficient of determination, low root mean square error of prediction and low maximum bias. That application of the quantitative midgebased inference model provided the first quantitative estimates of the thermal conditions that existed during the Holocene. Sedimentary records from three Canadian high Arctic ponds on Ellesmere Island, spanning the last several thousand years, show major shifts in pond communities within the last $\sim 200$ years according to Quinlan et al. (2005). These examples of paleolimnological research indicate that Chironomidae populations rapidly expanded and greatly increased in community diversity beginning in the 19th century. These invertebrate changes coincided with striking shifts in algal (diatom) populations, indicating strong food-web effects because of climate warming and reduced ice-cover in ponds. In a 2008 study conducted by Rolland et al. (2008), Chironomidae found in a Southampton Island (Nunavut, Canada) lake were utilized in an attempt to refine the knowledge of Holocene climatic variability in this region. This study, which was mainly based on fossil chironomid interpretations, suggested that there was no significant warming at that site since $\sim 7000 \mathrm{yr} \mathrm{BP}$. This is consistent with reconstructions further south in Quebec (Rolland et al., 2008), but contrasts with reconstructions obtained from the higher Arctic, and suggests that Southampton Island has not yet been influenced by climate warming trends that have been documented throughout the Arctic region. These are just a few examples of the important chironomid work that has been conducted in the 
Arctic region during the past decade. However, chironomid-based research in these remote Arctic regions is ongoing and is vital to gain a better understanding of how climate change has and continues to impact both the physical, biological and ecological components of the Arctic system. To date, chironomids have not been previously used to examine the ecological impacts of storm surges in the Arctic. This is where this study differs from other Arctic chironomid-based studies, and offers the potential to assess the fragility of an Arctic ecosystem.

In a different region, in what was found to be the only other study similar to ours, Clair \& Paterson (1974) examined two 90-cm sediment cores from Front Lake, New Brunswick, in an attempt to understand the ecological effects of a saltwater intrusion on a freshwater chironomidae community. Clair \& Paterson (1974) determined that the chironomid community consisted of at least 24 species prior to a saltwater storm surge. If it is assumed that the destruction of the original community has not modified the trophic potential of the habitat, then the question is raised as to whether the community that will become established upon removal of the disturbance will be identical to the predisturbance community (Clair \& Paterson, 1974). Following the dilution of the saltwater and a return to fresh water conditions, 23 species recolonized the lake, of which 22 occurred prior to the saltwater intrusion. Clair and Paterson (1974) concluded that the chironomid community established in Front Lake, both before and after the saltwater intrusion, had essentially identical species composition, relative abundances of each species and species diversity indices. The chironomid assemblage above $5 \mathrm{~cm}$ was found to be essentially identical to the assemblage seen below $67 \mathrm{~cm}$, prior to the saline 
inundation, in the $90 \mathrm{~cm}$ Front Lake core. Ultimately, the impacts of the storm surge did not significantly change the composition of the chironomid community in Front Lake.

However, the Front Lake, NB region is a very different environment than that of the Mackenzie Delta. Most importantly, the region lacks permafrost where chlorides can be sequestered for long periods of time, providing an ample source of chlorides to aquatic systems for potentially long periods of time. Additionally, most flooding in the Mackenzie Delta is the result of spring break-up and is a freshwater flood. The timing of break-up and the spring freshet in the Mackenzie Delta is controlled by conditions in more southern regions well upstream of the Mackenzie Delta (Marsh \& Hey, 1994). As snow melts and temperatures warm in the southern headwaters of the Mackenzie and Peel Rivers, a flood of water moves north into the still frozen Mackenzie Delta. Water levels rapidly rise and ice jams cause additional flooding (Marsh \& Hey, 1994). However, lakes that are not connected to the delta channels remain ice covered during this flooding. As a result, the influx of freshwater into these still frozen lakes (some of which may be frozen to the bottom) is inhibited. Summer flooding in the Mackenzie Delta is normally due to storm surge events. As storms move across the region, powerful northwest winds can push saline water into the delta and flood low-lying lakes. Some of the lakes that were flooded in the 1999 storm surge that impacted the outer Mackenzie Delta, still have chloride readings $>100 \mathrm{mg} \mathrm{L}^{-1}$ and in some cases $>5000 \mathrm{mg} \mathrm{L}^{-1}$ (Table 1). Similarly, soils in the impacted region continue to have high soil soluble chloride levels (Kokelj et al., 2012). Therefore, it appears that recovery in Arctic systems impacted by storm surges may take considerably longer than in more temperate coastal regions. 
Table 1. Select physical and chemical variables from five lakes in the outer Mackenzie Delta, including study lakes DZO-29 and DZO-30, ordered according to distance from the coast (according to Table 1 from Thienpont et al., 2012). Samples for water chemistry analysis were collected using a helicopter in August 2009, from the centre of the lakes approximately $1.0 \mathrm{~m}$ below the surface.

\begin{tabular}{|c|c|c|c|c|c|c|c|c|c|c|c|c|c|c|}
\hline Lake ID & $\begin{array}{l}\text { Latitude } \\
\qquad(\mathrm{N})\end{array}$ & $\begin{array}{c}\text { Longitude } \\
\left({ }^{\circ} \mathrm{W}\right)\end{array}$ & $\begin{array}{c}\text { Impacted } \\
\text { or not? }\end{array}$ & $\begin{array}{c}\text { Surface } \\
\text { Area } \\
\text { (ha) }\end{array}$ & $\begin{array}{c}\text { Distance } \\
\text { from } \\
\text { coast } \\
(\mathrm{km})\end{array}$ & $\begin{array}{c}\text { Cond. } \\
(\mu \mathrm{S} / \mathrm{cm})\end{array}$ & $\mathrm{pH}$ & $\begin{array}{c}\mathrm{NO}_{3}^{-} \\
(\mathrm{mg} / \mathrm{L})\end{array}$ & $\begin{array}{c}\mathrm{DOC} \\
(\mathrm{mg} / \mathrm{L})\end{array}$ & $\begin{array}{c}\mathrm{Ca}^{2+} \\
(\mathrm{mg} / \mathrm{L})\end{array}$ & $\begin{array}{c}\mathrm{Na}^{+} \\
(\mathrm{mg} / \mathrm{L})\end{array}$ & $\begin{array}{c}\mathrm{Cl}^{-} \\
(\mathrm{mg} / \mathrm{L})\end{array}$ & $\begin{array}{c}\mathrm{SO}_{4}{ }^{2-} \\
(\mathrm{mg} / \mathrm{L})\end{array}$ & $\begin{array}{c}\text { TP-F } \\
(\mu \mathrm{g} / \mathrm{L})\end{array}$ \\
\hline DZO-2 & $\begin{array}{l}6910^{\prime} \\
55.5^{\prime \prime} \\
\end{array}$ & $\begin{array}{c}13558^{\prime} \\
59.1^{\prime \prime}\end{array}$ & Impacted & 126.3 & 3.57 & 14955 & 8.08 & 0.44 & 8.1 & 244 & 2750 & 5920 & 716 & 8.0 \\
\hline DZO-29 & $\begin{array}{l}6909^{\prime} \\
20.5^{\prime \prime}\end{array}$ & $\begin{array}{c}13556^{\prime} \\
52.1^{\prime \prime}\end{array}$ & Impacted & 3.5 & 6.49 & 12722 & 8.01 & 0.38 & 9.8 & 251 & 2270 & 5030 & 496 & 10.2 \\
\hline DZO-30 & $\begin{array}{l}6909^{\prime} \\
12.5^{\prime \prime}\end{array}$ & $\begin{array}{c}13557^{\circ} \\
02.0^{\prime \prime}\end{array}$ & Impacted & 8.7 & 7.25 & 6855 & 8.19 & 0.27 & 12.9 & 125 & 1120 & 2530 & 208 & 10.7 \\
\hline$T-34$ & $\begin{array}{l}6917^{\prime} \\
28.6^{\prime \prime}\end{array}$ & $\begin{array}{c}13531^{\prime} \\
48.4^{\prime \prime}\end{array}$ & $\begin{array}{l}\text { Partially } \\
\text { Impacted }\end{array}$ & 75.3 & 7.58 & 567.8 & 8.57 & 0.14 & 9.5 & 33.3 & 57.8 & 120 & 44 & 12.3 \\
\hline DZO-3 & $\begin{array}{l}6907^{\prime} \\
54.1^{\prime \prime}\end{array}$ & $\begin{array}{c}13557^{\prime} \\
08.1^{\prime \prime}\end{array}$ & Impacted & 22.6 & 7.86 & 3090 & 8.63 & 0.28 & 13.1 & 79.9 & 475 & 1000 & 89 & 15.0 \\
\hline$C-28$ & $\begin{array}{l}6904^{\prime} \\
05.5^{\prime \prime}\end{array}$ & $\begin{array}{c}13454^{\prime} \\
52.9^{\prime \prime} \\
\end{array}$ & $\begin{array}{c}\text { Not } \\
\text { Impacted }\end{array}$ & 228.8 & 42.99 & 240.1 & 8.5 & 0.12 & 9.6 & 23.9 & 6.1 & 7.7 & 34 & 9.5 \\
\hline
\end{tabular}




\section{Chapter Three}

The impact of a large Arctic storm surge on chironomid community assemblages, Mackenzie Delta, Northwest Territories, Canada

Courtney Steele ${ }^{1}$, Jesse C. Vermaire ${ }^{1}$, Joshua Thienpont ${ }^{2}$, Steven V. Kokelj ${ }^{3}$, John Smol $^{2}$ and Michael F.J. Pisaric ${ }^{1.4}$

'Department of Geography and Environmental Studies, Carleton University, Ottawa, ON, Canada K1S 5B6

${ }^{2}$ Department of Biology, Paleoecological Environmental Assessment and Research Lab (PEARL), Queen's University, Kingston, ON, Canada K7L 3N6

${ }^{3}$ Aboriginal Affairs and Northern Development Canada, Box 1500 Northwest Territories Geoscience Office, Yellowknife, NT, Canada X1A 2R3

${ }^{4}$ Department of Geography, Brock University, St. Catharines, ON, Canada L2S 3A1

Keywords: chironomid, paleolimnology, climate warming, Northwest Territories, storm surge, saltwater intrusion, ecological disturbance, arctic cyclone, sea ice 


\subsection{Introduction}

The Arctic region has experienced some of the most dramatic impacts of global climate change, including significant temperature increases, decreasing sea ice extent and melting permafrost (Hudak \& Young, 2001). Declining sea ice coverage is among the best quantified and most dramatic of the changes occurring in the Arctic since the late 1970s (Comiso et al., 2008). Not only has climatic warming caused a decrease in the extent, and thickness of sea ice, but recent warming has also led to an increase in the frequency and intensity of cyclonic activity in Arctic regions (Comiso, 2006). These changes could potentially have major consequences on already vulnerable Arctic ecosystems.

The Mackenzie Delta is a sensitive region, whose climate and physical environment are influenced by the adjacent Beaufort Sea (Prowse et al., 2006). Due to recent climatic warming, an increased frequency and intensity of Arctic cyclones is anticipated (Sepp \& Jaagus, 2011). In the outer Mackenzie Delta, coastal inundation by strong storm surges during the ice-free season is an important agent of disturbance (Manson \& Solomon, 2007). Periodic pulses of saltwater associated with storm surges into this freshwater-dominated ecosystem could influence the survival of a range of biota. In most instances these impacts, especially increases in chloride concentration, are rapid and short-lived but, the consequences for freshwater biota are not fully understood (Nielsen et al., 2003).

In September 1999, a large storm and associated storm surge swept saltwater approximately $30 \mathrm{~km}$ inland at the outer Mackenzie Delta front. Nearly $200 \mathrm{~km}^{2}$ of the outer Mackenzie Delta was impacted by this storm surge event (Solomon et al., 2000; 
Pisaric et al., 2011; Kokelj et al., 2012). This sudden influx of saltwater altered the freshwater-adapted terrestrial and aquatic systems that typify the outer Mackenzie Delta, and freshwater lakes and ponds were rapidly converted to brackish or saltwater systems (Pisaric et al., 2011). However, the direct ecological impacts of storm surges across this region have not been extensively studied, as these storms are spatially variable and have not been well documented, due to intermittent or completely absent instrumental records.

Paleolimnology provides a unique opportunity to assess the ecological impacts on these coastal lake systems. To date, only a few studies have been conducted to examine the direct ecological impacts of saltwater inundations on biological communities in the outer Mackenzie Delta. Using diatoms preserved in a small lake (DZO-29) located approximately $4 \mathrm{~km}$ from the Mackenzie Delta front, Pisaric et al. (2011) showed a striking shift from freshwater-adapted to brackish diatom taxa as a result of the September 1999 storm surge. Pisaric et al. (2011) also concluded that the ecological significance of this event was unprecedented in the $\sim 1000$ year history of their study lake with diatoms indicating that no other ecologically-significant saline intrusion had occurred in the lake's $\sim 1000$ year history. The spatial extent of the ecological impacts on these lake systems was illustrated by Thienpont et al. (2012). Upon examination, the diatoms from five impacted lakes at the delta front, show synchronous increases in the relative abundance of brackish-water diatom taxa coincident with the timing of the 1999 storm surge. No similar changes occurred at a control lake located approximately $30 \mathrm{~km}$ inland from the delta front. Deasley et al. (2012) provided further evidence of the ecological impact of the 1999 storm surge, examining cladocera remains from another small lake (DZO-30) in the outer Mackenzie Delta. The cladocera occupy a higher 
trophic level than diatoms, but were impacted in a similar manner following the 1999 event (Deasley et al., 2012).

In this study, we analyze chironomid remains from two impacted lakes in the outer Mackenzie Delta (DZO-29 and DZO-30) as well as one control lake situated outside the impacted zone (C-27) of the 1999 storm surge. Our objectives are (1) to quantify the impacts the 1999 storm surge had on the abundance and community composition of chironomids in these freshwater lakes. In particular, we are interested in determining if chironomid communities were eliminated or if their species assemblages were altered following the sudden salinization of these lakes; and (2) determining if ecological recovery has occurred in the decade since the storm surge. Ultimately, this research will also improve our knowledge and understanding regarding the salinity tolerances of chironomid species in coastal Arctic lake systems. Given the transient and sensitive nature of delta ecosystems, climate change and its associated changes in frequency and intensity of saltwater intrusions are likely to have increasingly important ecological impacts on these Arctic systems in the future (Marsh \& Schmidt, 1993).

\section{$\underline{3.2 \text { Methods }}$}

\subsubsection{Site Description}

The Mackenzie Delta is a productive alluvial ecosystem located on the Beaufort Sea coast of Canada's Northwest Territories (Fig. 3). It spans approximately $13,000 \mathrm{~km}^{2}$, making it the world's second largest Arctic delta and the largest cold region delta in North America (Marsh \& Schmidt, 1993; Goulding et al., 2009; Burn \& Kokelj, 2009). It is a feature of the Holocene comprised of sediments deposited by the Mackenzie and 
Peel Rivers (Rampton, 1988). Topographic relief throughout the delta is low with surfaces within $10-20 \mathrm{~km}$ of the coast being less than $0.5 \mathrm{~m}$ above sea level. The low relief that characterises the outer Mackenzie Delta makes the region highly susceptible to high magnitude storm surge events (Cahoon, 2006). The study site for this project is located adjacent to the Beaufort Sea and approximately $130 \mathrm{~km}$ northwest of the town of Inuvik, NWT and approximately $120 \mathrm{~km}$ west of the hamlet of Tuktoyaktuk, NWT.

Vegetation in the outer Mackenzie Delta is dominated by willows (Salix sp.) and alders (Alnus sp.) which grow on aggrading point bars, while sedges (Cyperaceae) and mosses dominate the poorly drained wetlands away from the stream channels (Mackay, 1963) (Fig 4-9). Active-layer thickness ranges from about $60 \mathrm{~cm}$ in sedge wetlands to more than $120 \mathrm{~cm}$ in willow communities on aggrading point bars (Johnstone \& Kokelj, 2007).

The nearest climate station to our study site is located at Tuktoyaktuk, to the east of the Mackenzie Delta. It has been operational since 1948 (Johnstone \& Kokelj, 2007). The climate in this region is characterized by cold winters up to eight months in duration and short, cool summers (Burn, 2009). Mean January temperature is $-27.2^{\circ} \mathrm{C}$ and mean July temperature is $10.9^{\circ} \mathrm{C}$ (Environment Canada, $1971-2000$ climate normals). Regional differences in air temperature arise between inland sites such as Fort McPherson and cooler conditions at the coast due to the persistence of sea ice in early summer, and the contrast in albedo between boreal forest $(<0.3)$ and tundra $(0.75)$ as daily solar radiation increases in mid to late winter (Burn \& Kokelj, 2009). Mean annual air temperatures and total precipitation are $-7.3^{\circ} \mathrm{C}$ and $-9.8^{\circ} \mathrm{C}$ and $310 \mathrm{~mm}$ and $151 \mathrm{~mm}$ at Fort McPherson and Tuktoyaktuk, respectively (Burn \& Kokelj, 2009). Late winter snow depths at 
Tuktoyaktuk are less than $40 \mathrm{~cm}$ and throughout the year, coastal conditions tend to be drier than farther inland (Environment Canada, 2005). Local patterns of snow accumulation are related to topography or vegetation because winds redistribute the snow (Mackay \& MacKay, 1974).

Sea ice in the Beaufort Sea is present for the majority of the year, with a short icefree period along the coast occurring in late summer from August to September (Sepp \& Jaagus, 2011). The channels of the Mackenzie River become ice free much earlier, in late May to early June (Marsh \& Hey, 1994).

\subsubsection{Field Methods}

Lake selection was determined using a combination of satellite and ground observations. DZO-29 (unofficial name) is a small ( $\sim 3.5 \mathrm{ha}$ ), equant basin with a maximum depth of approximately $4.1 \mathrm{~m}\left(6^{\circ} 09^{\prime} 20.5^{\prime \prime} \mathrm{N}, 135^{\circ} 56^{\prime} 52.1^{\prime \prime} \mathrm{W}\right)$. DZO-30 (unofficial name) has a slightly larger surface area $(\sim 8.7 \mathrm{ha})$, is more elongate and is approximately $1.8 \mathrm{~m}$ in depth $\left(69^{\circ} 09^{\prime} 12.5^{\prime \prime} \mathrm{N}, 135^{\circ} 57^{\prime} 02.0^{\prime \prime} \mathrm{W}\right)$. Both lakes are located near the delta front, approximately $4 \mathrm{~km}$ from the present day coastline and within the 1999 surge affected area. C-27 (unofficial name) has a maximum depth of approximately $3 \mathrm{~m}$, surface area of $\sim 258 \mathrm{ha}$ and is located approximately $28 \mathrm{~km}$ inland, and beyond the area impacted by the 1999 storm surge $\left(69^{\circ} 06^{\prime} 41.64^{\prime \prime} \mathrm{N}, 135^{\circ} 18^{\prime} 15.12^{\prime \prime} \mathrm{W}\right)$. C-27 serves as a control site for this study (Fig. 3).

Sediment cores were collected from DZO-29 and DZO-30 in July 2010, and C-27 in August 2009, using a Maxi-Glew gravity corer, with an internal diameter of $7.62 \mathrm{~cm}$ (Glew, 1988) and extruded using a high-resolution extruding device (Glew et al., 2002)

(Fig. 4-9). Sediment cores from DZO-29, DZO-30 and C-27 measured $45.5 \mathrm{~cm}, 25.5 \mathrm{~cm}$ 
and $16.5 \mathrm{~cm}$ in length, respectively. Cores from each lake were sectioned at $0.25 \mathrm{~cm}$ intervals for the top $5 \mathrm{~cm}$ of the core, and $0.5 \mathrm{~cm}$ intervals below a depth of $5 \mathrm{~cm}$. Samples were placed in Whirlpak ${ }^{\circledR}$ bags and shipped to the Carleton University Palaeoecology Laboratory where they were stored at $4^{\circ} \mathrm{C}$ until analysis. 


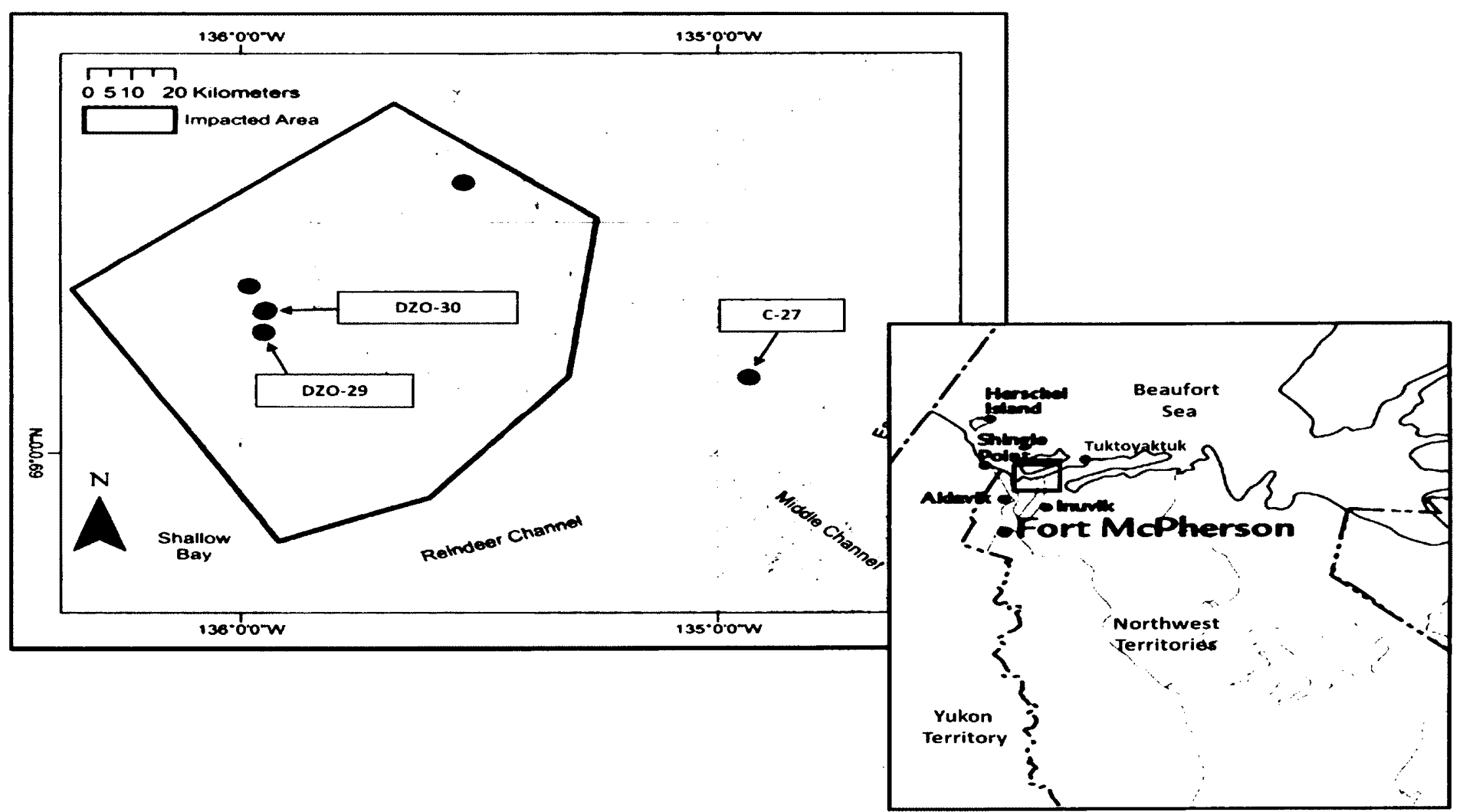

Figure 3 - Enlarged map of study region (left) in the outer Mackenzie Delta, Northwest Territories, Canada. The black circles with labels indicate the approximate position of the lakes discussed in this study, while those without labels were sampled for use in another study. The black box within the map delineates the approximate area impacted by the 1999 storm surge. DZO-29 and DZO-30 are located within the impacted zone while C- 27 is more than $20 \mathrm{~km}$ outside the impacted zone. The smaller map (right) indicates the location of the study area (red box) within the broader context of the Mackenzie Delta region in the Northwest Territories, Canada. 


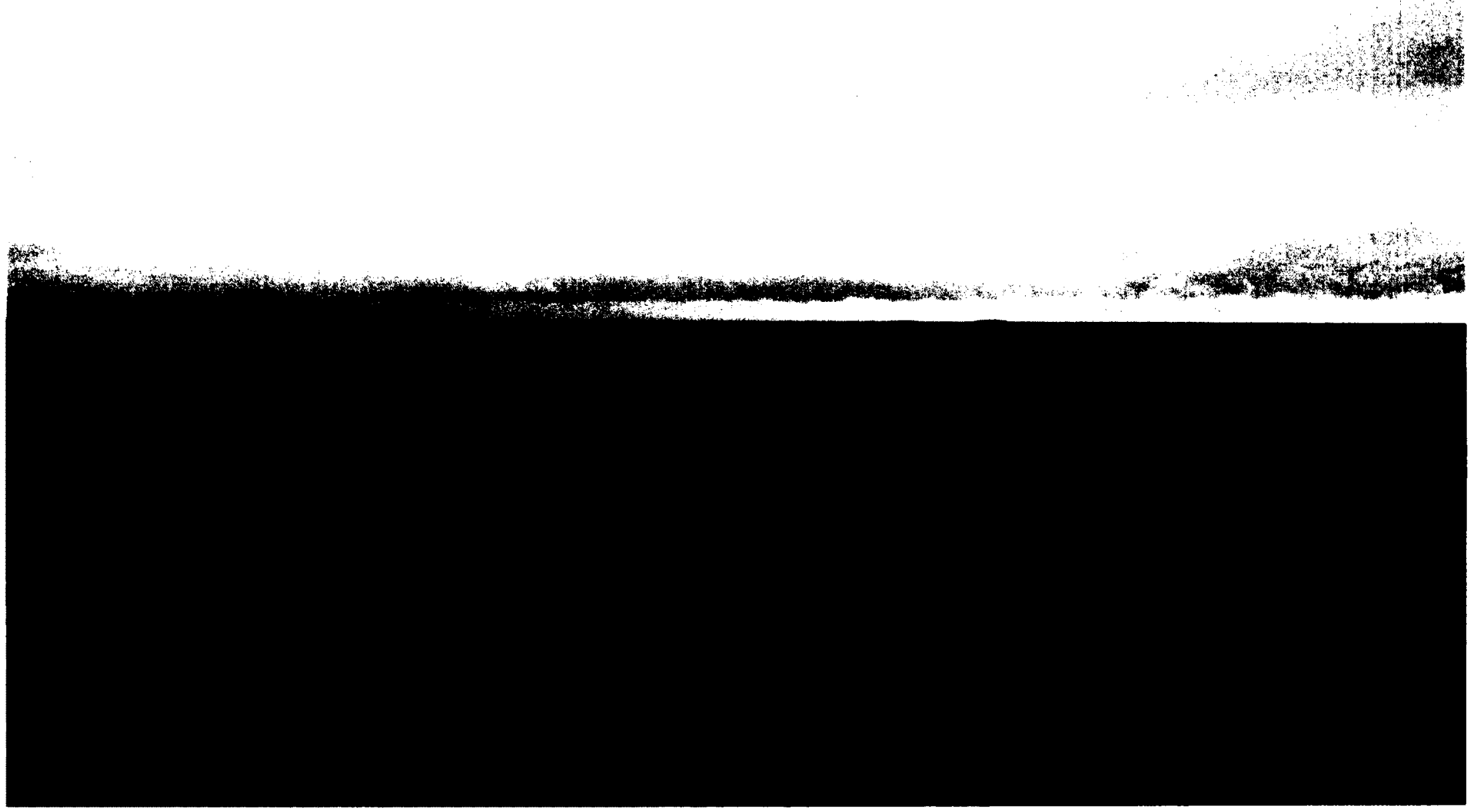

Figure 4 - Vegetation affected by 1999 storm surge surrounding DZO-29 (taken July 2010). Greenish-coloured areas suggest minor recovery by vegetation (most noticeably sedges (Cyperaceae) and mosses), while brown areas indicate dead vegetation. The vast majority of willow (Salix sp.) and alder (Alnus sp.) bushes in the surge impacted zone remain deceased to this day. 


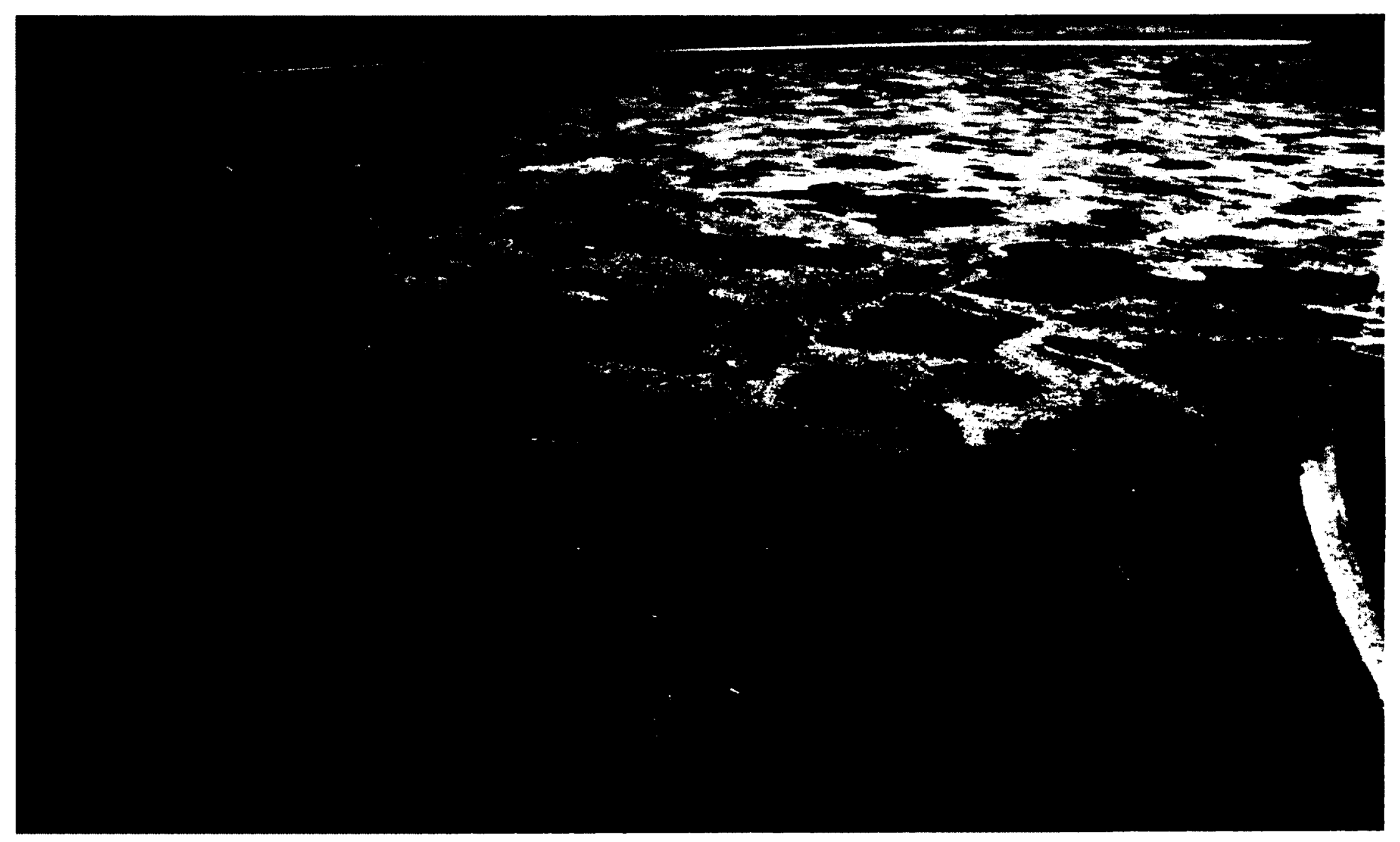

Figure 5 - This image shows the severity of the impacted vegetation of the outer Mackenzie Delta 'dead zone' (taken August 2011). Green patches indicate new areas of growth (sedges (Cyperaceae) and mosses), while the brown and grey areas indicate the extent of the dead vegetation. Prior to the 1999 storm surge event, the entire field of view would have been covered in green sedges (Cyperaceae) and mosses as well as willow (Salix sp.) and alder (Alnus sp.) shrubs. 


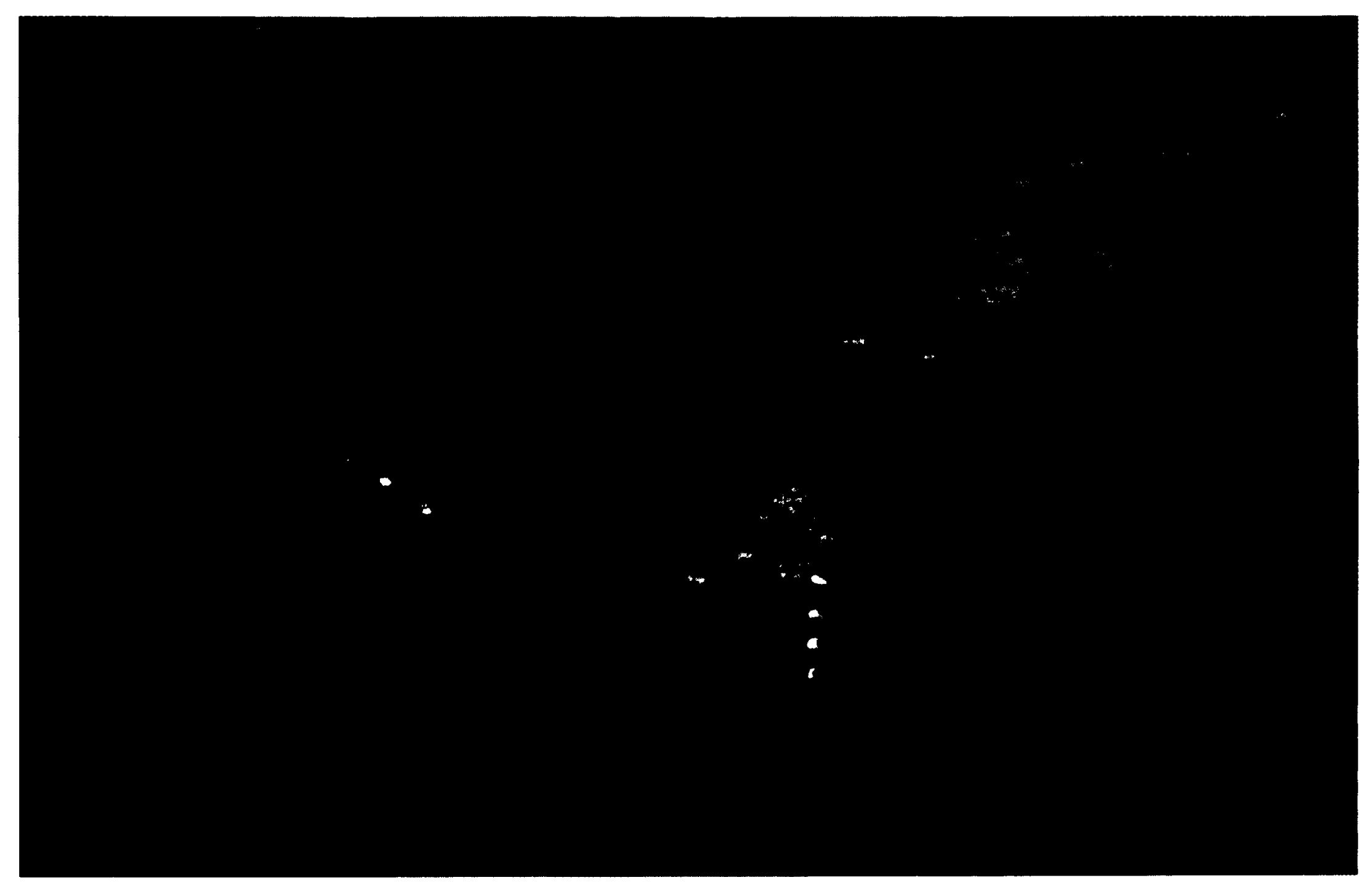

Figure 6 - Aerial view of the outer Mackenzie Delta 'dead zone' depicting the spatial variation of saltwater impact on the region's lakes and vegetation (taken August 2011). 


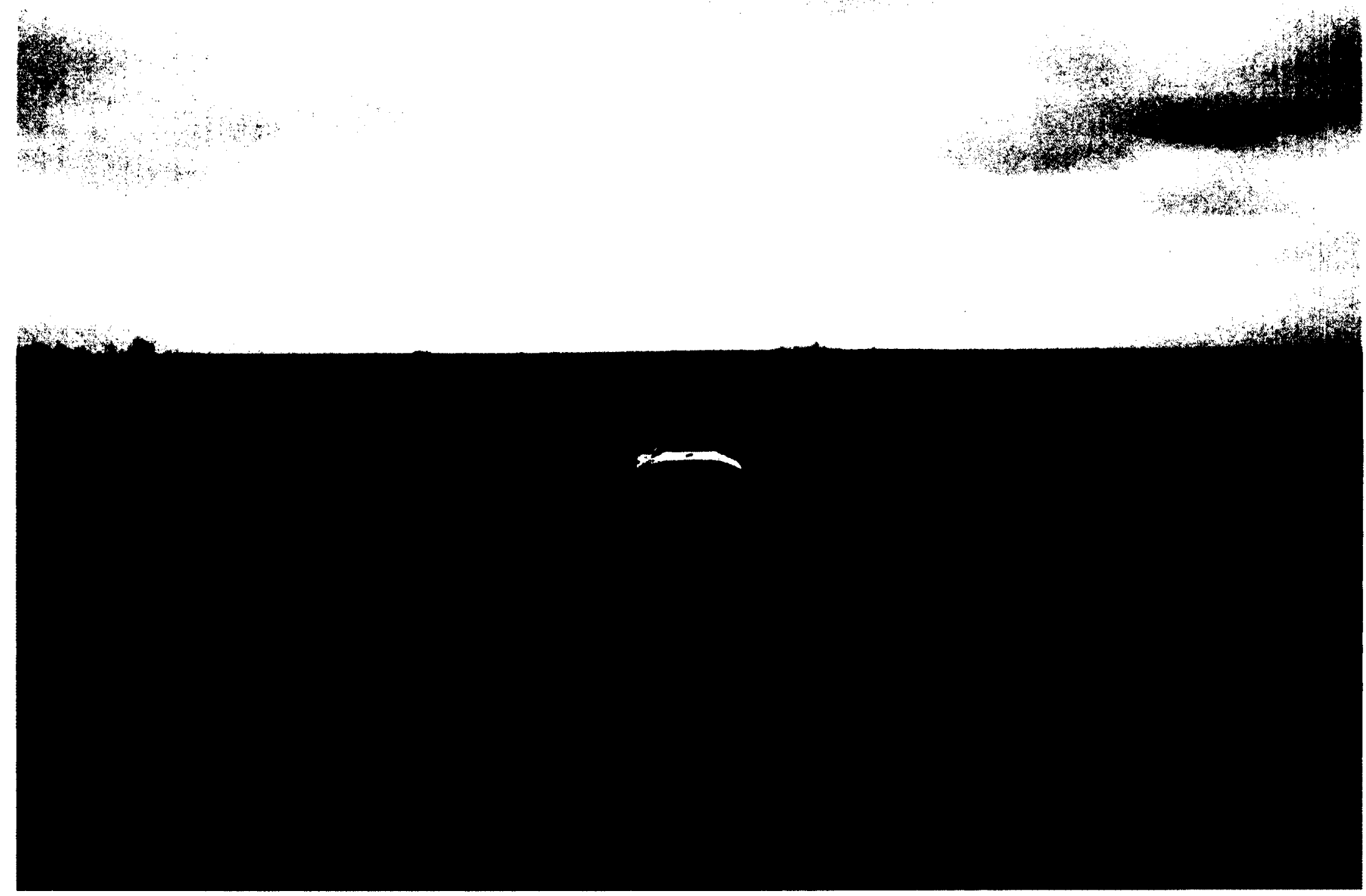

Figure 7 - Collection of cores from DZO-29 (taken July 2010). 


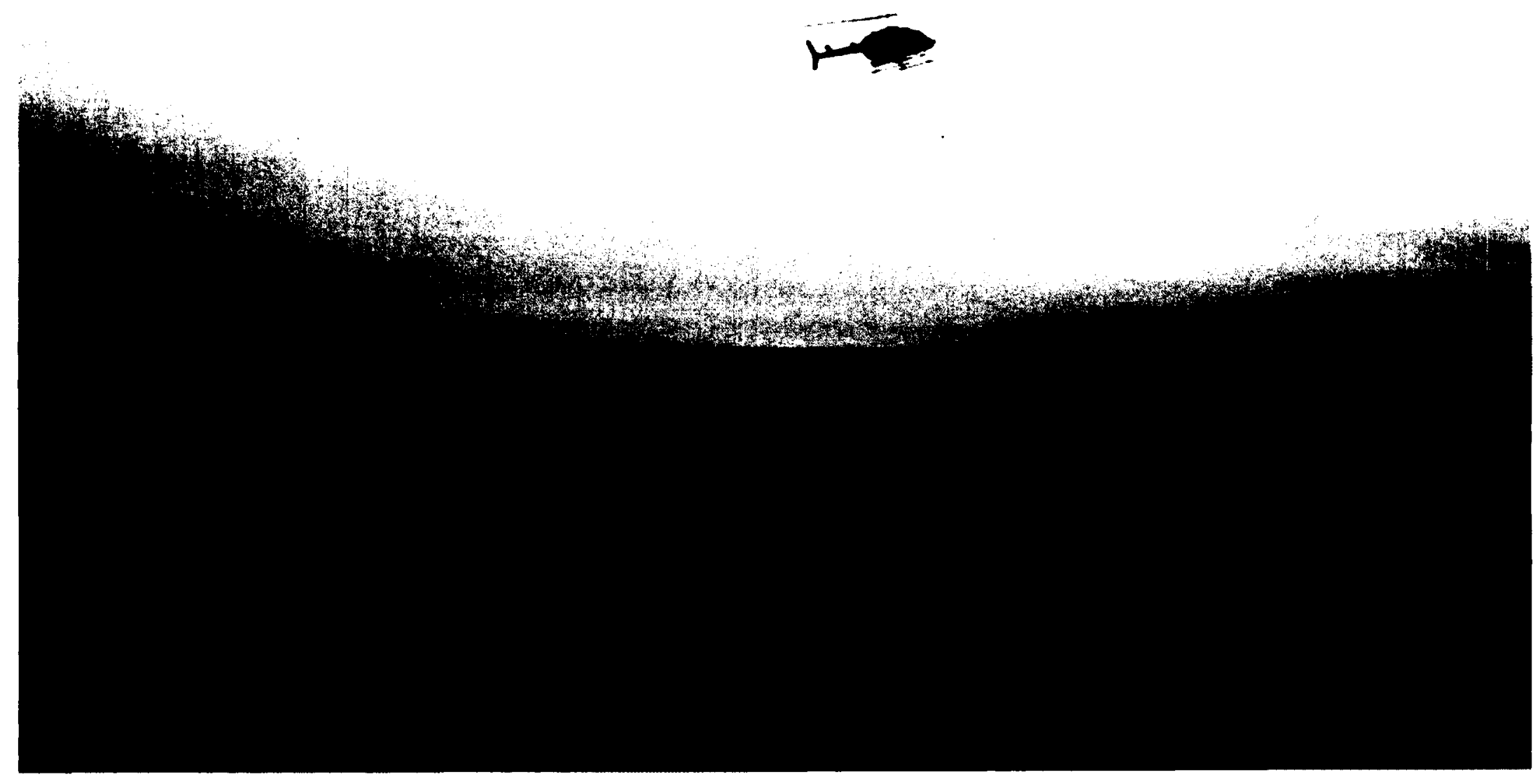

Figure 8 - Vegetation affected by 1999 storm surge surrounding DZO-30 (taken July 2010). 


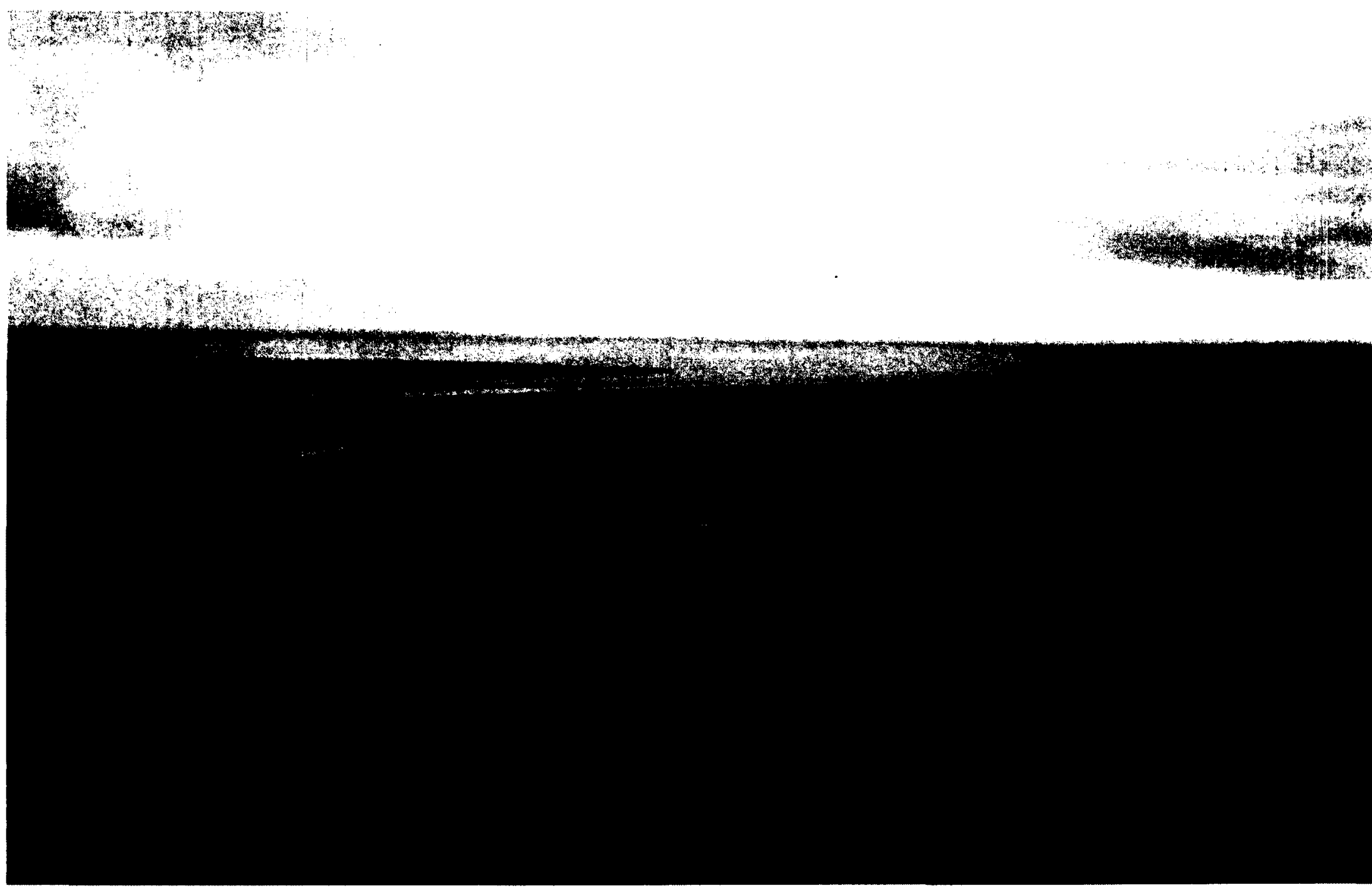

Figure 9 - Aerial view of the most northern portion of the 'dead zone' with its sparse vegetation and multitude of small lakes and ponds (taken August 2011). 


\subsubsection{Chronological dating and laboratory analyses}

\subsubsection{1 ${ }^{210} \mathrm{~Pb}$ chronology development}

Cores C-27 and DZO-30 were dated at MyCore Scientific Inc (Deep River, ON, Canada). Alpha counting using ${ }^{210} \mathrm{Po}$ was used to determine sediment age for core DZO30 with the CRS model used for sediment age determination. The granddaughter of ${ }^{210} \mathrm{~Pb}$ is ${ }^{210} \mathrm{Po}$ (Flynn, 1968). ${ }^{210} \mathrm{Po}$ decays with a half-life of 138 days and emits an alpha particle. These emissions can be detected by alpha spectrometry and can be combined with isotope dilution using ${ }^{208} \mathrm{Po}$ or ${ }^{209} \mathrm{Po}$ to increase the accuracy of the analysis. The radioactive decay of ${ }^{210} \mathrm{Po}$ emits an alpha particle that has energy of $5.3 \mathrm{MeV}$, while the energy of the ${ }^{209}$ Po alpha particle is about $5.1 \mathrm{MeV}$ (Flynn, 1968). Particles emitted at these two energies can be identified using the alpha spectroscopy system. The system consists of a surface barrier detector, preamplifier, amplifier, mixer router, analog to digital converter, multi-channel analyzer, and appropriate computer software (Flynn, 1968). The samples are counted for periods of 0.25 to 2 days depending upon the activity

of ${ }^{210} \mathrm{~Pb}$ in the samples. The activity of ${ }^{210} \mathrm{Po}$ in the sample is determined from the ratio of the total counts of ${ }^{209} \mathrm{Po}$ to ${ }^{210} \mathrm{Po}$ and from the quantities of sediment and ${ }^{209} \mathrm{Po}$ added to the sample. Blanks and standards are measured to verify the performance of all aspects of the procedures and the instrumentation. The ${ }^{209} \mathrm{Po}$ standard that is added to each sample also serves as an excellent internal standard to monitor the quality of the analysis. Details are presented in Flynn (1968) and Evans and Rigler (1980) with modifications described in Cornett et al. (1984) and Rowan et al. (1995). 
It is important to note that all dates are approximate. ${ }^{210} \mathrm{~Pb}$, a radioactive form of lead, is one of the last elements created by the radioactive decay of the isotope uranium$238\left({ }^{238} \mathrm{U}\right)$ and decays with a half-life of about 22 years (Appleby \& Oldfield, 1978). As such this dating method accurately covers the past period of approximately 75-100 years.

Since it takes about 7 half-lives, or 150 years for the ${ }^{210} \mathrm{~Pb}$ in a sample to reach near-zero radioactivity, it is no longer considered an accurate dating method for longer timespans (Appleby \& Oldfield, 1978).

\subsubsection{Chironomid analysis}

Sediments were prepared for the analysis of chironomid remains using standard procedures outlined in Walker et al. (1995). Samples were first placed in $5 \% \mathrm{KOH}$ and heated for 30 minutes at low temperature $\left(\sim 30^{\circ} \mathrm{C}\right)$, then gently sieved through an $80 \mu \mathrm{m}$ mesh. For each interval, approximately 50 head capsules (Quinlan \& Smol, 2001) were picked from the processed sediment, using a Bolgorov tray, and mounted on microscope slides using Permount ${ }^{\circledR}$. The amount of wet sediment used ranged from $1.0 \mathrm{~g}$ to $5.0 \mathrm{~g}$ to obtain the minimum of 50 chironomid head capsules recommended for statistical analyses (Quinlan and Smol, 2001). Unfortunately, a uniform amount of sediment could not be used for each sample as previous studies conducted on the same cores depleted the available sediment. Due to low head capsule counts in selected intervals in all 3 cores, adjacent $0.25 \mathrm{~cm}$ intervals were amalgamated into $0.5 \mathrm{~cm}$ intervals. This ensured that all depths in the cores were analyzed throughout and that each interval contained as close to 50 head capsules as possible, while still maintaining reasonably high resolution for analysis. 
Identification of chironomids was performed at 200 to $400 \mathrm{x}$ magnification using a Nikon Eclipse 80i light microscope. A taxonomic guide of key distiniguishing head capsule features prepared by Oliver and Rousell (1983) was used to identify chironomids to the lowest taxomomic level based on available head capsule features. Due to the abundance of broken, partially missing or disintegrated head capsules, in some cases identification could only be made to the genus level.

\subsubsection{Statistical analysis}

For each interval, relative abundances of each taxon based on count data as well as the total number of chironomid individuals per gram of dry sediment per year (chironomid accumulation rate) were calculated to estimate changes in chironomid density through time. Relative abundance stratigraphic plots including all chironomid taxa, were prepared for each core using the computer program C2 (Juggins, 1991). During the creation of the stratigraphic plots, chironomid taxa were ordered from lowest to highest salinity tolerances based on criteria by Walker et al. (1995). Constrained incremental sums of squares (CONISS) cluster analysis was conducted using the rioja package (Juggins, 2012) in the R statistical program ( $\mathrm{R}$ Core Team, 2012) on the complete chironomid count datasets for each lake. This was done to better illustrate the main biostratigraphic zones of change within the cores (Bennett, 2006). The significance of the CONISS zones was determined using the broken stick model (Bennett, 2006).

In addition, inferred average July air temperatures were calculated using the original interpolated count data. Taxa names were replaced with corresponding taxa code names from Barley et al. (2006). July temperature reconstructions were calculated for each of the 3 cores using the transfer function presented Barley et al. (2006) that was 
developed from a northwest North American training set consisting of midge assemblages and data for 17 environmental variables collected from 145 lakes across Alaska, British Columbia, Yukon, Northwest Territories, and the Canadian Arctic Archipelago. This was performed using the statistical program $\mathrm{R}$ and is plotted on the relative abundance plots for all 3 lakes. The inferred temperatures from all 3 lakes were also plotted against the actual average July air temperature for Inuvik as provided by Environment Canada. A Loess smoother, a locally weighted polynomial regression, was applied to the Inuvik temperature data in order to more easily identify the trend in the average July air temperature data. Correlations between the inferred average July air temperature reconstructions and the 5-year running average of the raw Inuvik temperature data was calculated using the Pearson Product Moment Correlation (PPMC) method. Moving averages are commonly used with time series data in order to smooth out short-term fluctuations and highlight longer-term trends or cycles (Chou, 1975).

Taxon richness was calculated using rarefied uninterpolated count data, as well as rarefied interpolated count data of all taxa for each of the 3 lakes. Smol (1981) indicates that calculating taxon richness in paleolimnology is difficult using uninterpolated data as the time steps between samples are not always the same and suggests that interpolation of the data to create equal time steps between samples is an attempt to address this problem. Interpolated count data for each lake was determined using AnalySeries software (Version 2.0.4). Rarefaction is based on a statistical procedure that is used to calculate the number of species expected in a sub-sample of individuals selected at random from a larger sample (Koellner et al., 2004). Rarefaction was used to calculate taxon richness as opposed to other diversity measures as it can be used to standardize samples that differ in 
terms of individual or plot size (Koellner et al., 2004). This cannot be done by simple linear interpolation, because the relationship between richness and count size is not linear (Birks \& Line, 1992). It removes the unavoidable bias in richness estimates caused by differing count sizes, separating the possible effects of sample size on variability from true ecologically-meaningful differences (Birks \& Line, 1992).

\section{$\underline{3.3 \text { Results }}$}

\subsubsection{Physical nature of DZO-29, DZO-30 and C-27}

The physical appearance of the sediment from DZO-29, DZO-30 and C-27 was similar. Sediment from all 3 cores was greyish-brown in colour throughout, with no visible laminations. Interestingly, reddish-coloured sediments were noted at various intervals throughout all 3 cores. Lead-210 dating indicates that sedimentation rates of the two dated cores are comparable (Fig. 10). Sedimentation rates for impacted lake DZO-30 range between 4 and 10 year $\mathrm{cm}^{-1}$. Control lake, C-27, has similar sedimentation rates (ranging between 3 and 9 year $\mathrm{cm}^{-1}$ ) as DZO-30 until a depth of $\sim 10 \mathrm{~cm}$. Below $10 \mathrm{~cm}$, the sedimentation rate of the two dated cores increases to above 10 year $\mathrm{cm}^{-1}$ and must be used with caution as the error becomes too large for the dates to be considered reliable. Due to the relatively short length of the $\mathrm{C}-27$ core, background ${ }^{210} \mathrm{~Pb}$ levels were not reached and the average activity of ${ }^{214} \mathrm{Bi}$ was used to estimate the background ${ }^{210} \mathrm{~Pb}$ activity (Appleby \& Oldfield, 1978). Unfortunately, due to the lack of available sediment from DZO-29 following chironomid analysis, it was not possible to date this core for the purpose of this study. 


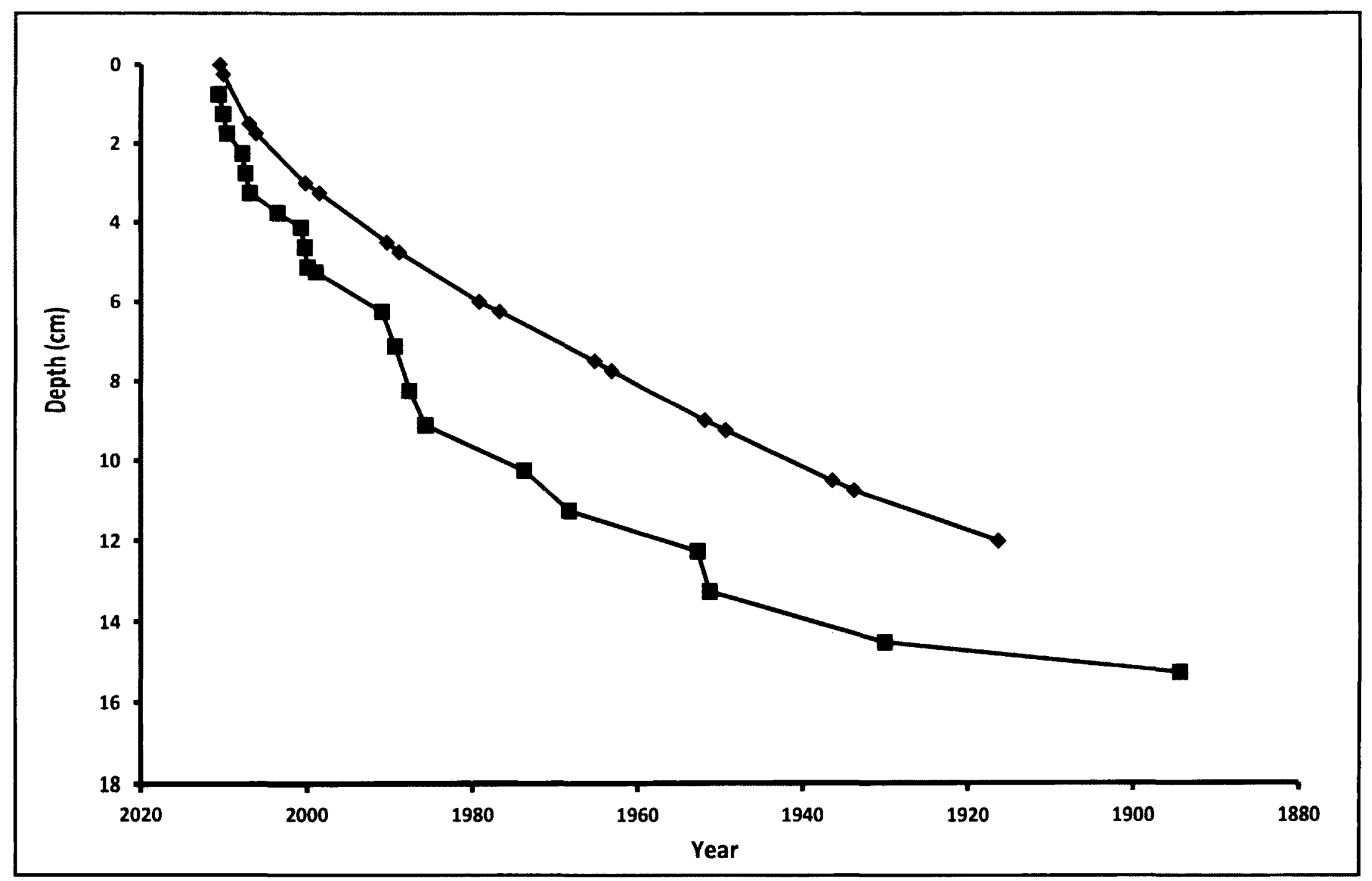

Figure 10 - Suggested age-depth relationships for sediment cores DZO-30 (blue line) and C-27 (red line) using ${ }^{210} \mathrm{~Pb}$ ages (constant rate of supply (CRS) model). 


\subsubsection{Chironomid assemblage changes for lake DZO-30}

Thirteen chironomid taxa were identified in the $25.5-\mathrm{cm}$ long sediment core from DZO-30 (Table 2). CONISS analysis of DZO-30 chironomid head capsule counts indicates that there are two significant breaks in the chironomid assemblage data (Fig. 11a) resulting in 3 distinct zones. The first significant change in the chironomid assemblage occurred at a core depth of $13.75 \mathrm{~cm}$. Zone 1 extends from the base of the core to $13.75 \mathrm{~cm}$, and is dominated by Cricotopus/Orthocladius with relative abundances ranging from 30 to $50 \%$ and Chironomus accounting for $\sim 20 \%$ of indentified head capsules. Corynocera oliveri type-1, Procladius and Paratanytarsus, Pseudochironomini and Sergentia have very low abundances $(<10 \%)$, while Tanytarsus and Psectrocladius have abundances of $\sim 20 \%$. 
Table 2. Indicates the presence or absence of select chironomid taxa in study lakes DZO29, DZO-30 and C-27.

\begin{tabular}{|c|c|c|c|}
\hline Chironomid Taxon & DZO-29 & DZO-30 & $\mathrm{C}-27$ \\
\hline $\begin{array}{l}\text { Paratanytarsus } \\
\text { (Thienemann \& Bause, 1913) }\end{array}$ & Present & Present & Present \\
\hline Tanytarsus (van der Wulp, 1874) & Present & Present & Present \\
\hline $\begin{array}{l}\text { Tanytarsus lugens-type } \\
\text { (Kieffer in Thienemann \& Kieffer, 1916) }\end{array}$ & Present & Absent & Absent \\
\hline $\begin{array}{l}\text { Corynocera oliveri type } 1 \\
\text { (Zetterstedt, 1838) }\end{array}$ & Present & Present & Present \\
\hline Cryptotendipes (Kieffer, 1913) & Present & Present & Absent \\
\hline Dicrotendipes (Kieffer, 1913) & Present & Absent & Absent \\
\hline Microtendipes (Kieffer, 1915) & Present & Present & Present \\
\hline Chironomus (Meigen, 1803) & Present & Present & Present \\
\hline $\begin{array}{l}\text { Chironomus anthracinus-type } \\
\text { (Zetterstedt, 1860) }\end{array}$ & Present & Present & Present \\
\hline $\begin{array}{l}\text { Chironomus plumosus-type } \\
\text { (Linnaeus, 1758) }\end{array}$ & Present & Absent & Absent \\
\hline Endochironomus (Kieffer, 1918) & Present & Absent & Absent \\
\hline Sergentia (Kieffer, 1922) & Present & Present & Present \\
\hline Stempellinella/Zavrelia (Brundin, 1949) & Present & Absent & Absent \\
\hline $\begin{array}{l}\text { Cladotanytarsus mancus-type } \\
\text { (Kieffer, 1921) }\end{array}$ & Present & Absent & Absent \\
\hline $\begin{array}{l}\text { Cricotopus/Orthocladius } \\
\text { (van der Wulp, 1874) }\end{array}$ & Present & Present & Present \\
\hline Psectrocladius (Kieffer, 1906) & Present & Present & Present \\
\hline Pseudochironomini Malloch, 1915) & Present & Present & Present \\
\hline Procladius (Skuse, 1889) & Absent & Present & Present \\
\hline Cryptochironomus (Kieffer, 1918) & Absent & Present & Absent \\
\hline
\end{tabular}

DZO-30 Zone 2, which occurs between $13.75 \mathrm{~cm}$ and $3.25 \mathrm{~cm}(\sim \mathrm{AD} 2000)$ is marked by distinct decreases in Cricotopus/Orthocladius, Psectrocladius and Chironomus, to relative abundances $<20 \%$. At approximately the same time Corynocera oliveri type- 1 becomes more abundant accounting for 25 to $50 \%$ of all identified head capsules. Also notable in Zone 2 is the complete disappearance of Procladius from the lake.

DZO-30 Zone 3, from $3.25 \mathrm{~cm}(\sim \mathrm{AD} 2000)$ to the top of the core ( $\sim \mathrm{AD} 2010)$, was once again dominated by Cricotopus/Orthocladius, but also by Paratanytarsus with 
relative abundances ranging from $20 \%$ to upwards of $50 \%$. Zone 3 is also distinguished by the almost complete disappearance of Sergentia as well as the dramatic decrease in the relative abundance of Corynocera oliveri type-1 from abundances greater than $25 \%$ in Zone 2 to less than $10 \%$ in Zone 3. Chironomus remains low in abundance $(<10 \%)$, while the relative abundances of Pseudochironomini, Tanytarsus, Chironomus anthracinustype, remained relatively constant throughout the core.

The July air temperature reconstruction for core DZO-30 indicates that temperatures peak at $\sim 23 \mathrm{~cm}$ around $12^{\circ} \mathrm{C}$, followed by a decrease to an average of approximately $11^{\circ} \mathrm{C}$ between 22 and $17 \mathrm{~cm}$ (Fig. $11 \mathrm{a}$ and 12). This is followed by an increase in average temperature to $\sim 12^{\circ} \mathrm{C}$ at $14 \mathrm{~cm}$. From a depth of approximately $14 \mathrm{~cm}$ until $6.5 \mathrm{~cm}$, temperatures remain relatively stable around $11.5^{\circ} \mathrm{C}$, with a slight increase. Above $6.5 \mathrm{~cm}$, temperatures become more variable with a noticeable drop to $\sim 10^{\circ} \mathrm{C}$ at approximately $4.25 \mathrm{~cm}(\sim \mathrm{AD} 1995)$. In Zone 3, average July air temperature remains variable, with a notable drop to $10.5^{\circ} \mathrm{C}$ at approximately $2.75 \mathrm{~cm}$ ( AD 2001) followed by a sharp increase to $11.5^{\circ} \mathrm{C}$ and remains high until the top of the core ( AD 2010). This reconstructed average July air temperature record is plotted along with the average July air temperatures, as provided by Environment Canada dating back to 1926 (Fig. 12). The Pearson Product Moment Correlation calculated, based on the 5 year moving average for DZO- 30 was, $\mathrm{r}=0.13, \mathrm{p}=0.24$.

Total CAR of all taxa in DZO-30 indicates an increase in the concentration of chironomid head capsules following the 1999 storm surge event at $\sim 2.50 \mathrm{~cm}(\sim \mathrm{AD} 2003)$ to concentrations exceeding 300 to upwards of 500 head capsules $g^{-1}$ year ${ }^{-1}$ (Fig. 13a). No large increase in CAR was seen prior to the 1999 storm surge event and chironomid head 
capsule concentrations were generally found to be below 100 head capsules $\mathrm{g}^{-1}$ year $^{-1}$ for the majority of the core.

Taxon richness in DZO-30 ranged between 6 and 10 taxa (Fig. 14a). A decrease in taxon richness to 7 taxa occurred in the early $1930 \mathrm{~s}(\sim 11.25 \mathrm{~cm})$, but is followed by a general increase to a peak of approximately 10 taxa in the early $1980 \mathrm{~s}(\sim 6.0-6.5 \mathrm{~cm})$. There is a drop in richness prior to the 1999 event at $4.0 \mathrm{~cm}(\sim \mathrm{AD} 1998)$. Following the 1999 storm surge, taxon richness in DZO-30 suggests an overall decreasing trend.

\subsubsection{Chironomid assemblage changes for lake DZO-29}

Seventeen chironomid taxa were identified in the $45.5-\mathrm{cm}$ sediment core of DZO29 (Table 2).

Three significant shifts in chironomid assemblages were identified by CONISS for DZO-29 (Fig. $11 \mathrm{~b}$ ). DZO-29 Zone 1 extends from the base of the core to $\sim 37 \mathrm{~cm}$. The zone is dominated by Cricotopus/Orthocladius with relative abundances of $\sim 20-40 \%$, and Paratanytarsus with abundances between $\sim 10-30 \%$, while Corynocera oliveri type-1 and Sergentia are less common attaining relative abundances of only $\sim 5 \%$ and $10 \%$, respectively.

DZO-29 Zone 2 extends from -37 to $9 \mathrm{~cm}$ core depth and is characterised by a slight increase in Tanytarsus abundances and a more significant change in the relative abundance of Corynocera oliveri type-1 from values of $\sim 5 \%$ in Zone 1 to upwards of 20$40 \%$ in Zone 2 . Concomitant with these changes, are decreases in the relative abundance of Cricotopus/Orthocladius (from $\sim 20-40 \%$ to $<20 \%$ ) and Paratanytarsus $(\sim 10-20 \%$ to $<5 \%$ early in Zone 2) (Fig. $11 \mathrm{~b}$ ). 
Zone 3 which occurs from a depth of $\sim 9 \mathrm{~cm}$ to the top of the core is broken into 2 subzones, $3 \mathrm{a}$ and $3 \mathrm{~b}$. Zone $3 \mathrm{a}$, from $\sim 9 \mathrm{~cm}$ to $\sim 4.25 \mathrm{~cm}$ is marked by a distinguishable increase in the relative abundance of Cricotopus/Orthocladius from $\sim 10-20 \%$ in Zone 2 to up to $\sim 30 \%$ in Zone $3 \mathrm{a}$ as well as the complete disappearance of Sergentia and Corynocera oliveri type-1 (Fig. 11b). Prior to Zone 3, Sergentia had remained relatively constant throughout the core at $\sim 5-15 \%$. In addition, Paratanytarsus becomes more abundant in Zone $3 \mathrm{a}$ accounting for $20-40 \%$ of the chironomid assemblages in this zone. Zone $3 \mathrm{~b}$, which extends from $\sim 4.25 \mathrm{~cm}$ to the top of the core, is differentiated from Zone 3a due to the rapid and dramatic rise in the relative abundance of Cricotopus Orthocladius from $<30 \%$ to $>30 \%$ as well as increased abundances of Tanytarsus.

In much the same manner as that of DZO-30, the July air temperature reconstruction for core DZO-29 suggests that temperatures peak at $\sim 12^{\circ} \mathrm{C}$ around $23 \mathrm{~cm}$, then decrease to an average of approximately 10.5 to $11^{\circ} \mathrm{C}$ between 22 and $16 \mathrm{~cm}$ (Fig. 12b). This is followed by an increase in average temperature to $\sim 12^{\circ} \mathrm{C}$ at $15 \mathrm{~cm}$. From a depth of approximately $15 \mathrm{~cm}$ until $6 \mathrm{~cm}$, there is an overall general decrease in the average July air temperature with a noticeable drop to $\sim 9^{\circ} \mathrm{C}$ at approximately $6 \mathrm{~cm}$. Following this sudden drop, the average July air temperature becomes more variable, increasing rapidly to approximately $11^{\circ} \mathrm{C}$ at $\sim 4 \mathrm{~cm}$, before decreasing once again.

Finally, the chironomid inferred temperature reconstruction increases sharply to $\sim 14^{\circ} \mathrm{C}$ at the top of the core. The reconstructed average July air temperature record for DZO-29 is also consistent with the average July air temperature data as provided by Environment Canada as well as the reconstruction from DZO-30. Using the Pearson Product Moment Correlation between the records, the DZO-29 temperature 
reconstruction was also not found to be correlated to the Inuvik temperature record $(r=-$ $0.036, \mathrm{p}=0.75)$

CAR for all taxa in DZO-29 total less than $\sim 100$ head capsules $\mathrm{g}^{-1}$ year $^{-1}$ from the bottom of the core until $\sim 4 \mathrm{~cm}$. An abrupt increase in CAR to between 400 and 700 head capsules $\mathrm{g}^{-1}$ year $^{-1}$ ) occurs from $\sim 4 \mathrm{~cm}$ to the top of the sediment core (Fig. 13b).

Taxon richness is relatively constant throughout the core, ranging from 5 to 8 species, but does indicate an increase until a depth of approximately $9 \mathrm{~cm}$ based on the uninterpolated as well as interpolated count data incorporating all taxa (Fig. 14b). Taxon richness peaks at a depth of $\sim 25 \mathrm{~cm}$ and $\sim 13.5-16.5 \mathrm{~cm}$ at a maximum of 8 taxa, but drops rapidly to approximately 2 taxa at $\sim 4-5.5 \mathrm{~cm}$ depth. Taxon richness in DZO-29 quickly recovers to 6 taxa at $\sim 2.75 \mathrm{~cm}$, before dropping dramatically to 3 taxa at $2.25 \mathrm{~cm}$. There appears to be a recovery to $\sim 7$ taxa near the very top of the core at $\sim 1 \mathrm{~cm}$. Overall, taxon richness is found to be lower above a depth of $9 \mathrm{~cm}$ (Fig. 14b).

\subsubsection{Chironomid assemblage changes for lake C-27}

In the 16-cm long sediment core from control lake (C-27), situated outside the storm surge impacted zone, eleven chironomid taxa were identified of which nine are present in all 3 cores (Table 2). C-27 had no significant shifts in the chironomid assemblage as determined by CONISS (Fig. 11c). The core was dominated by Chironomus throughout, ranging in abundances from 30 to $40 \%$, followed by Cricotopus/Orthocladius with relative abundances consistent around $20 \%$. With the exception of Paratanytarsus and Procladius, the remaining 8 taxa found in the core, have relative abundances below $10 \%$, though Procladius disappeared completely from the record at a depth of approximately $5 \mathrm{~cm}(\sim \mathrm{AD} 2000)$. Unlike the changes in chironomid 
assemblages recorded in DZO-29 and DZO-30, there were no significant increases of Paratanytarsus near the top of the C-27 sediment core. There was an increase in one sample in the relative abundance of Cricotopus/Orthocladius, however this increase could be due to changes in the relative abundance of other chironomid types such as Chironomus, Paratanytarsus and Tanytarsus which all decrease at the same time. In addition, there was no noticeable decrease or disappearance of Sergentia which occurred in both cores from the impacted zone.

The inferred average July air temperature reconstruction for control core C-27 indicates an overall decreasing trend in temperature and was less variable then those of impacted cores DZO-29 and DZO-30 (Fig. 11c). Unfortunately, the record from C-27 is short, only $16 \mathrm{~cm}$ in length and does not extend beyond the $20^{\text {th }}$ century. Therefore, it fails to capture the more variable conditions recorded in DZO-29 and DZO-30 at the likely termination of the Little Ice Age. Overall, the reconstructed July air temperature record for C-27 is comparable with those from DZO-29 and DZO-30 as well as the July air temperature data, as provided by Environment Canada (Fig. 12). The PPMC calculated for $\mathrm{C}-27$ based on 5-year moving averages is $\mathrm{r}=0.18, \mathrm{p}=0.10$.

CAR of all taxa for $\mathrm{C}-27$ remained below 100 head capsules $\mathrm{g}^{-1}$ year ${ }^{-1}$ from the base of the core until $\sim 7 \mathrm{~cm}(\sim \mathrm{AD} 1916$ to $\sim 1990 \mathrm{AD})$ where it increases to $\sim 300$ to 400 head capsules $\mathrm{g}^{-1}$ year $^{-1}$ until $\sim 4 \mathrm{~cm}(\sim \mathrm{AD} 2002)$. Between $\sim 4 \mathrm{~cm}$ and $\sim 1.5 \mathrm{~cm}(\sim \mathrm{AD}$ 2002 to $\sim \mathrm{AD} 2008$ ) CAR returns to below 100 head capsules $\mathrm{g}^{-1}$ year $^{-1}$, but increases dramatically to greater than 400 head capsules $\mathrm{g}^{-1}$ year $^{-1}$ from $\sim 1.5 \mathrm{~cm}$ to the top of the core ( $\sim \mathrm{AD} 2008$ to $\sim \mathrm{AD} 2010)$ (Fig. 13c). Taxon richness in C-27 was less variable then that for DZO-29 and DZO-30, ranging between 6 and 9 taxa, but remained relatively high 
at $\sim 9$ taxa throughout the majority of the core with no discernible decrease following the 1999 storm surge event (Fig. 14c). Abrupt decreases in taxon richness to 6 taxa occurred at $\sim 14.5 \mathrm{~cm}(\sim \mathrm{AD} 1932), \sim 9 \mathrm{~cm}(\sim \mathrm{AD} 1985), \sim 8 \mathrm{~cm}(\sim \mathrm{AD} 1987)$ and $\sim 3.50 \mathrm{~cm}(\sim \mathrm{AD}$ 2004). 


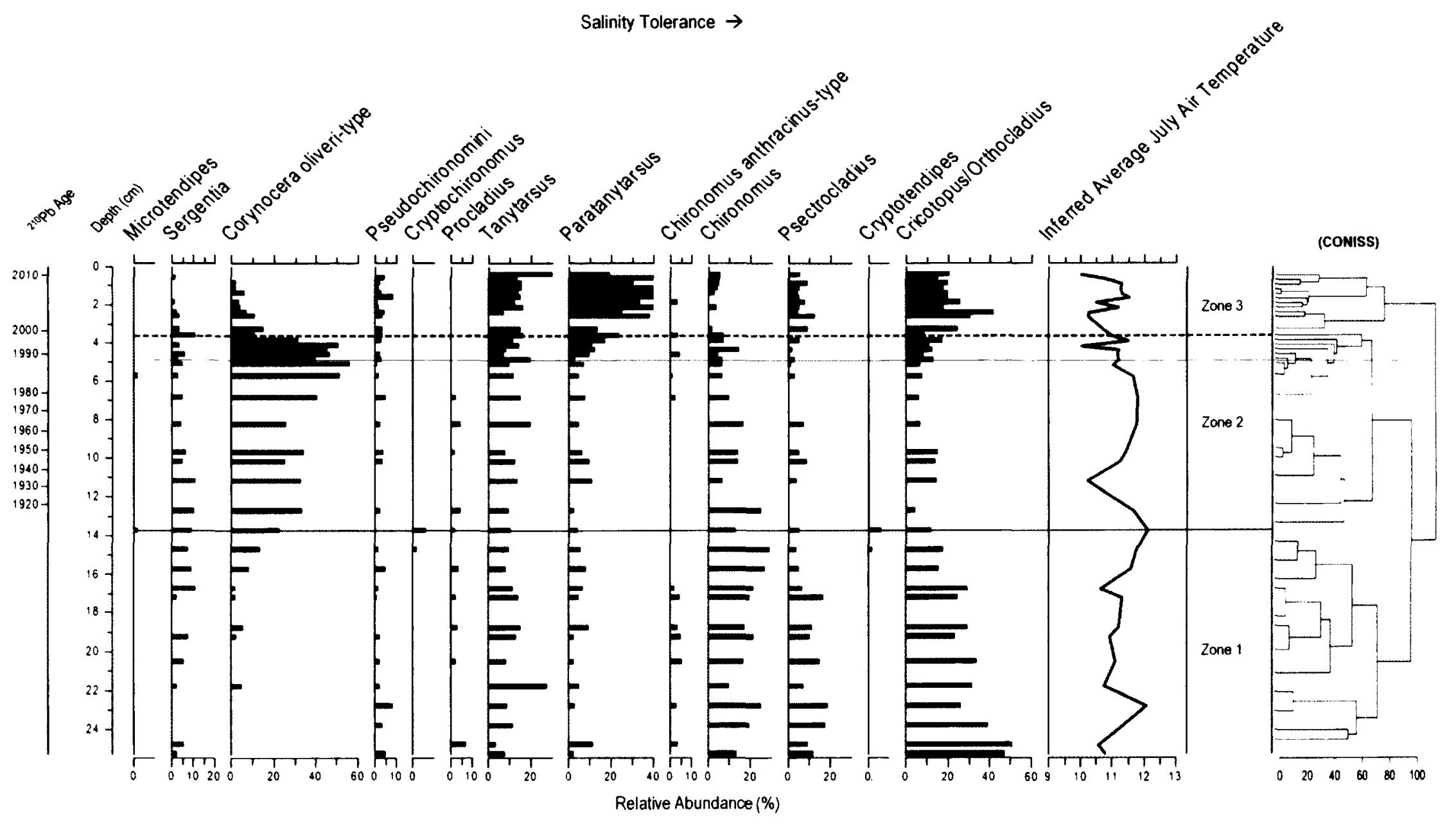

Figure 11a - Relative abundance diagrams for the chironomid taxa from impacted lake DZO-30. Taxa are organized from left to right according to their increasing salinity tolerances. Cluster analysis was used to determine the main zones of change in species assemblage, and is displayed next to the plots. The solid black lines delineate chironomid community zones as determined by CONISS, while the dashed red line indicates the 1999 storm surge. The additional column on the right hand side indicates the reconstruction of July air temperatures as inferred by the chironomid data (using a transfer function from Barley et al. (2006)). 


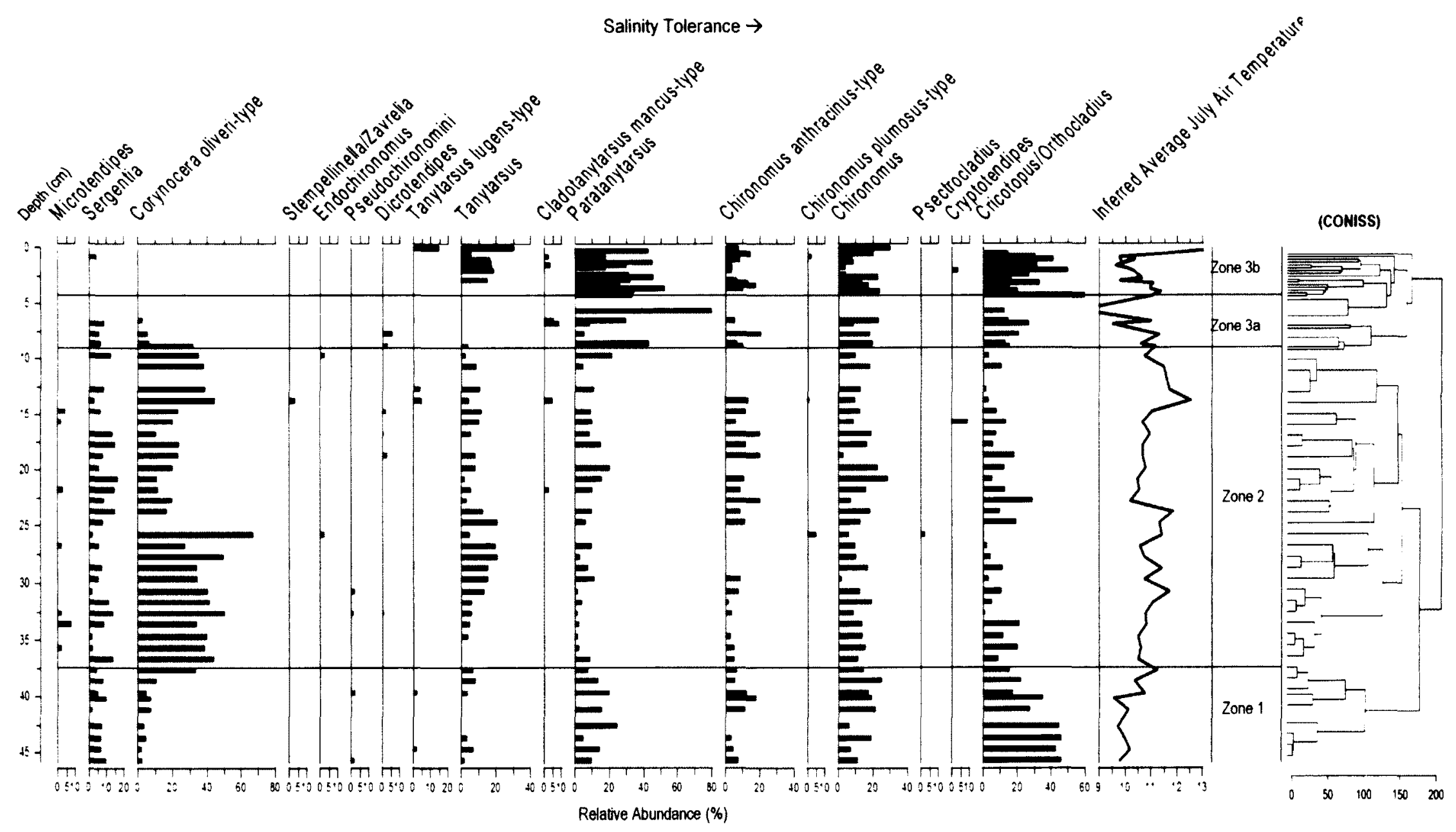

Figure $11 \mathrm{~b}$ - Relative abundance diagrams for the chironomid taxa from impacted lake DZO-29. Taxa are organized from left to right according to their increasing salinity tolerances. Cluster analysis was used to determine the main zones of change in species assemblage, and is displayed next to the plots. The solid black lines delineate chironomid community zones as determined by CONISS. The additional column on the right hand side indicates the reconstruction of inferred average July air temperatures as inferred by the chironomid data (using a transfer function from Barley et al. (2006)). 


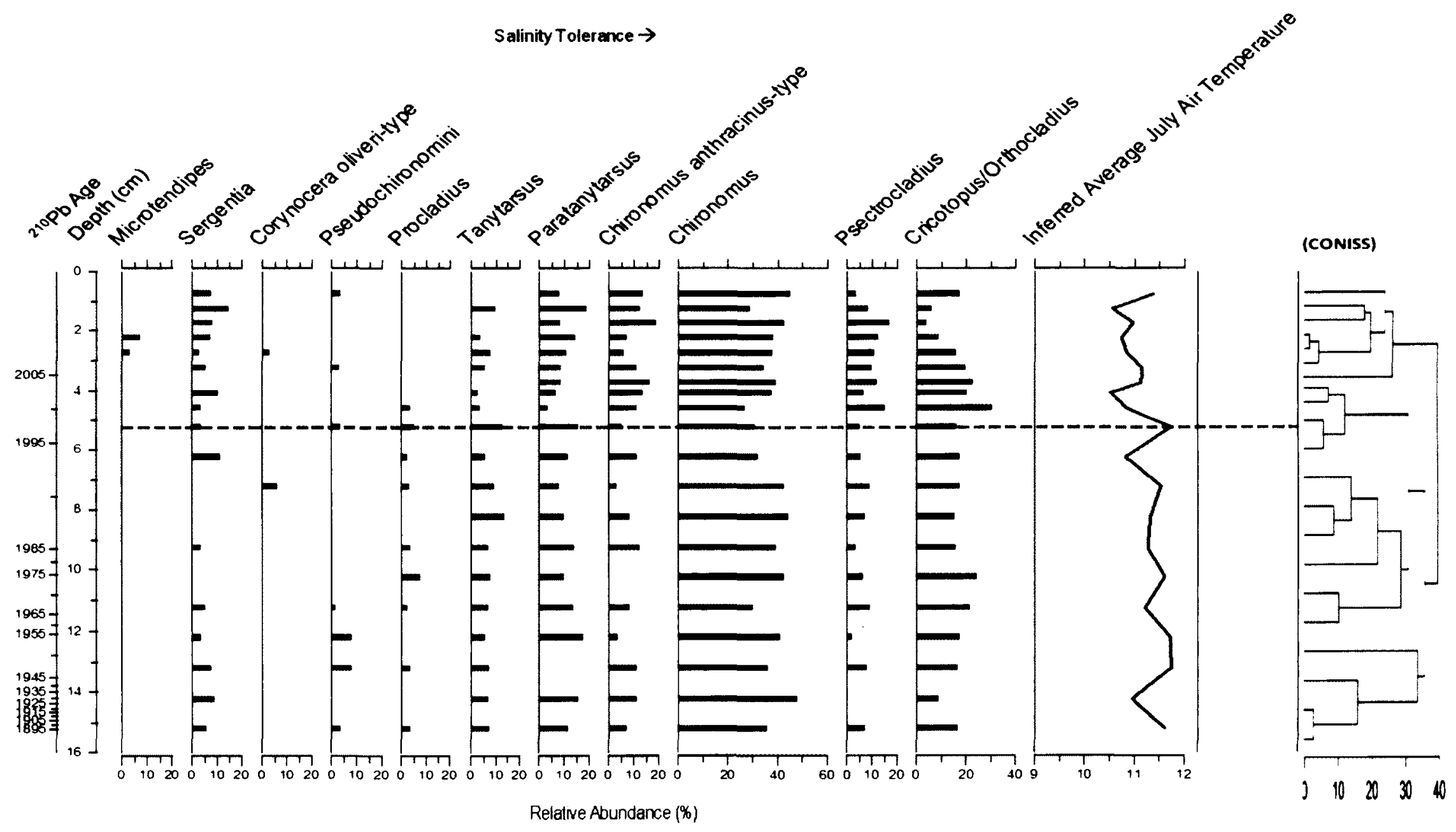

Figure 11c - Relative abundance diagrams for the chironomid taxa from control lake C-27. Taxa are organized from left to right according to their increasing salinity tolerances. Cluster analysis was used to determine the main zones of change in species assemblage, and is displayed next to the plots. The red dashed line indicates the 1999 storm surge event. The additional column on the right hand side indicates the reconstruction of inferred average July air temperatures as determined by the chironomid data using a transfer function from Barley et al. (2006). 

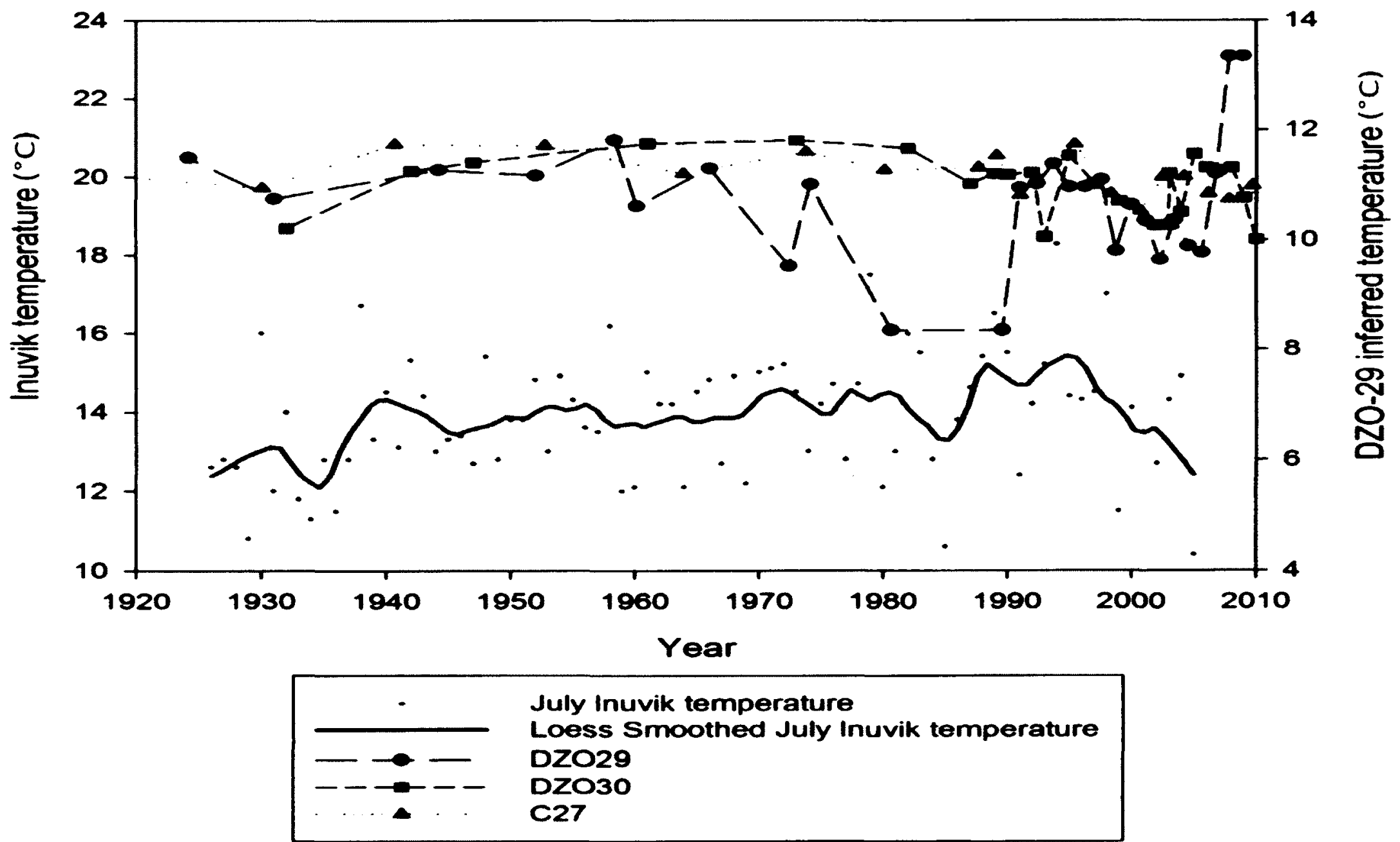

Figure 12 - Reconstructed inferred average July air temperature from DZO-29, DZO-30 and C-27 (axis on right) as well as the actual average July air temperature data from Inuvik (axis on left) according to Environment Canada and the associated Loess smoother. 

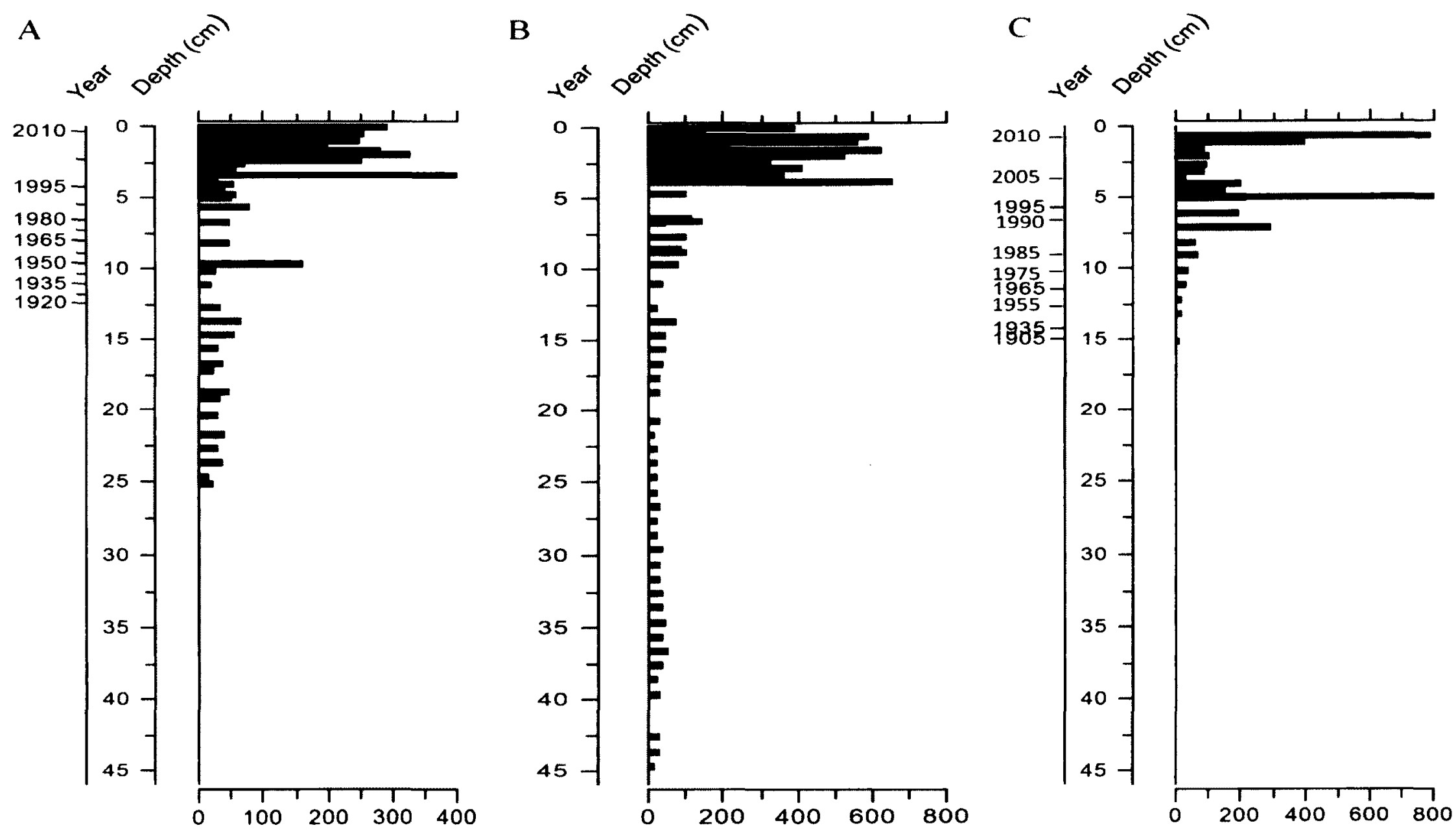

Total Chironomid Accumulation for All Taxa (\# head capsules g of dry sediment ${ }^{-1}$ year $^{-1}$ )

Figure 13 - Total chironomid accumulation rate (CAR) data (number of chironomid head capsules per gram of dry sediment per year) of all taxa for A) impacted lake DZO-30 and B) impacted lake DZO-29 and C) control lake C-27. The red line represents the 1999 storm surge event. 


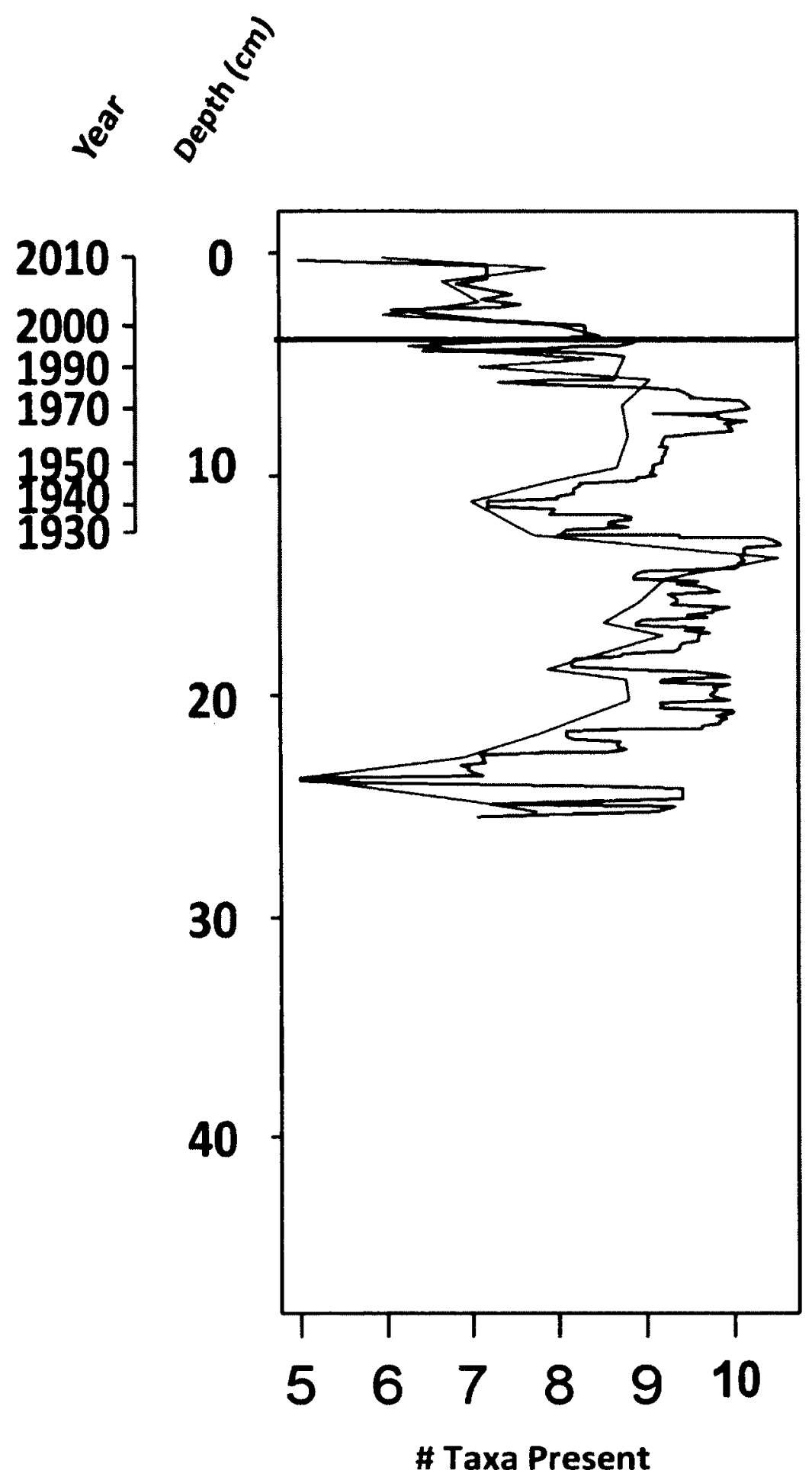

Figure 14a - Uninterpolated (red) and interpolated (blue) taxon richness plots as calculated by $\mathrm{R}$ software (version 0.94 .110 ) using chironomid count data of all taxa for impacted lake DZO-30. Black line indicates the 1999 storm surge event. 

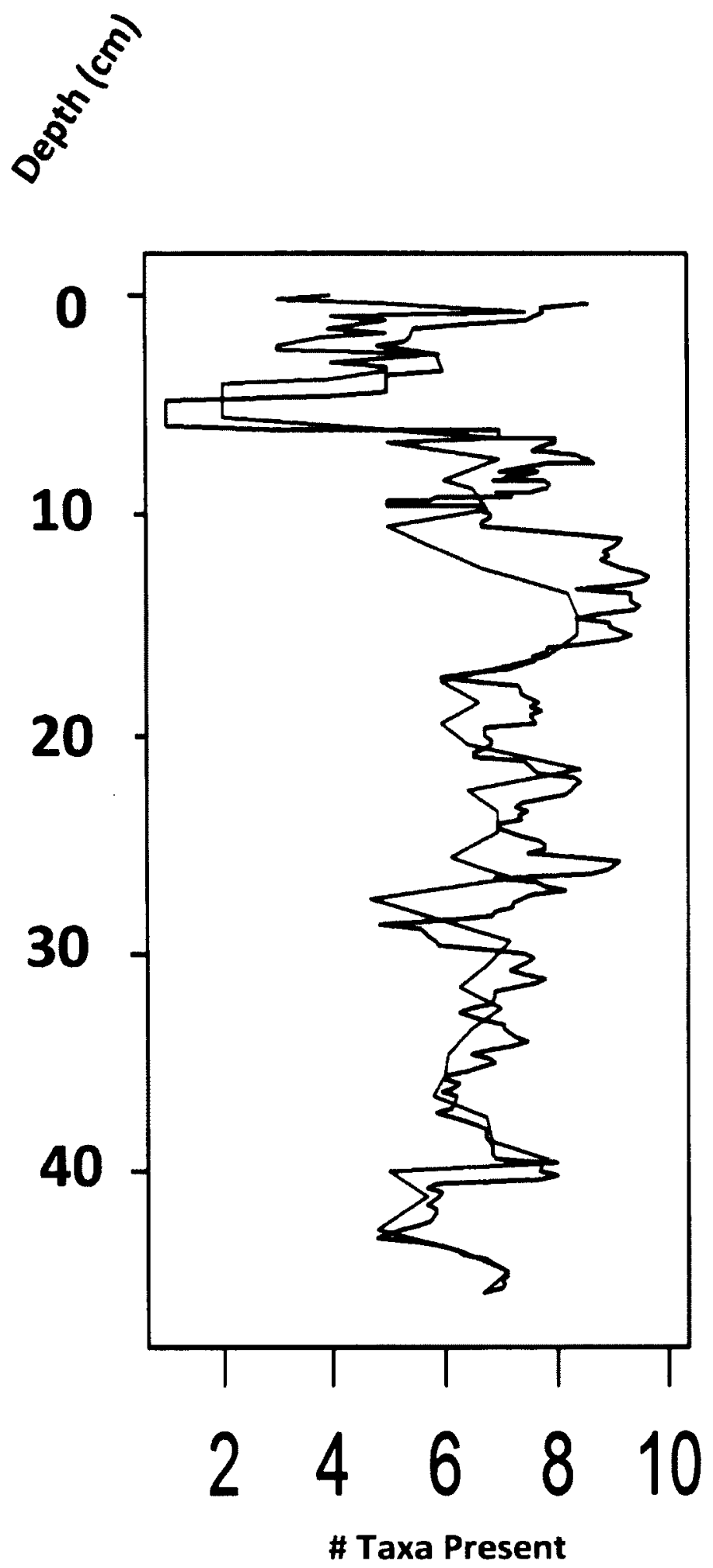

Figure $14 \mathrm{~b}$ - Uninterpolated (red) and interpolated (blue) taxon richness plots as calculated by $\mathrm{R}$ software (version 0.94 .110 ) using chironomid count data of all taxa for impacted lake DZO-29. 

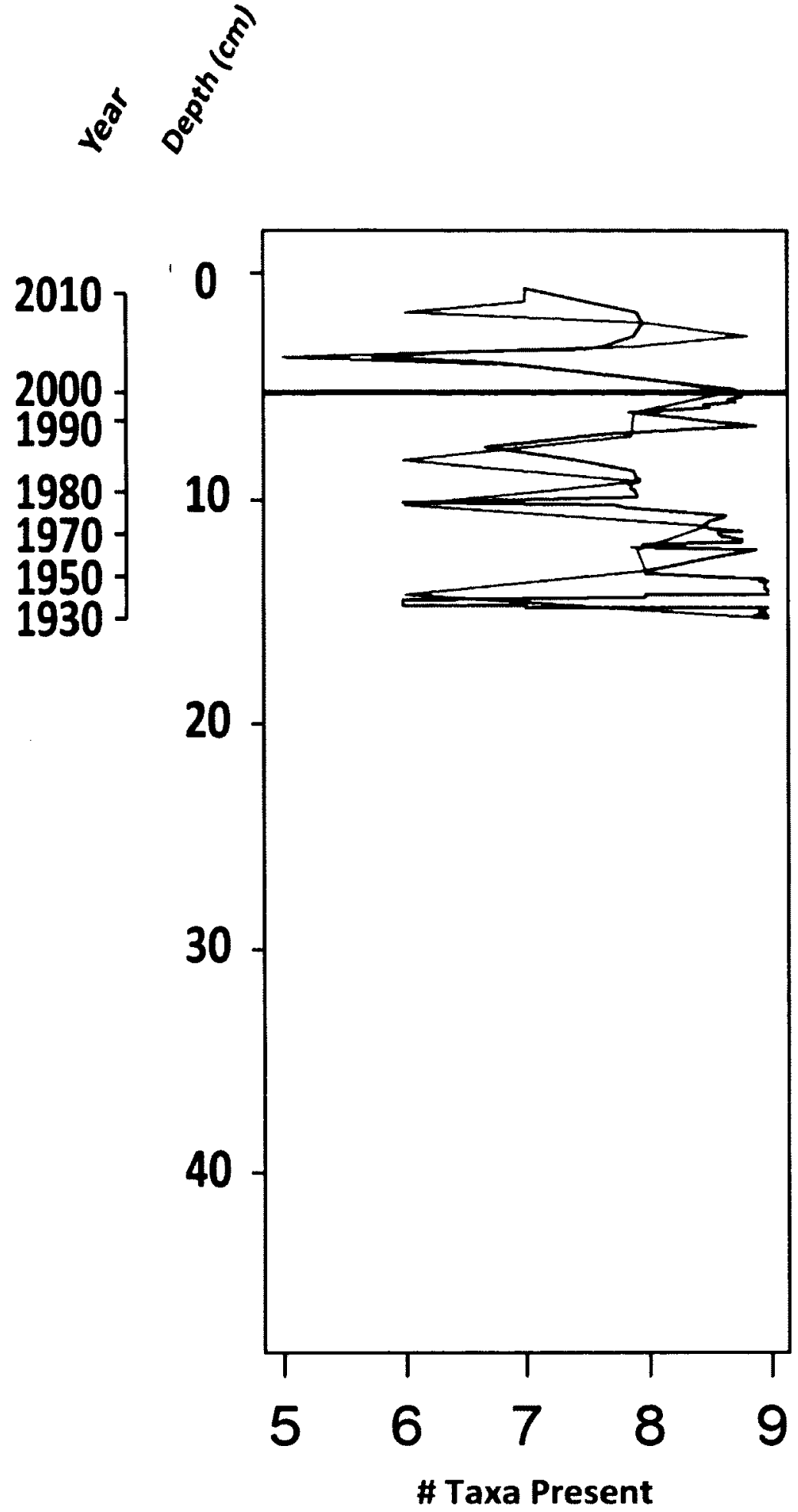

Figure $14 \mathrm{c}$ - Uninterpolated (red) and interpolated (blue) taxon richness plots as calculated by R software (version 0.94.110) using chironomid count data of all taxa for impacted lake C-27. Black line indicates the 1999 storm surge event. 


\subsection{Discussion}

\subsubsection{Chironomid response to the 1999 storm surge event}

The chironomid data from DZO-30 is consistent with the dramatic shifts in diatom assemblages in DZO-29 following the rapid inundation of saltwater in September 1999 (Thienpont et al., 2012) and suggest similar ecosystem impacts. The marked decrease in the relative abundances of Sergentia and Corynocera oliveri type -1 and the dramatic increase in Cricotopus/Orthocladius and Paratanytarsus abundances following the 1999 surge indicate the storm surge had an immediate ecological impact on chironomid communities living in these lakes. Despite having a low temperature optima of $10.3^{\circ} \mathrm{C}$, Sergentia is highly intolerant of saline conditions and survives only under dilute salinity levels (0-100 $\left.\mathrm{mg} \mathrm{L}^{-1}\right)$ (Walker et al., 1995). Thus its disappearance after the storm surge and the rapid transition to higher salinity levels (in excess of 1000-5920 $\mathrm{mg} \mathrm{L}^{-1} \mathrm{Cl}^{-}$in some instances (Table 1)), is not surprising and illustrates the ecological impact this event had on chironomid communities living in these lakes. After the rapid inundation of saline/brackish water in September 1999, Paratanytarsus and Cricotopus/Orthocladius, two cold water, saline-tolerant taxa (Walker et al., 1995), became abundant in DZO-30 and both continue to be important components of the chironomid assemblage of this lake to present day. It is important to note that although Paratanytarsus is shown in the relative abundance plots to have a lower salinity optima then the salt-adapted Cricotopus/Orthocladius taxa, Paratanytarsus could only be identified to the genus level and as such it should $b$ kept in mind that species within this genus can be abundant over a broad salinity range $\left(0-15,000 \mathrm{mg} \mathrm{L}^{-1}\right)$. 
In core DZO-29, a significant shift in chironomid assemblages occurred at a depth of $9 \mathrm{~cm}$ and is represented by the nearly identical changes in the chironomid assemblage described in the dated sediment core from DZO-30. The rapid and dramatic decreases in Corynocera oliveri type-1, and Sergentia coupled with increases in the relative abundances of Paratanytarsus and Cricotopus/Orthocladius suggest that the chironomid assemblage change occurring at $9 \mathrm{~cm}$ in DZO-29 is likely an ecological response to the 1999 storm surge, but must be viewed with caution due to the lack of dating control.

The difference in the depths of the assemblage changes between cores DZO-29 and DZO-30 is likely due to differing sedimentation rates between the two lakes, but without dates associated with DZO-29, this is speculative. However, sedimentation rates are known to differ greatly not only between lakes with close proximity to one another (Hatfield et al., 2008), but also from cores from different parts of the same lake (Callendar \& Robbins, 1993). This is due to a number of factors including the morphology of the lake bottom, sediment focusing, occurrence of complete mixing (e.g. spring and autumn mixing), wave action, sediment sliding on slopes and the random redistribution of sediments (Tylmann, 2004). In general, sedimentation rates at any given site are variable with respect to time periods and are variable between coring locations (Van Metre et al., 2001). Although ${ }^{210} \mathrm{~Pb}$ dating was performed on another core from impacted lake DZO-29, it was determined that the sedimentation rates between these cores were sufficiently different that it was not possible to apply that chronology to the core used in this study. This is not entirely surprising given the two cores were collected in different years and from different locations within the lake. 
Analysis of sodium and chloride concentrations from water and soil samples within the impacted zone, indicate soils and lakes remain highly saline more than a decade later, suggesting chemical recovery has been very slow to occur (Pisaric et al., 2011; Table 1). Recent measurements of chloride concentrations in lake water from DZO-29 and 30 are in the range of 2,500 to $5,900 \mathrm{mg} \mathrm{L}^{-1}$ (Pisaric et al., 2011). Few chironomid taxa are able to withstand these highly saline conditions, although Cricotopus/Orthocladius are one of few chironomid taxa that are known to tolerate salinity levels exceeding $10,000 \mathrm{mg} \mathrm{L}^{-1}$ (Walker et al., 1995). Walker et al. (1995) found that in lakes of southern British Columbia, Cricotopus/Orthocladius is uncommon at salinities below $150 \mathrm{mg} \mathrm{L}^{-1}$ and common, but never dominant, in lakes with salinities ranging from $150-600 \mathrm{mg} \mathrm{L}^{-1}$. At salinities exceeding 10,000 $\mathrm{m} \mathrm{L}^{-1}$, CricotopuslOrthocladius usually composes $>75 \%$ of the fauna (Walker et al., 1995). Thus, the relatively high abundance of Cricotopus/Orthocladius $(\sim 20-40 \%)$ as well as salt-tolerant Paratanytarsus, near the surface of both cores reflects the continued presence of saline/brackish conditions in these impacted lakes, over a decade after the storm surge occurred.

Conversely, control lake C-27, which was likely not impacted by the 1999 storm surge, does not indicate any significant shifts in chironomid community composition during the approximate 110-year period represented by the sediment core. Based on the chironomid assemblages preserved in Lake C-27, there does not appear to be any clearly discernible ecological impacts of the 1999 storm surge similar to those that occurred in Lakes DZO-29 and DZO-30. For example, in C-27 there were no decreases in Sergentia or Corynocera oliveri type -1 . However, Corynocera oliveri type -1 was not abundant in 
Lake C-27 at anytime during the period recorded in the lake sediment core. Both of these chironomid types are salt-intolerant taxa, and both experienced significant declines in abundance in lakes DZO-29 and DZO-30 following the 1999 storm surge. Further, there was no significant increase in the salt-tolerant taxa Paratanytarsus. Cricotopus/ Orthocladius increased slightly in C-27 following 1999 . While a storm surge impact on this lake which is located far from the coast is not likely, this cannot be completely ruled out. Saline water pushed well into the Mackenzie Delta during this storm event (Kokelj et al., 2012). It is common during periods with strong onshore winds such as those that occurred during the storm in September 1999 (Kokelj et al., 2012) for water levels within the delta to rise as water from the Beaufort Sea pushes into the delta. Therefore, it is possible that as Beaufort Sea water pushed into the delta, minor flooding could have resulted, allowing some saline water to reach $\mathrm{C}-27$. The impacts of this are very short lived however, as indicated by the chironomid relative abundances in C-27. Cricotopus/ Orthocladius relative abundances decreased to pre-1999 levels by $\sim 2002 / 2003$ which is very different than those changes recorded in DZO-29 and DZO-30.

\subsubsection{Temperature change, ice cover and changing aquatic communities}

Deasley et al. (2012), studying the ecological impact of the 1999 storm surge on cladocera in lake DZO-29, indicated that while the cladocera community was affected by the 1999 event, earlier changes in cladocera relative abundance indicated a gradual shift from benthic to pelagic production. These changes are consistent with post-1850 climate warming, making this the likely explanation for the major assemblage changes in the cladoceran record prior to the 1999 storm surge. This is also consistent with the chironomid data from DZO-30 and DZO-29. While there were significant changes in the 
chironomid assemblages of DZO-30 and DZO-29 (most likely) at the time of the 1999 storm surge, there were other changes in the chironomid communities that occurred prior to the surge event. Corynocera oliveri type-1, a salt-intolerant species with an optimum temperature of $12.3^{\circ} \mathrm{C}$ (Barley et al., 2006) is abundant prior to 1999. Post-1999, Cricotopus/Orthocladius and Paratanytarsus, two salt-tolerant taxa with lower temperature optima of $11.1^{\circ} \mathrm{C}$ (Barley et al., 2006), dominated the chironomid assemblage. These trends suggest that regional temperature change may be the driver of chironomid community change prior to the 1999 storm surge.

Additional evidence of regional warming during the late 1800 s and early 1900 s in the Mackenzie Delta region and northwest Canada more broadly, has also been documented using tree ring growth records. Tree-ring width and maximum latewood density chronologies from latitudinal treeline sites along the Coppermine River in the Northwest Territories (NWT), in the Thelon River Sanctuary, Nunavut (D'Arrigo et al., 2009) and along East channel of the Mackenzie Delta, Northwest Territories (Porter et al.,2009) all suggest a period of warming commenced in the mid to late $1800 \mathrm{~s}$ in response to the end of Little Ice Age conditions. This suggests that prior to the shift to Cricotopus/Orthocladius dominated assemblages in $\sim 1999$, regional temperature change may have been driving the shifts in the chironomid communities of DZO-30 and DZO29. After September 1999 and the rapid shift to saline conditions in many lakes of the outer Mackenzie Delta, salinity concentrations now dictated the chironomid assemblages of these lakes. However as previously mentioned for $\mathrm{DZO}-29$, the lack of $\mathrm{Pb}^{210}$ dates precludes a definitive attribution of the 1999 storm surge. 
Inferred July air temperatures based on the chironomid data suggest that temperatures in this region have fluctuated between $10-12^{\circ} \mathrm{C}$ during the $20^{\text {th }}$ century (Fig. $11 \mathrm{a}$ and c) and possibly between $9-10^{\circ} \mathrm{C}$ prior to the $20^{\text {th }}$ century (Fig. $11 \mathrm{~b}$ ). Interestingly, the temperature reconstructions are in good agreement with actual air temperatures recorded at Tuktoyaktuk and Inuvik during the 30-year period from 19712000. Average July temperature for Tuktoyaktuk from $1971-2000$ is $11^{\circ} \mathrm{C}$ while July temperature at Inuvik is slightly warmer at $14.2^{\circ} \mathrm{C}$ (Environment Canada Climate Normals, 1971-2000). Disentangling the impact of temperature versus salinity changes on the chironomid communities in the uppermost sediments of the records from DZO-29 and DZO-30 is difficult and makes interpretation of the chironomid inferred temperature after 1999 complicated. However, comparing the chironomid data with previously published records of cladocera and diatoms from these lakes, it appears that the increased salinity concentrations resulting from the 1999 storm surge now override the response of chironomid communities to changing temperature regimes. Although this study was not initially designed for the reconstruction of air temperatures, the inferred July air temperatures from the chironomid data are in good agreement with measured temperatures from Inuvik and Tuktoyaktuk during recent decades.

High latitude lakes are known to be responsive to climate change, as even slight warming results in decreased ice cover and longer growing seasons, having implications for algae and other organisms (Scrimgeour et al., 1994). Lake ice has a significant effect in these ecosystems (Smol et al., 2005). For example, during colder periods, lakes will retain more extensive ice covers that may persist throughout the short Arctic summer, resulting in only a small, shallow moat of open water. With warmer temperatures, more 
of the central raft of snow and ice will melt, exposing additional, deeper open-water habitats for algal and other biological growth (Smol \& Douglas, 2007). With continued warming, all the ice may melt, resulting in a dramatically altered physical, chemical, and biological environment, including different regimes of light penetration, mixing, gas exchange, and other characteristics (Smol \& Douglas, 2007). As a result, an increase in primary production may lead to a greater density of biological organisms preserved in the sediments (Smol \& Douglas, 2007). In DZO-29 and DZO-30 we see this trend illustrated by an overall increase in total CAR throughout both cores. The total CAR of impacted core DZO-30 is clearly confounded by the 1999 storm surge (Fig. 13a), and although there are no dates associated with impacted core DZO-29, the marked increase of total CAR at approximately $9 \mathrm{~cm}$, which is consistent with the timing of the significant change in chironomid assemblage, suggests that perhaps this is additional evidence of the ecological impact of the 1999 storm surge. The increase in chironomid accumulation rate is not as pronounced in the control lake C-27, located further inland and outside of the impacted zone, however an increasing trend throughout the record is observed nonetheless (Fig. 13c).

To date, the majority of paleolimnological research has focused on algal indicators of environmental change (primarily diatoms) (Walker et al., 1995). However, if the impacts of climate change can lead to pronounced ecosystem shifts at the lowest trophic levels, it is not difficult to envision similar shifts at higher trophic levels that depend on the primary producers, indicating strong food-web linkages (Smol \& Douglas, 2007). As temperatures continue to increase and as thresholds of ice cover, habitat availability and thermal stratification are surpassed, aquatic community composition 
turnover is predicted to be significant and regime shifts towards new ecological states may occur (Smol et al., 2005).

The overall trend and timing of chironomid assemblage changes in impacted lake DZO-30 and DZO-29 prior to the 1999 storm surge suggests that these changes may be driven by regional warming across the study area. This conclusion is supported by diatom (Thienpont et al., 2012), cladocera (Deasley et al., 2012) and grain size data (Vermaire et al., 2013), all of which imply that changing regional temperatures were driving chironomid community composition until the 1999 surge when changes in salinity became the dominant control of chironomid assemblages in the impacted lakes. Despite lacking dating control, the similarity in the changing composition of chironomid assemblages in Lakes DZO-29 and DZO-30, suggest that similar climatic and environmental drivers were responsible for the chironomid community changes in both lakes before and after the 1999 storm surge event.

\section{$\underline{3.5 \text { Conclusion }}$}

Located in an ecologically sensitive region, the freshwater ecosystems of the outer Mackenzie Delta are susceptible to rapid saltwater inundations resulting from storm surges (Pisaric et al., 2011; Kokelj et al., 2012). As sea-ice cover decreases and the open water season lengthens, the frequency and intensity of storms in the Arctic region is expected to increase due to climatic warming. This makes assessing the ecological impacts of salt water intrusions on aquatic ecosystems critical in understanding the controls of community composition within these lake systems. 
A sediment core from impacted lake DZO-30 indicated that chironomid communities were not eradicated following the 1999 storm surge, however the chironomid composition did not return to pre-intrusion community makeup. Chironomid analysis shows that there were significant changes to the chironomid communities $i$ following the 1999 storm surge, from a less salt-tolerant community dominated by Corynocera oliveri type- 1 to a cold water, highly salt-tolerant Cricotopus/Orthocladius and Paratanytarsus-dominated assemblage. These salt-tolerant taxa persist in the most recent sediments of the lake, likely due to the elevated salt concentrations in these lakes as indicated by analysis of recent water samples collected more than a decade after the 1999 storm surge event. These persistent saline conditions suggest that ecological recovery is occurring extremely slow if at all. However, a significant shift in the chironomid assemblage deeper in the core and dated to the early $20^{\text {th }}$ century or late $19^{\text {th }}$ century, suggests the influence of warming climatic conditions on chironomid communities. The prevalence of Corynocera oliveri type-1 and Sergentia, as well as previously discussed changes in diatom communities all suggest that regional warming across the Mackenzie Delta and more broadly across the Arctic, were driving the early changes in the chironomid communities in both lakes DZO-29 and DZO-30. After the 1999 storm surge, salinity levels have become the primary controlling factor of chironomid communities in the outer Mackenzie Delta lake systems.

Although lake DZO-29, which is also located in the surge impacted zone but lacks dating control, the similar changes in chironomid community assemblages in Lake DZO29 to those recorded in Lake DZO-30, suggests the timing of these changes were likely synchronous and being driven by similar climatic and environmental controls. Without 
${ }^{210} \mathrm{~Pb}$ dates, it is difficult to conclusively say that the decreases in the relative abundances of Corynocera oliveri type-1 and Sergentia and the dramatic increase in Cricotopus/ Orthocladius and Paratanytarsus that occurred at a depth of approximately $9 \mathrm{~cm}$ are a result of the 1999 storm surge. However, it can be cautiously concluded that this is the case, and that similar to DZO-30, the chironnomid assemblage prior to $9 \mathrm{~cm}$ is driven by regional warming trends, while above $9 \mathrm{~cm}$ salinity takes over as the dominant control. Not surprisingly, no similar changes in chironomid assemblages were observed at control lake, C-27, located much further inland, suggesting that this lake has most likely not been impacted by the 1999 storm surge.

As environmental thresholds are exceeded with continued rising temperatures in the Arctic region, aquatic community composition turnover is predicted to increase, and regime shifts toward new ecological states may occur (Smol et al., 2005). This research provides evidence of ecological changes in chironomid assemblages related to climate change in the Canadian Arctic. It suggests that as temperatures continue to increase as a result of climatic warming, and as storm surges become a greater risk to freshwater coastal ecosystems, critical changes in chironomid assemblages have and will likely continue to occur. 


\section{Chapter Four}

\section{Conclusion}

\subsection{Study conclusions}

The Arctic has experienced dramatic change in many physical and environmental variables in recent decades due to significant increases in temperature. Warming in the Arctic has not only resulted in a decrease in the extent and thickness of sea ice (Stroeve, 2012), but sea level is on the rise (Intergovernmental Panel on Climate Change, 2007) and the frequency and intensity of Arctic storms appears to be increasing (Manson \& Solomon, 2007). With more available open water and a longer open-water season, storm waves and surges are posing a greater risk for low-lying coastlines.

The Mackenzie Delta along the Beaufort Sea coast, spanning an area of more than $13,000 \mathrm{~km}^{2}$, is the second largest Arctic delta, smaller only than the Lena River Delta in Russia. One of the most important features of the Mackenzie Delta is the 25,000+ freshwater lakes that are situated within its boundaries (Marsh \& Hey, 1994). Freshwater flooding across the outer Mackenzie Delta is common, occurring annually during the spring freshet (Goulding et al., 2009). Terrestrial and aquatic ecosystems throughout the Mackenzie Delta are tolerant of spring flooding since most of these systems are still dormant, or in the case of lakes, remain cutoff due to the persistence of ice cover at the time of the spring freshet (Marsh \& Hey, 1994). Conversely, marine intrusions associated with storm-induced surges appear to be less common and occur during the warmer part of the season when lakes are ice free and vegetation is not dormant (Solomon et al., 2000; Pisaric et al., 2011). Marine storm surges can produce flooding levels 1-2 m above the 
low-lying land surfaces of the outer Mackenzie Delta, which is vulnerable to such saltwater inundations.

In September 1999, an intense storm surge left nearly $200 \mathrm{~km}^{2}$ of the Mackenzie Delta front impacted due to a massive saltwater intrusion, causing the freshwater lakes and ponds to rapidly shift to brackish or saltwater systems. Therefore, assessing the ecological impact of salt water intrusions on freshwater aquatic ecosystems is critical in understanding the influence of these rapid disturbances, especially in remote Arctic lake systems. This is particularly important for this region given the impending likelihood of increasing industrial activities.

Chironomids provide a wealth of information on the ecological characteristics of a lake system through time, and as such have become increasingly popular amongst paleolimnologists to classify lakes in terms of their trophic status or biological productivity and to quantitatively reconstruct past ecological changes in lake conditions (Porinchu \& MacDonald, 2003). Due to the capacity of chironomids to tolerate large gradients in $\mathrm{pH}$, salinity, depth, oxygen concentration, temperature and productivity as well as their near global distribution and abundance, makes them highly suitable for paleolimnological/paleoecological research. In addition their chitinous head capsules are normally well-preserved and easily recovered and identified with practice. Through the use of fossil chironomid remains found in lake sediments, this study was able to provide new and exciting ecological data concerning storm surge impacts for this region where written or instrumental records are short and often incomplete.

Sediment core DZO-30, located within the surge impacted area, indicated that although chironomid communities were not eradicated following the 1999 storm surge, 
chironomid community composition did not return to pre-intrusion assemblages. In Thienpont et al. (2012), the diatom assemblages in DZO-30 show that the 1999 storm surge resulted in significant impacts to the freshwater ecosystems with minimal recovery. Chironomid analysis from impacted lake DZO-30 supports this finding as it indicates a dramatic shift from a less saline-tolerant assemblage dominated by Corynocera oliveri type- 1 and Sergentia, to a Cricotopus/Orthocladius and Paratanytarus-dominated assemblage, with much greater salt tolerances. Cricotopus/Orthocladius and Paratanytarus continue to dominate to the top of the core which is likely due to the elevated salinity levels that now characterise these lakes more than a decade after the surge event. The ecological impact of the 1999 storm surge is also illustrated by the gradual increase in total chironomid accumulation rate over time with the most notable increase occurring after the 1999 storm surge event.

While impacted lake DZO-29 has not been dated, the chironomid community changes in Lake DZO-29 are similar to those occurring in DZO-30. Though the significant shift in chironomid assemblage occurred deeper in the core at a depth of $9 \mathrm{~cm}$, possibly due to differing sedimentation rates, the rapid loss of Corynocera oliveri type-I and Sergentia and dramatic increase in the relative abundance of Cricotopus/ Orthocladius and Paratanytarsus suggests that these changes are likely driven by the impacts of the 1999 storm surge. No similar changes in chironomid assemblages were observed at the control site C-27, located much further inland. A slight increase in total CAR throughout time does not appear to be related to the 1999 storm surge, suggesting that this lake has likely not been impacted by the 1999 storm surge. 
The discovery of significant shifts in the chironomid communities of DZO-29 and DZO-30 much deeper in the core, prior to the 1999 storm surge, suggest the chironomid assemblages of these lake were influenced by other environmental variables until the time of the 1999 storm surge, possibly regional warming. Following the surge event, it appears that salinity became the primary driver of chironomid community composition within impacted lakes DZO-29 and DZO-30. Previously studied cladoceran and diatom data from this region is also consistent with the chironomid data, suggesting that regional temperatures were likely exerting significant control on the biological communities found in these lakes until the 1999 storm surge.

The intense and ongoing impact to aquatic ecosystems in the outer Mackenzie Delta and the continued dominance of salt-tolerant Paratanytarsus and Cricotopus/Orthocladius in both impacted lakes for the past decade, suggests that ecological recovery has been extremely slow. In terms of salinity concentrations, these lake systems appear to now support saline-tolerant chironomid taxa as there has been no recovery from the saline conditions. This study highlights the importance of better understanding the ecological changes happening in the Arctic, and adds to the evidence that even the world's northern ecosystems are being impacted by climatic warming.

\subsection{Future research}

There remains an enormous amount of research to be conducted regarding the ecological impacts of storm surges in remote Arctic regions. Future research possibilities could include the collection of an additional core from DZO-29 for dating purposes, the collection of cores from additional lakes and ponds in the outer Mackenzie Delta for high resolution chironomid analysis as well as other biological proxies to examine the full 
scope of the ecological impact of the 1999 storm surge at various trophic levels. Additional chironomid research would also help to better understand the limiting factors which influence chironomids in these harsh environments and how they are responding to ever-changing climatic conditions. While this study examined chironomid remains in short cores from two 1999 storm surge impacted lakes, it would be beneficial to examine changes in chironomid communities across even longer timescales to fully comprehend the range of ecological response of these organisms to climatic and environmental change.

The use of chironomids in paleoecology appears to be a valuable and useful technique in documenting past ecological changes associated with the impacts of a warming climate. It is hoped that future paleoeocological reconstructions will provide a clearer and more accurate interpretation of earlier ecological conditions not only in the Western Canadian Arctic, but in circumpolar Arctic regions. 


\section{References}

Appleby, P.G. \& F. Oldfield. 1978. The calculation of ${ }^{210} \mathrm{~Pb}$ assuming a constant rate of supply of unsupported ${ }^{210} \mathrm{~Pb}$ to the sediments. Catena $5: 1-8$.

Armitage, P.D., Cranston, P.S. \& Pinder, L.C., (editors), 1995: The Chironomidae: the biology and ecology of nonbiting midges. London: Chapman and Hall.

Barley, E.M., Walker, I.R., Kurek, J., Cwynar, L.C., Mathewes, R.W., Gajewski, K. \& B.P. Finney. 2006. A northwest North American training set: distribution of freshwater midges in relation to air temperature and lake depth. Journal of Paleolimnology 36: 295-314.

Bennett, K.D. 2006. Determination of the number of zones in a biostratigraphical sequence. New Phytologist 132(1): 155-170.

Bengtsson, L., Semenow, V.A. \& O.M. Johannessen. 2004. The early twentieth-century warming in the Arctic: A possible mechanism. Journal of Climate 17: 40454057.

Birks, H.J.B. \& H.H. Birks. 1980. Quaternary Palaeoecology, E. Arnold, London.

Birks, H.J.B., Heiri, O., Seppä, H. \& A.E. Bjune. 2010. Strengths and Weaknesses of Quantitative Climate Reconstructions Based on Late-Quaternary Biological Proxies. The Open Ecology Journal 3: 68-110.

Birks, H.J.B. \& J.M. Line. 1992. The use of Rarefaction Analysis for Estimating Palynological Richness from Quaternary Pollen-Analytical Data. The Holocene 2(1): $1-10$. 
Blytt, A. 1881. Die Theorie der wechselnden kontinentalen und insularen Klimate. Englers Botanisch Jahrbüch 2: 1-50.

Bonsal, B.R. \& B. Kochtubajda. 2009. An assessment of present and future climate in the Mackenzie Delta and the near-shore Beaufort Sea region of Canada. International Journal of Climatology 29: 1780-1795.

Bonsal, B.R. \& T.D. Prowse. 2003. Trends and variability in spring and autumn $0^{\circ} \mathrm{C}$ isotherm dates over Canada. Climatic Change 57: 341-358.

Bonsal, B.R., Zhang, X., Vincent, L.A. \& W.D. Hogg. 2001. Characteristics of daily and extreme temperature over Canada. Journal of Climate 14: 1959-1976.

Brooks, S.J. \& H.J.B. Birks. 2000. Chironomid-inferred late-glacial and early-Holocene mean July air temperatures for Krakenes Lake, western Norway. Journal of Paleolimnology 23: 77-89.

Brown, R.I.E. 1957. Observations on Break-up in the Mackenzie River and its Delta in 1954. Journal of Glaciology 3(22): 133-142.

Brown, R.D. 2000. Northern Hemisphere snow cover variability and change, 19151997. Journal of Climate 13: 2339-2355.

Burn, C.R. 1997. Cryostratigraphy, paleogeography, and climate change during the early Holocene warm interval, western Arctic coast, Canada. Canadian Journal of Earth Sciences 39: 1281-1298.

Brundin, L., 1949. Die bodenfaunistischen Seetypen und ihre Anwendbarkeit auf die Sudhalbkugel. Zugleich eine Theorie der produktionsbiologischen Bedeutung 
der glazialen Erosion. Technical Report, Report of the Institute of Freshwater Research, Drottningholm 37.

Burn, C. \& S.V. Kokelj. 2009. The Environment and Permafrost of the Mackenzie Delta Area. Permafrost and Periglacial Processes 20: 83-105.

Cahoon, D.R. 2006. A Review of Major Storm Impacts on Coastal Wetland Elevations. Estuaries and Coasts 29(6A): 889-898.

Callender, E.\& J. Robbins. 1993. Transport and accumulation of radionuclides and stable elements in a Missouri River reservoir. Water Resources Research 29(6): doi: $10.1029 / 93 W R 00387$.

Carson, M.A., Jasper, J.N \& F.M. Conley. 1998. Magnitude and sources of sediment input to the Mackenzie Delta, Northwest Territories. Arctic 51: 116-124.

Chou, L. 1975. Statistical Analysis: Section 17.9. Holt, Rinehart \& Winston of Canada Ltd ( $2^{\text {nd }}$ edition). ISBN 0-03-089422-0. $894 \mathrm{p}$.

Clair, T. \& C.G. Paterson. 1974. Effect of a salt water intrusion on a freshwater chironomidae community: a palaeolimnological study. Hydrobiologia 48(2): $131-135$.

Coffman, W.P. 1995. Conclusions. In Armitage, P.D., Cranston, P.S. \& Pinder, L.C., editors. The Chironomidae: the biology and ecology of nonbiting midges. London: Chapman and Hall, 436-446.

Colwell, Robert K. 2009. Biodiversity: Concepts, Patterns and Measurement. In Levin, S.A., (editors), The Princeton Guide to Ecology. Princeton: Princeton University Press, 257-263. 
Comiso, J.C. 2006. Abrupt decline in the Arctic winter sea ice cover. Geophysical Research Letters 33: L18504, doi:10.1029/2006GL027341.

Comiso, J.C., Parkinson, C.L., Gersten, R. \& L. Stock. 2008. Accelerated decline in the Arctic sea ice cover. Geophysical Research Letters 35: L01703, doi: 10.1029/2007GL031972.

Cornett, R, Chant, L.A. \& D. Link. 1984. Water Pollution Research Journal of Canada 19: 97-109.

Cranston, P.S. \& D.R. Oliver. 1987. Problems in Holarctic chironomid biogeography. Entomologica Scandinavica Supplement 29: 51-56.

Cure, V. 1985. Chironomidae (Diptera - Nematocera) aus Rumanien unter besonderer Berucksichtigung jener aus dem hydrographischen Einzugsgebiet der Donau. Archiv Hydrobiologie Supplement 68: 163-217.

Dallimore, S.R., Wolfe, S.A., Matthews, J.V. \& J-S. Vincent. 1997. Mid-Wisconsinan eolian deposits of the Kittigazuit Formation, Tuktoyaktuk Coastlands, Northwest Territories, Canada. Canadian Journal of Earth Sciences 34: 1421-1441.

D’Arrigo, R. Jacoby, G., Buckley, B., Sakulich, J., Frank, D., Wilson, R., Curtis, A. \& K. Anchukaitis. 2009. Tree growth and inferred temperature variability at the North American Arctic treeline. Global and Planetary Change 65: 71-82.

Deasley K., Korosi, J.B., Thienpont, J.R., Kokelj, S.V., Pisaric, M.F.J. \& J.P. Smol. 2012. Investigating the response of Cladocera to a major saltwater intrusion event in an Arctic lake from the outer Mackenzie Delta (NT, Canada). Journal of Paleolimnology 48(2): 287-296. 
Department of Public Works. 1971. Investigation of Storm, September 13-16, 1970. Mackenzie Delta region, Beaufort Sea. Unpublished Technical Report by Public Works of Canada, Ottawa. Available at the Department of Public Works, Ottawa.

Deser, C., Walsh, J.E. \& S.M. Timlin. 2000. Arctic Sea Ice Variability in the Context of Recent Atmospheric Circulation Trends. Bulletin of the American Meteorological Society 13: 617-633.

Dixon, J., Dietrich, J.R. \& D.H. MacNeil. 1992. Upper Cretaceous to Pleistocene sequence straigraphy of the Beaufort-Mackenzie and Banks Island areas, Northwest Canada, Bulletin 407. Geological Survey of Canada: Ottawa. $90 \mathrm{pp}$.

Emmerton, C.A., Lesack, L.F.W. \& P. Marsh. 2007. Lake abundance, potential water storage, and habitat distribution in the Mackenzie delta, western Canadian Arctic. Water Resources Research 43. 14 Pp.

Environment Canada. 2005 National Climate Data and Information Archive, (29, Nov.. 2012) $<$ http://climate.weatheroffice.gc.ca/climate_normals/index_e.html $>$ (visited 6 November, 2012)

Evans, R.D. \& F.H. Rigler. 1980. Measurement of whole lake sediment accumulation and phosphorus retention using $210 \mathrm{~Pb}$ dating. Canadian Journal of Fisheries and Aquatic Sciences 37: 817-822. 
French, H.M. and O. Slaymaker, editors, 1993. Part One: Cold Land, Cold Seas. In Canada's Cold Environments (pp. 1-64). Montreal, QC, Canada: McGillQueen's University Press.

Flynn, W.W. 1968. The Determination of Low Levels of Polonium-210 in Environmental Materials. Analytical Chimica Acta 43: 221-227.

Gajewski, K., Bouchard, G., Wilson, S.E., Kurek, J. \& L.C. Cwynar. 2005. Distribution of Chironomidae (Insecta: Diptera) head capsules in recent sediments of Canadian Arctic lakes. Hydrobiologia 549: 131-143.

Glew, J.R. 1988. A portable extruding device for close interval sectioning of unconsolidated core samples. Journal of Paleolimnology 1: 235-239.

Glew, J.R., Smol, J.P. \& W.M. Last 2002. Tracking environmental change using lake sediments. In W.M. Last \& J.P. Smol, (editors), 2002. Tracking Environmental Change Using Lake Sediments. Volume 1: Basin Analysis, Coring, and Chronological Techniques. Kluwer Academic Publishers, Dordrecht, The Netherlands. 548 pp.

Goodison, B.E., Louie, P.Y.T., \& D. Yang. 1998. WMO Solid Precipitation Measurement Intercomparison - Final Report, WMO/TD-No.872. World Meteorological Organization: Geneva: 212.

Goulding, H.L., Prowse, T.D. \& S. Beltaos. 2009. Spatial and temporal patterns of break-ups and ice-jam flooding in the Mackenzie Delta, NWT. Hydrological Processes 23: 2654-2670. 
Harper, J.R., Henry, R.F. \& G.G. Stewart. 1988. Maximum Storm Surge Elevations in the Tuktoyaktuk Region of the Canadian Beaufort Sea. Arctic 41(1): 48-52.

Hatfield, R.G, Maher, B.A., Pates, J.M. \& P.A. Barker. 2008. Sediment dynamics in an upland temperate catchment: changing sediment sources, rates and deposition. Journal of Paleolimnology 40: 1143-1158.

Henry, R.F. 1975. Storm surges. Beaufort Sea Project Technical Report No. 19. Institute of Ocean Sciences Department of Fisheries and Oceans Canada. Sidney, B.C.: $41 \mathrm{pp}$.

Henry, R.F. \& N.S. Heaps. 1976. Storm surges in the southern Beaufort Sea. Journal of the Fisheries Research Board of Canada 33: 2362-2376.

Hofmann, W. 1988. The Signficance of Chironomid Analysis (Insecta: Diptera) for Paleolimnological Research. Palaeogeography, Palaeoclimatology, Palaeoecology 62: 501-509.

Holland, M.M., Bitz, C.M. \& B. Tremblay. 2006. Future abrupt reductions in the summer Arctic sea ice. Geophysical Research Letters 33: L23503, doi:10.1029/2006GL028024.

Hubbell, S.P. 2001. The unified neutral theory of biodiversity and biogeography. Princeton University Press, Princeton, N.J. 448 pp.

Hudak, D.R. \& J.M.C. Young. 2001. Storm Climatology of the Southern Beaufort Sea. Atmosphere-Ocean 40(2): 145-158.

Hudson, R. D. 1987. Multiyear sea ice flow distribution in the Canadian Arctic Ocean. Journal of Geophysical Research 92(C13): 14,663-14,669. 
Intergovernmental Panel on Climate Change (2007) Climate Change 2007: The Physical Science Basis. Contribution of Working Group I to the Fourth Assessment Report of the Intergovernmental Panel of Climate Change (Cambridge University Press, Cambridge, United Kingdom). 996 pp.

Iversen, J. 1944. Viscum, Hedera and Ilex as climate indicators. A contribution to the study of the post-glacial temperature climate. Geologiska Föreningens $i$ Stockholm Förhandlingar 66: 463-83.

Johnstone, J.F. \& S.V. Kokelj. 2007. Environmental Conditions and Vegetation Recovery at Abandoned Drilling Mud Sumps in the Mackenzie Delta Region, Northwest Territories, Canada. Arctic 61(2): 199-211.

Jones, B.M. Arp, C.D., Jorgenson, M.T., Hinkel, K.M., Schmutz, J.A. \& P.L. Flint. 2009. Increase in the rate and uniformity of coastline erosion in Arctic Alaska. Geophysical Research Letters Volume 36(3): 1-5.

DOI: 10.1029/2008GL036205.

Juggins, S. 1991. C2 (Version 1.7.2) [Computer Software]. Newcastle upon Tyne, Tyne and Wear United Kingdom: Newcastle University. Retrieved June 1 ${ }^{\text {st }}, 2012$. Available from http://www.staff.ncl.ac.uk/staff/stephen.juggins/software.htm.

Juggins, S. 2012. Rioja: Analysis of Quaternary Science Data (Version 0.7-3) [Computer Software]. Vienna, Austria: Vienna University of Economics and Business. Retrieved June $1^{\text {st }}, 2012$. Available from http://www.rproject.org/index.html. 
Koellner, T., Hersperger, A. M. \& T. Wohlgemuth. 2004. Rarefaction method for assessing plant species diversity on a regional scale. Ecography 27: 532-544.

Kokelj, S.V., Lantz, T.C., Solomon, S., Pisaric, M.F.J., Keith, D., Morse, P., Thienpont, J.R., Smol, J.P. \& D. Esagok. (2012). Utilizing multiple sources of knowledge to investigate northern environmental change: Regional ecological impacts of a storm surge in the outer Mackenzie Delta, N.W.T. Arctic 65(3): 245-366.

Kriwoken, L.A. 1983. Historical Flood Review: Fort Simpson, Fort Norman, Fort Good Hope, Fort McPherson, Aklavik, Fort Liard, Nahanni Butte. Report for the Northern Hydrology Section, Surface Water Division. National Hydrology Research Institute, Environment Canada: Ottawa. $69 \mathrm{pp}$.

Kwong, Y.T.J. \& T.Y. Gan. 1994. Northward Migration of Permafrost Along the Mackenzie Highway and Climatic Warming. Climate Change 26(4): 399-419.

Lacroix, M.P., Prowse, T.D., Bonsal, B.R., Duguay, C.R. \& P. Menard. 2005. River ice trends in Canada. In Proceedings, Committee on River Ice Processes and the Environment 13th Workshop on the Hydraulics of Ice Covered Rivers, Hanover, September 15-16, 2005. $507 \mathrm{pp}$.

Lantz, T.C., Gergel, S.E. \& S.V. Kokelj. 2010. Spatial Heterogeneity in the Shrub Tundra Ecotone in the Mackenzie Delta Region, Northwest Territories: Implications for Arctic Environmental Change. Ecosystems 13: 194-204.

Lindsay, R.W. \& J. Zhang. 2005. The thinning of Arctic sea ice, 1988-2003: Have we passed a tipping point? Journal of Climate 18: 4879-4894. 
Lindsay, R. W., Zhang, J., Schweiger, A., Steele, M. \& H. Stern. 2009. Arctic Sea Ice Retreat in 2007 Follows Thinning Trend. Journal of Climate 22: 165-176.

Lotter, A.F., Walker, I.R., Brooks, S.J. \& W. Hofmann. 1999. An intercontinental comparison of chironomid palaeotemperature inference models: Europe vs. North America. Quaternary Science Reviews 18: 717-735.

Mackay, J.R. 1963. The Mackenzie Delta area, N.W.T. Memoir 8. Ottawa: Department of Mines and Technical Surveys, Geographic Branch. Ottawa, Canada. $90 \mathrm{pp}$.

Mackay, J.R. \& L. Dyke. 1990. Geological Features of the Mackenzie Delta Region, N.W.T. Scientific Report No.1. Scientific Services Program: Science Institute of the Northwest Territories. Yellowknife, N.W.T, Canada. 16 pp.

Mackay, J.R. \& D.K. MacKay. 1974. Snow cover and ground temperatures, Garry Islands, N.W.T. Arctic 27: 287-296.

Manabe, S., Spelman, M.J. \& R.J. Stouffer. 1992. Transient response of a couples ocean-atmosphere model to gradual changes of atmospheric $\mathrm{CO}$, Part II: Seasonal response. Journal of Climate 5: 105-126.

Manson, G.K. \& S.M. Solomon. 2007. Past and future forcing of Beaufort Sea coastal change. Atmosphere-Ocean 45(2): 107-122.

Marsh, P. \& M. Hey. 1994. Analysis of spring high water events in the Mackenzie Delta and implications for lake and terrestrial funding. Geografiska Annaler. Series A. Physical Geography 76(4): 221-234.

Marsh, P., Onclin, C. \& N. Neumann. 2002. Water and energy fluxes in the lower Mackenzie Valley, 1994/95. Atmosphere-Ocean 40: 245-256. 
Marsh, P. \& T. Schmidt. 1993. Influence of a Beaufort Sea storm surge on channel level in the Mackenzie Delta. Arctic 48(1): 35-41.

McBean, G., Alekseev, G., Chen, D., Forland, E., Fyfe, J., Groisman, P.Y., King, R., Melling, H., Vose, R. \& P.H. Whitfield. 2005. Chapter 2: Arctic Climate - Past and Present. In Symon, C., Arris, L., \& B. Heal., (editors), Arctic Climate Impact Assessment. Cambridge: Cambridge University Press, 21-60.

McCabe, G.J., Clark, M.P. \& M.C. Serreze. 2001. Trends in Northern Hemisphere surface cyclone frequency and intensity. Journal of Climate 14: 2763-2768.

McGarrigle, M.L. 1980. The distribution of chironomid communities and controlling sediment parameters in L. Derravarah, Ireland. In Murray, D.A., (editor), Chironomidae: ecology, systematic, cytology and physiology. Oxford: Pergamon Press, 275-282.

Murton, J.B. 1996. Thermokarst-lake-basin sediments, Tuktoyaktuk Coastlands, western arctic Canada. Sedimentology 43: 737-760.

Murton, J.B. 2009. Stratigraphy and palaeoenvironments of Richards Island and the eastern Beaufort Continental Shelf during the last glacial-interglacial cycle. Permafrost and Periglacial Processes 20: 107-125.

Murty, T.S. \& R.J. Polavarapu. 1979. Influence of an ice layer on the propagation of long waves. Marine Geodesy 2: 99-125.

Nielsen, D.L., Brock, M.A., Rees, G.N. \& D.S. Baldwin. 2003. Effects of increasing salinity on freshwater ecosystems in Australia. Australian Journal of Botany 51: $655-685$. 
National Oceanic and Atmospheric Administration (NOAA): National Climatic Data Centre. 2012. Paleolimnology. Retrieved December 13, 2012, from http://www.ncdc.noaa.gov/paleo/paleolim/paleolim.html.

Olander, H., Korhola, A. \& T. Blom. 1997. Surface sediment Chironomidae (Insecta: Diptera) distributions along an ecotonal transect in subarctic Fennoscandia: developing a tool for palaeotemperture reconstructions. Journal of Paleolimnology 18: 45-59.

Olander, H., Birks, H.J.B., Korhola, A. \& T. Blom. 1999. An expanded calibration model for inferring lakewater and air temperatures from fossil chironomid assemblages in northern Fennoscandia. The Holocene 9: 279-294.

Oliver, D.R., and Roussel, M.E. 1983. The Insects and Arachnids of Canada. In Part 11: The genera of larval midges of Canada. Agriculture Canada, Ottawa. 263 pp.

Paillard, D. 2006. AnalySeries (Version 2.0.4) [Computer Software]. St.-Quentin-enYvelines: Université de Versailles. Retrieved June $1^{\text {st }}, 2012$. Available from http://www.lsce.ipsl.fr/logiciels/index.php

Parkinson, C.L., Cavalieri, D.J., Gloersen, P., Zwally, H.J. \& J.C. Comiso. 1999. Arctic Sea ice extents, areas, and trends, 1978-1996. Journal of Geophysical Research 104: 837-856.

Perrie, W., Mulligan, R. P., Solomon, S. M., Hoque, A. \& L. Zhang. 2008. Nearshore Circulation and Storm Surge Along the Mackenzie Delta Coast. American Geophysical Union, Fall Meeting 2008: abstract \#OS41B-1217. 
Pinder, L.C.V. 1980. Spatial distribution of Chironomidae in an English chalk stream. In Murray, D.A., editor, Chironomidae: ecology, systematic, cytology and physiology. Oxford: Pergamon Press, 153-161.

Pisaric, M.F.J., Thienpont, J.R., Kokelj, S.V., Nesbitt, H., Lantz, T.C., Solomon, S. \& J.P. Smol. 2012. Impacts of a recent storm surge on an Arctic delta ecosystem examined in the context of the last millennium. Proceedings of the National Academy of Sciences 108(22): 8960-8965.

Polyak, L., Alley, R.B., Andrews, J.T., Brigham-Grette, J., Cronin, T.M., Darby, D.A., Dyke, A.S., Fitzpatrick, J.J., Funder, S., Holland, M., Jennings, A.E., Miller, G.H., O'Regan, M., Savelle, J., Serreze, M., St. John, K., White, J.W.C. \& E. Wolff. 2010. History of sea ice in the Arctic. Quaternary Science Reviews 29: $1757-1778$.

Porinchu, D.F. \& G.M. MacDonald. 2003. The use and application of freshwater midges (Chironomidae: Insecta: Diptera) in geographical research. Progress in Physical Geography 27(3): 378-422.

Porinchu, D.F., Rolland, N. \& K. Moser. 2009. Development of a chironomid-based air temperature inference model for the central Canadian Arctic. Journal of Paleolimnology 41(2): 349-368.

Porter, T.J., Pisaric, M.F.J., Kokelj, S.V. \& T.W.D. Edwards. 2009. Climatic Signals in $\delta 13 \mathrm{C}$ and $\delta 180$ of Tree-rings from White Spruce in the Mackenzie Delta Region, Northern Canada. Arctic, Antarctic, and Alpine Research 41(4): 497505. 
Prowse, T.D., Wrona, F.J., Reist, J.D., Hobbie, J.E., Levesque L.M.J. \& W.F. Vincent. 2006. General Features of the Arctic Relevant to Climate Change in Freshwater Ecosystems. Ambio 35(7): 330-338.

Quinlan, R. \& J.P. Smol. 2001. Setting minimum head capsule abundance and taxa deletion criteria in chironomid-based inference models. Journal of Paleolimnology 26: 327-342.

Quinlan, R., Douglas, M.S.V. \& J.P. Smol. 2005. Food web changes in arctic ecosystems related to climate warming. Global Change Biology 11: 1381-1386.

Rampton, V.N. 1988. Quaternary geology of the Tuktoyaktuk coastlands, Northwest Territories. Geological Survey of Canada, Natural Resources Canada, Ottawa Memoir 423. 103pp.

Randall, D. \& Curry, J., Battisti, D., Flato, G., Grumbine, R., Hakkinen, S., Martinson, D., Preller, R., Walsh, J. \& J. Weatherly. 1998. Status of and outlook for largescale modeling of atmosphere-ice-ocean interactions in the Arctic. Bulletin of the American Meteorological Society 79(2): 197-219.

R Core Team. 2012. R Statistical Package (Version 2.15.2) [Computer Software]. Newcastle upon Tyne, Tyne and Wear United Kingdom: Newcastle University. Retrieved June $1^{\text {st }}, 2012$. Available from $<$ http://cran.r-project.org/web/packages/rioja/index.html $>$.

Reimnitz, E. \& D.K. Maurer. 1979. Effects of Storm Surges on the Beaufort Sea Coast, Northern Alaska. Arctic 32(4): 329-344. 
Rigor, I.G., Colony, R.L. \& S. Martin. 2000. Variations in surface air temperature observations in the Arctic, 1979-97. Journal of Climate 13: 896-914.

Ritchie, J.C. 1985. Late-Quaternary climatic and vegetational change in the Lower Mackenzie Basin, northwest Canada. Ecology 66: 612-621.

Ritchie, J.C., Cwynar, L.C. \& R.W. Spear. 1983. Evidence from north-west Canada for an early Holocene Milankovitch thermal maximum. Nature 305: 126-128.

Rolland, N., Larocque, I., Francus, P., Pienitz, R. \& L. Laperriere. 2008. Holocene climate inferred from biological (Diptera, Chironomidae) analyses in a Southampton Island (Nunavut, Canada) lake. The Holocene 18(2): 229-241.

Rossaro, B. 1991. Chironomids and water temperature. Aquatic Insects: International Journal of Freshwater Entomology 13(2): 87-98.

Rowan, D.J., Cornett, R.J., King, K.J. \& B.A. Risto. 1994. Journal of Paleolimnology 13: 107-111.

Rull, V. 2010. Ecology and Palaeoecology: Two Approaches, One Objective. The Open Ecology Journal 3: 1-5.

Sahney, S., Benton, M.J. \& P.A. Ferry. 2010. Links between global taxonomic diversity, ecological diversity and the expansion of vertebrates on land. Biology Letters 6(4): 544-547.

Scrimgeour, G.J., Prowse, T.D., Culp, J.M. \& P.A. Chambers. 1994. Ecological effects of river ice break-up: a review and perspective. Freshwater Biology 32: 261275. 
Sepp, M. \& J. Jaagus. 2011. Changes in the activity and tracks of Arctic cyclones. Climatic Change 205: 577-595.

Serreze, M.C., and Barry, R.G., 2005: Recent climate variability, trends and the future. In The Arctic Climate System. Cambridge, U.K.: Cambridge University Press, $291-334$.

Serreze, M.C., Walsh, J.E., Chapin, S.F., Osterkamp, T., Dyurgerov, M., Romanovsky, V., Oechel, W.C., Morison, J., Zhang, T. \& R.G. Barry. 2000. Observational evidence of recent change in the northern high-latitude environment. Climate Change 46: 259-207.

Simmonds, I., Burke, C. \& K. Keay. 2008. Arctic Climate Change as Manifest in Cyclone behaviour. Bulletin of the American Meterological Society 21: 57775796.

Simmonds, I. \& K. Keay. 2009. Extraordinary September Arctic sea ice reductions and their relationships with storm behavior over 1979-2008. Geophysical Research Letters 36: L19715, doi:10.1029/2009GL039810.

Smol, J.P. 1981. Problems associated with use of 'species diversity' in paleolimnological studies. Quaternary Research 15: 209-212.

Smol, J.P. \& M.S.V. Douglas. 2007. From controversy to consensus: making the case for recent climate change in the Arctic using lake sediments. Frontiers in Ecology and the Environment 5: 466-474.

Smol, J.P., Wolfe, A.P., Birks, H.J.B., Douglas, M.S.V., Jones, V.J., Korhola, A., Pienitz, R., Ruhland, K., Sorvari, S., Antoniades, D., Brooks, S.J., Fallu, M., 
Hughes, M., Keatley, B.E., Laing, T.E., Michelutti, N., Nazarova, L., Nyman, M., Paterson, A.M., Perren, B., Quinlan, R., Rautio, M., Saulnier-Talbot, E., Siitonen, S., Solovieva, N. \& J. Weckstrom. 2005. Climate-driven regime shifts in the biological communities of arctic lakes. Proceedings of the National Academy of Sciences 102(12): 4397-4402.

Smol, J.P. 1990. Paleolimnology - Recent advances and future challenges. In De Bernardi, R., Giussani, G., and Barbanti, L., (Editors). Scientific Perspectives in Theoretical and Applied Limnology. C.N.R. Instituto Italiano di Idrobiologia, Verbania Pallanza, Italy 47: 253-276.

Solomon, S.M., Mudie, P.J., Cranston, R., Hamilton, T., Thibaudeau, S.A. \& E.S. Collins. 2000. Characterisation of marine and lacustrine sediments in a drowned thermokarst embayment, Richards Island, Beaufort Sea, Canada. International Journal of Earth Sciences 89: 503-521.

Stahl, J.B. 1969. The uses of chironomids and other midges in interpreting lake histories. Mitteilugen Internationale Vereinigung fur Theoretische und Angewandte Limnologie 17: 111-125.

Stroeve, J.C., Kattsov, V., Barrett, A., Serreze, M., Pavlova, T., Holland, M. \& W.N. Meier. 2012. Trends in Arctic sea ice extent from CMIP5, CMIP3 and observations. Geophysical Research Letters 39: L16502, doi: 10.1029/2012GL052676. 
Tarnocai, C., Nixon, F.M. \& L. Kutny. 2004. Circumpolar-active-layer-monitoring (CALM) sites in the Mackenzie Valley, southwestern Canada. Permafrost and Periglacial Processes 15: 141-153.

Thienpont, J.R., Johnson, D., Nesbitt, H., Kokelj, S.V., Pisaric, M.F.J. \& J.P. Smol. 2012. Arctic coastal freshwater ecosystem responses to a major saltwater intrusion: a landscape-scale palaeolimnological analysis. The Holocene 22(12): $1451-1460$.

Taylor, P.D. \& M.A. Wilson. 2003. Palaeoecology and evolution of marine hard substrate communities. Earth-Science Reviews 62: 1-103.

Tylmann, W. 2004. Estimating Recent Sedimentation Rates Using $210 \mathrm{~Pb}$ on the Example of Morphologically Complex Lake (Upper Lake Radunskie, Poland). Journal on Methods and Applications of Absolute Chronology 23: 21-26.

Van Metre, P.C., Wilson, J.T., Fuller, C.C., Callender, E. \& B.J. Mahler. 2004. Collection, analysis, and age-dating of sediment cores from 56 U.S. lakes and reservoirs sampled by the U.S. Geological Survey, 1992-2001: U.S. Geological Survey Scientific Investigations Report 2004-5184, 120 p.

Vermaire, J.C., Pisaric, M.F.J., Thienpont, J.R., Mustaphi, C.J.C., Kokelj. S.V. \& J.P. Smol. Submitted to The Holocene. Arctic climate warming and sea ice declines lead to increased storm surge activity.

von Post, L. 1946. The prospect for pollen analysis in the study of the Earth's climatic history. New Phytologist 45: 193-217. 
Walker, I. R. 1987. Chironomidae (Diptera) in paleoecology. Quaternary Science Reviews 6: 29-40.

Walker, I.R. 1990. Modern assemblages of arctic and alpine Chironomidae as analogues for late-glacial communities. Hydrobiologia 214: 223-227.

Walker, I.R., Levesque, A.J., Cwynar, L.C. \& A.F. Lotter. 1997. An expanded surfacewater palaeotemperature inference model for use with fossil midges from eastern Canada. Journal of Paleolimnology 18: 165-178.

Walker, I.R. 2001. Midges: Chironomidae and related Diptera in Smol, J.P., Birks, H.J.B. and Last, W.M., editors. Tracking environmental change using lake sediments. Volume 4: zoological indicators. Dordrecht Kluwer Academic Publishers, 43-66.

Walker, I.R. \& G.M. MacDonald. 1995. Distributions of Chironomidiae (Insecta: Diptera) and other freshwater midges with respect to treeline, Northwest Territories, Canada. Arctic and Alpine Research 27: 258-263.

Walker, I.R., Wilson, S.E. \& J.P. Smol. 1995. Chironomidae (Diptera): quantitative palaeosalinity indicators for lakes of western Canada. Canadian Journal of Aquatic Sciences 52: 950-960.

Winnell, M.H. \& D.S. White. 1985. Trophic status of southeastern Lake Michigan based on the Chironomidae (Diptera). Journal of Great Lakes Research 11: 4048. 
Willard, D.A. \& T.M. Cronin. 2007. Paleoecology and ecosystem restoration: case studies from Chesapeake Bay and the Florida Everglades. Front in Ecology and the Environment 5(9): 491-498.

Willis, K.J., Bailey, R.M., Bhagwat, S.A. \& H.J.B. Birks. 2010. Biodiversity baselines, thresholds, and resilience: testing predictions and assumptions using palaeoecological data. Trends in Ecology and Evolution 25: 583-91.

Willis, K.J. \& S.A. Bhagwat. 2009. Biodiversity and climate change. Science 326: 806807.

Wooller, M.J., Francis, D., Fogel, M.L., Miller, G.H., Walker, I.R. \& A.P. Wolfe. 2003. Quantitative paleotemperature estimates from $\delta^{18} \mathrm{O}$ in chironomid head capsules from Arctic lake sediment. Congress of the International Union for Quaternary Research, 16, 158, XVI INQUA congress; Shaping the Earth; a Quaternary perspective

Woo, M.K. \& R. Thorne. 2003. Streamflow in the Mackenzie Basin, Canada. Arctic 56: $328-340$. 